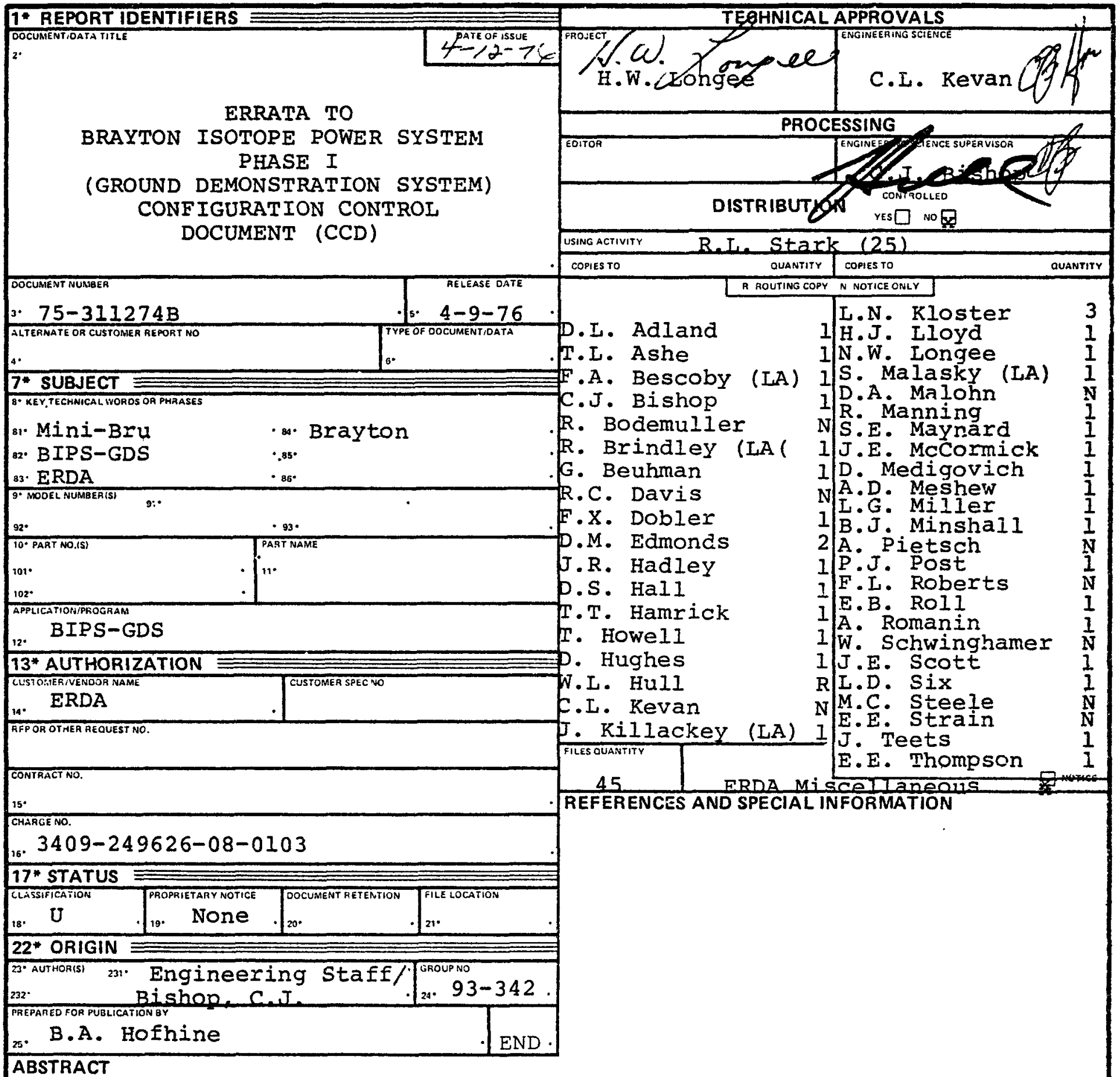

This errata has been prepared to correct and supplement data included in the $B$ revision of the CCD. 


\section{DISCLAIMER}

This report was prepared as an account of work sponsored by an agency of the United States Government. Neither the United States Government nor any agency Thereof, nor any of their employees, makes any warranty, express or implied, or assumes any legal liability or responsibility for the accuracy, completeness, or usefulness of any information, apparatus, product, or process disclosed, or represents that its use would not infringe privately owned rights. Reference herein to any specific commercial product, process, or service by trade name, trademark, manufacturer, or otherwise does not necessarily constitute or imply its endorsement, recommendation, or favoring by the United States Government or any agency thereof. The views and opinions of authors expressed herein do not necessarily state or reflect those of the United States Government or any agency thereof. 


\section{DISCLAIMER}

Portions of this document may be illegible in electronic image products. Images are produced from the best available original document. 


\author{
ERRATA \\ TO \\ BRAYTON ISOTOPE POWER SYSTEM \\ PHASE I \\ (GROUND DEMONSTRATION SYSTEM) \\ CONFIGURATION CONTROI DOCUMENT (CCD) \\ $75-311274 B$
}

Errata

Item No.

I Page i: At the top of the page, as the first entry under the heading "TABLE OF CONTENTS," add:

"BIPS PROGRAM ABBREVIATIONS AND ACRONYMS iv"

On Abbreviations and Acronyms table (following Page iii) at the bottom of the page add:

\title{
$75-311274 \mathrm{~B}$ \\ Page iv
}

Under (H) on the same page, in the definition of HSA, change:

$$
\text { "HSS" to read "EHS" }
$$

3 On the second page of the Abbreviations and Acronyms table at the bottom of the page add:

\section{5-311274B \\ Page $v$}

Under (M) on the same page, as a last item, add:

"MW Molecular Weight" 


\section{ERRATA (Contd)}

Errata

Item No.

Page 3-3, Item (f): In the third line, add the word "AIRPHX" ahead of "Monthly"

5

Page 3-12, Table 3-1: In the first line under "Mini-BRU," change:

$$
" M=83.8 " \text { to read "MW }=83.8 "
$$

6

Page 3-16, Paragraph 3.4.1.1: In the last sentence, add the word "AIRPHX" ahead of "Mini-BRU"

7 Page 3-19, first paragraph: In the last sentence, add the word "AIRPHX" ahead of "Mini-Brayton"

Page 3-19, fourth paragraph: In the last sentence, add the word "AIRPHX" ahead of "Report"

8 Page 3-22, Table 3-4: In the third column heading, change:

\section{"Garrett" to read "AiResearch"}

9

Page 3-26, Table 3-5: In the first line under "General," change:

$$
\text { "83.8 M.W." to read "MW }=83.8 "
$$




\section{ERRATA (Contd)}

\section{Errata}

Item No.

10 Page 3-32, first paragraph: In the sixth line, change:

$$
\text { "G" to read "g" }
$$

11 Page 3-38, Table 3-7: In the second item, change:

$$
"(M . W .=83.8) " \text { to read " }(M W=83.8) "
$$

12

Page 3-47, Paragraph 3.4.3: In Item (c), change:

$$
\text { "24 } W_{t} \text { " to read " } 2400 w_{t} "
$$

Page 3-47, Paragraph 3.4.3: In Item (d), change:

$$
"(M . W .=83.8) " \text { to read " }(M W=83.8) "
$$

13 Page 3-66, first paragraph: In the third line, change:

$$
\text { "whereever" to read "wherever" }
$$

14 Page 3-70, Paragraph 3.4.6.4: In the first sentence, change:

$$
\text { "Mini-BRU" to read "GDS" }
$$

Page 3-70, Paragraph 3.4.6.4: In Item (c), add the words "High local" ahead of "thermal" 


\section{ERRATA (Contd)}

Errata

Item No.

15

Page 3-72, fourth paragraph: In the equation, add brackets as follows:

$\frac{Q}{A}=\frac{4.457 \times 10^{-13}}{N} \quad\left[T_{\text {HOT }} 4.82702-T_{\text {COLD }} 4.82703\right]$

Page 4-2, Table 4-1: In the first line under "Miscellaneous," change:

"Low" to read "Ion"

Page 4-3, Paragraph 4.2: In the third line, change:

$$
\text { "requirement" to read "requirements" }
$$

Page 4-3, Paragraph 4.3: In the first line, add the word "AIRPHX" ahead of "Engineering"

Page 4-3, Paragraph 4.3.1: In the eleventh line, change:

"perferably" to read "preferably"

18 Page 4-4, second paragraph: In the first line, add the words "AIRPHX Report" following the parenthesis and ahead of "76-311736)"

Page 4-4, second paragraph: In the sixth line, change:

$$
\text { "to } 200^{\circ} \mathrm{F} \text { " to read "at } 200^{\circ} \mathrm{F} "
$$




\section{ERRATA (Contd)}

\section{Errata}

Item No.

Page 44, third paragraph: In the fifth and sixth lines, delete the words "with outgassing rate virtually the same"

Page 4-4, fourth paragraph: In the fifth line, change:

$$
\text { "parts" to read "ports" }
$$

Page 4-4, fourth paragraph: In the seventh line, change:

$$
\text { "part" to read "port" }
$$

Page 4-7, Paragraph 4.3.2: In the first paragraph, fourth line, add the word "AIRPHX" ahead of "En-

Page 4-7, Paragraph 4.3.2: In the first paragraph, twelfth line, change:

"... is only a matter of hours."

$$
\text { to read }
$$

$$
\text { "... is only a few hours." }
$$

Appendix I: Replace the appendix with Appendix I, attached. 
21 Appendix II, Page 1: In the second paragraph, lines three and five, change:

"MB-IBFS" to read "BIPS"

Appendix II, Page 3, Table II-2: Under the column heading "Contractor", change:

"AiPHX" to read "AIRPHX" (8 places)

"AiRLA" to read "AIRLA" (1 place)

23 Appendix II, Page 8, Figure II-5: Change the figure title to read:

"GENERAL ELECTRIC PHASE I PROGRAM SUPPORT SCHEDULE"

Appendix II, Page 8, Figure II-5: In Program Element (2), change:

"IBFS" to read "FS" (2 places)

24 Appendix II, Page 9, Figure II-6: Under Documents and Data block, change:

"G.A. Hofhine" to read "B.A. Hofhine"

Appendix II, Page 9, Figure II-6: Under Laboratory Engineering block, change:

"G. Beuhman" to read "V.P. Corcoran" 


\section{ERRATA (Contd)}

Errata

Item No.

Appendix III, Table III-1: Under Document No. QCGI NO. 137 :

$$
\begin{aligned}
& \text { - Delete "(Rough Draft)" } \\
& \text { - Revise Publication Date to } \\
& \text { November 19, } 1975 \text { (Revised) }
\end{aligned}
$$

Appendix III, Table III-1: Under Document No. $75-311274 B$ :

$$
\begin{aligned}
& \text { Revise Publication Date to } \\
& \text { March 15, } 1976 \\
& \text { Delete "(Proposed)" }
\end{aligned}
$$

26 Appendix III, Table III-1, second page: Under Document No. 75-311665, change the first line of the title to read:

"Preliminary Hazards Analysis for the"

This errata will be incorporated during the next CCD revision/update.

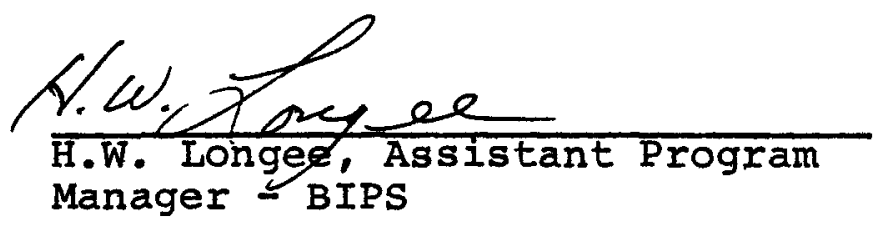




\author{
APPENDIX I \\ BRAYTON ISOTOPE POWER SYSTEM FLIGHT SYSTEM (BIPS FS)
}

\title{
1.0 INTRODUCTION
}

This CCD is for a GDS designed to be representative of a flight system utilizing the Mini-BRU, MBR, and HSA designed for application in a space power system. This appendix briefly describes the BIPS FS design, operating parameters used in performance parametric studies, and design-point operating conditions. A conceptual system layout ( 13621582 ) is included in Appendix III, which is based on $4800 \mathrm{w}_{t}$ total from two radioisotope heat sources. Conceptual BIPS FS estimated performance is shown in.Figure I-1, and the energy balance in Figure I-2.

BIPS FS design is such that optional features can easily be incorporated into delivered units. One such feature is one-g bearings that may be desirable for low power-level applications, or high-g bearings required for operation during launch.

The Mini-BRU is designed as an "all purpose" machine, capable of operating over a wide spectrum of power levels $\left(0.35\right.$ to $\left.2.1 \mathrm{kw}_{e}\right)$ and orbital environments (near earth, synchronous, and deep space), with little compromise in performance. An example of this flexibility is that the "all purpose" Mini-BRU designed for $2.1 \mathrm{kw}$ output adds only a six percent weight penalty to the BIPS FS when integrated into a 0.4 $k w_{e}$ system.

GDS features, not in the BIPS FS, include a turbine bypass valve for overspeed protection, and a valved fill system. The BIPS FS will have no valves with external stems that could result in working fluid (gas) leakage. 


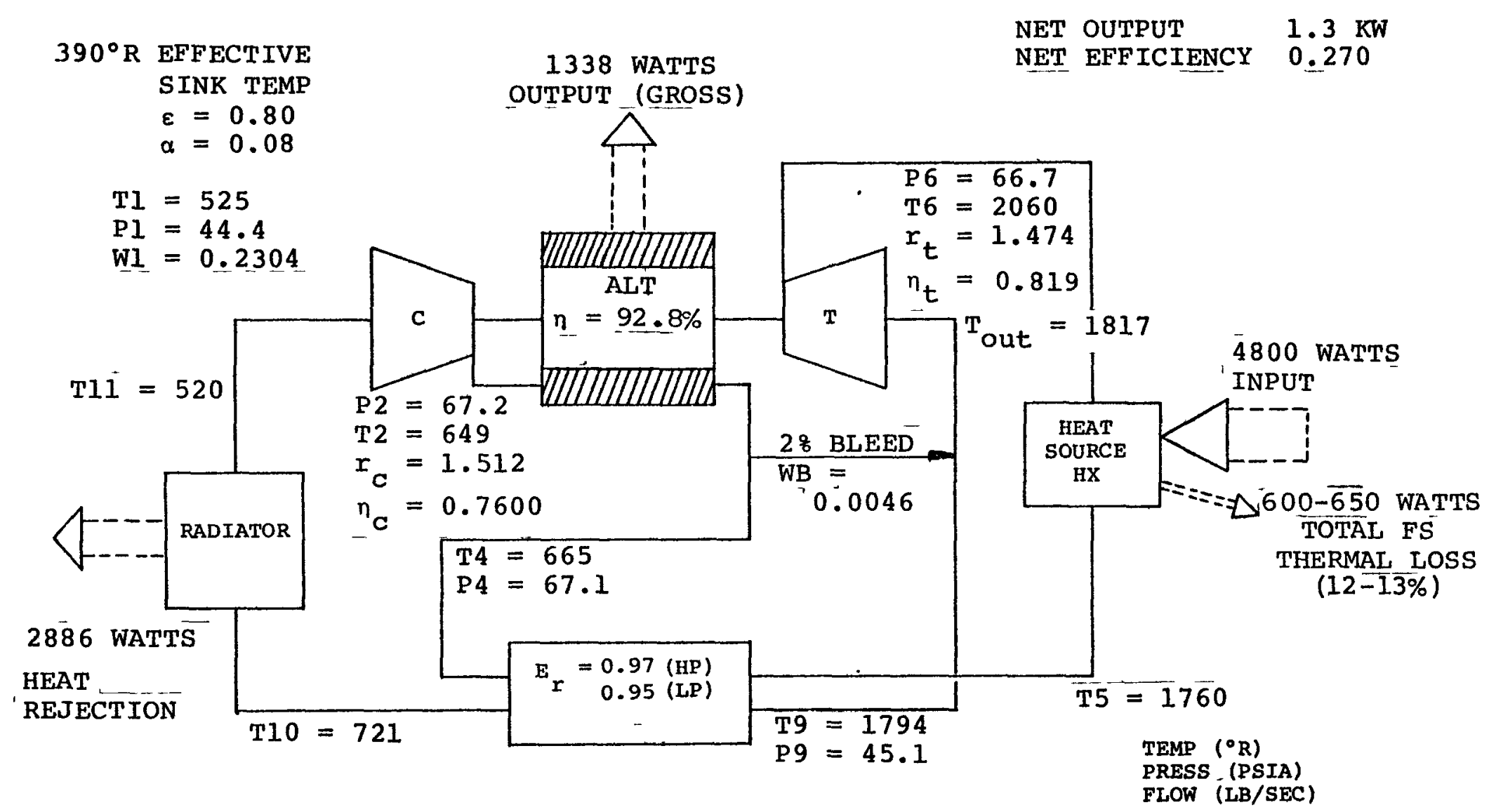

FLOW SCHEMATIC AND ESTIMATED PERFORMANCE

FOR THE $4800 \mathrm{w}_{t}$ ERDA BIPS FS

EIGURE $I-1$ 
COMPRESSOR

POWER

$1.786 \mathrm{KW}_{\mathrm{s}}$

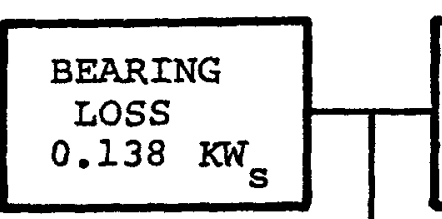

WINDAGE

LOSS

$0.059 \mathrm{KW}_{\mathbf{s}}$

ALTERNATOR

INPUT

$1.441 \mathrm{KW}_{\mathrm{S}}$

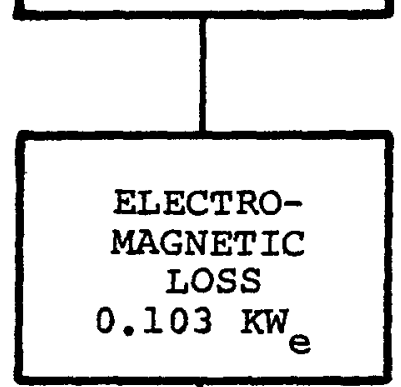

FIELD

CONTROL LOSS

$0.010 \mathrm{KW}_{\mathrm{e}}$

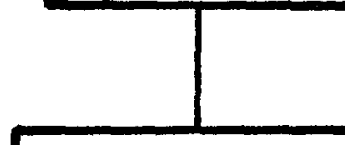

DOUBLY

REDUNDANT

RECTIFIER LOSS

$0.034 \mathrm{KW}_{\mathrm{e}}$

NET DC OUTPUT $=1.294 \mathrm{KW}$
TURBINE

OUTPUT

$3.424 \mathrm{KW}_{\mathrm{S}}$

$$
\begin{aligned}
& \text { ENERGY BALANCE - } 4800 \mathrm{~W}_{t} \\
& \text { FIGURE I-2 } \\
& 75-311274 \mathrm{~B} \\
& \text { Appendix I } \\
& \text { Page 3 }
\end{aligned}
$$


The GDS HRHX (radiator simulator) will be replaced by a space radiator for the BIPS FS. The ducting system will necessarily be different, but will have a similar pressure drop.

All references noted in the paragraphs that follow are presented on the last page of this appendix. 


\subsection{BIPS FS OBJECTIVES AND DESIGN}

The FS performance objectives are delineated on Table I-1. GDS design is based on these objectives except that an HRHX replaces the space radiator, and electrical resistance heat sources replaces radioisotope heat sources. FS components and subcomponents are delineated in Table $I-2$.

The BIPS FS conceptual layout (L3621582) shows the Mini-BRU in the vertical position (same as GDS). This orientation was selected for two reasons :

(a) For gyroscopic compatibility with a spin-stabilized spacecraft when mounted with the vehicle axis coincident with (or parallel to) the BIPS Mini-BRU axis.

(b) Launch loads are usually greater in the vertical direction, and as presently designed, thrust bearings will withstand more load than journal bearings.

A horizontal orientation is equally feasible, but requires that some support structure and ducting be changed with the result that the MBR will be slightly lowered.

Because of potential future system requirements, some configuration changes may be required. These are:

(a) Provision for Operation Through Launch - Since the BIPS FS is designed to operate in a space environment hard vacuum, a bell-jar approach must be taken to provide an inert gas atmosphere for refractory metals and MultiFoil insulation protection. Bearings must also be checked for load adequacy (present journal and thrust bearing configurations are designed to accept 7 and $10 \mathrm{~g}$ acceleration loads, respectively). 
TABLE I-1

FS PERFORMANCE OBJECTIVES

(1) The FS will be capable of power output from 500 to $2000 \mathrm{~W}_{e}$, EOM, with minimum redesign and requalification.

(2) $28 \pm 2$ percent vdc is the reference output voltage.

NOTE

A capability for higher ac voltage output may be advantageous if the output can be achieved directly from the generator.

(3) The control system will be capable of modulating power to the spacecraft from 0 to 100 -percent in $20 \mathrm{milliseconds}$ response times. This will be accomplished by a parasitic load.

(4) FS life time requirements is $I=7$ years and mean mission duration $(M M D)=$ 5 years.

where $M M D=\int_{0}^{I} R d t$

and $R=$ probability of producing design power at time $t$

(Notwithstanding this requirement, AIRPHX has established a more stringent objective of $\mathrm{R}=0.95$ after 5 years operation)

Prelaunch, launch, and operational phase failure modes will be identified.

(5) Based on a GFE heat source cost of $\$ 1000$ per $W_{t}$, the recurring cost goal for the FS at $1300 \mathrm{w}_{e}$ will be less than $\$ 5000$ per $\mathrm{w}_{e}$.

(6) A FS weight goal, at $1300 \mathrm{w}_{\mathrm{e}}$, is 450 pounds.

(7) The FS will be capable of launch on the space shuttle.

(8) Due to a potential explosive vapor environment, the on-pad temperature of exposed surfaces will be maintained below $380^{\circ} \mathrm{F}$.

(9) The system will be designed with an assumed sink temperature equal to, or greater than, that of a geo-synchronous orbit $(19,323 \mathrm{~nm})$. The system will be capable of stable operation with unbalanced solar input.

(10) Thermal input to the spacecraft must be of an amount that will not cause the spacecraft to rise above $100^{\circ} \mathrm{F}$.

(11) The magnetic field at one meter is not yet defined.

(12) The on-pad biological dose at one meter will be $\leq 0.20$ REM per hour.

(13) The FS will be resistant to natural and man-made radiations.

(14) FS components will be inherently flexible in mounting to facilitate integration with the required spacecraft configuration.

(15) On pad and in-orbit fueling capabilities should be provided. 
TABLE I-2

BIPS-FS COMPONENTS

Mini-BRU

- $1600^{\circ} \mathrm{F}$ turbine inlet temperature (working fluid is Xe-He, $M=83.8$ )

- Single shaft turbine, Rice alternator and compressor supported on foil bearings with compressor bleed cooling

- Alternator cooled by compressor discharge

- Refractory metal turbine plenum (Columbium c-103)

Recuperator

- Hastelloy $X$ construction with gold alloy braze

- Fin/plate counterflow design

\section{Radiator}

- Material [Be, aluminum alloy or Lockalloy (alloy of $\mathrm{Al}$ and Be)]

- Cylindrical design, offset fin/tube geometry

- Sink temperature, $390^{\circ} \mathrm{R}$

- Micrometeroid survival, 0.99 (assumed)

- Used as part of a low gage pressure vessel to contain an inert gas for protection of the C-103 and multifoil insulation from launch to orbit.

Heat Source

- ERDA Multi-Hundred Watt (MHW) heat source, (advanced ERDA HS concepts will also be investigated)

- Electrically heated heat source simulator (EHS) for Fs checkout,

Heat Source Assembly (HSA)

- Columbium Alloy C-103 Heat Source Heat Exchanger (HSHX)

- Auxiliary cooling system - Helium short circuit of HSFX Multi-Foil insulation

- Emergency cooling system - Melting of HSHX Multi-Foil insulation (alternatives have been identified)

Insulation

- High temperature Multi-Foll insulation

- Eight percent heat loss from HSA (Goal)

- Two percent heat loss from turbine and hot interconnecting ducting (Goal)

Controls

- Motor start inverter

- Parasitic load

- Speed control

- Voltage regulatur

- Power supply

- Rectifier/filter

Piping and Structure

- Ducting

- Bellows

- Support structure (Beryllium or aluminum alloy)

- Radiator is used as part of the support structure

75-3112748

Appendix I

Page 7 
(b) Operation on a Spin-Stabilized Platform - Bearing load limits must not be exceeded [see (a) above]. If the Mini-BRU axis is transverse to the vehicle spin axis, the resulting coning angle must not exceed that allowed by mission requirements. For a spinning vehicle and Mini-BRU combination, the coning half-angle $(\phi)$ is defined by:

$$
\phi=\mathrm{M}_{\mathrm{m}} / \mathrm{M}_{\mathrm{V}}
$$

where:

$$
\begin{aligned}
& M_{m}=\text { Mini-BRU angular momentum }(0.68 \text { lb-ft rad sec) } \\
& M_{v}=\text { Vehicle angular momentum, lb-ft-sec } \\
& \phi \quad=\text { Vehicle coning angle, rad }
\end{aligned}
$$

Presuming that $M_{\mathrm{v}}$ is 500 , the coning half-angle would be approximately 0.08 degrees.

(c) Spacecraft Integration - Launch vehicle constraints, heat input to the space vehicle, and/or BIPS placement on the space vehicle may require that the assumed BIPS FS be reconfigured. As presently configured, the BIPS can be mounted on any flat surface, and be designed to limit heat input to the spacecraft. The BIPS power supply furnishes the most power at $120 \mathrm{vdc}$, but by adding other power conversion components, any desired voltage and frequency combination may be obtained. 
The BIPS FS schematic, Figure I-3, shows all components within the working fluid loop, and inter-connecting ducting. The duct numbers correlate with Table I-3 data. Note that the radiator and radiator ducting materials have not yet been selected. Approximate duct sizes, and lengths of ducts $7,8,12,13$, and 14 (Table I-3) are based on the conceptual design, shown on Drawing $\mathrm{L} 3621582$ and will vary with different radiator configurations. 

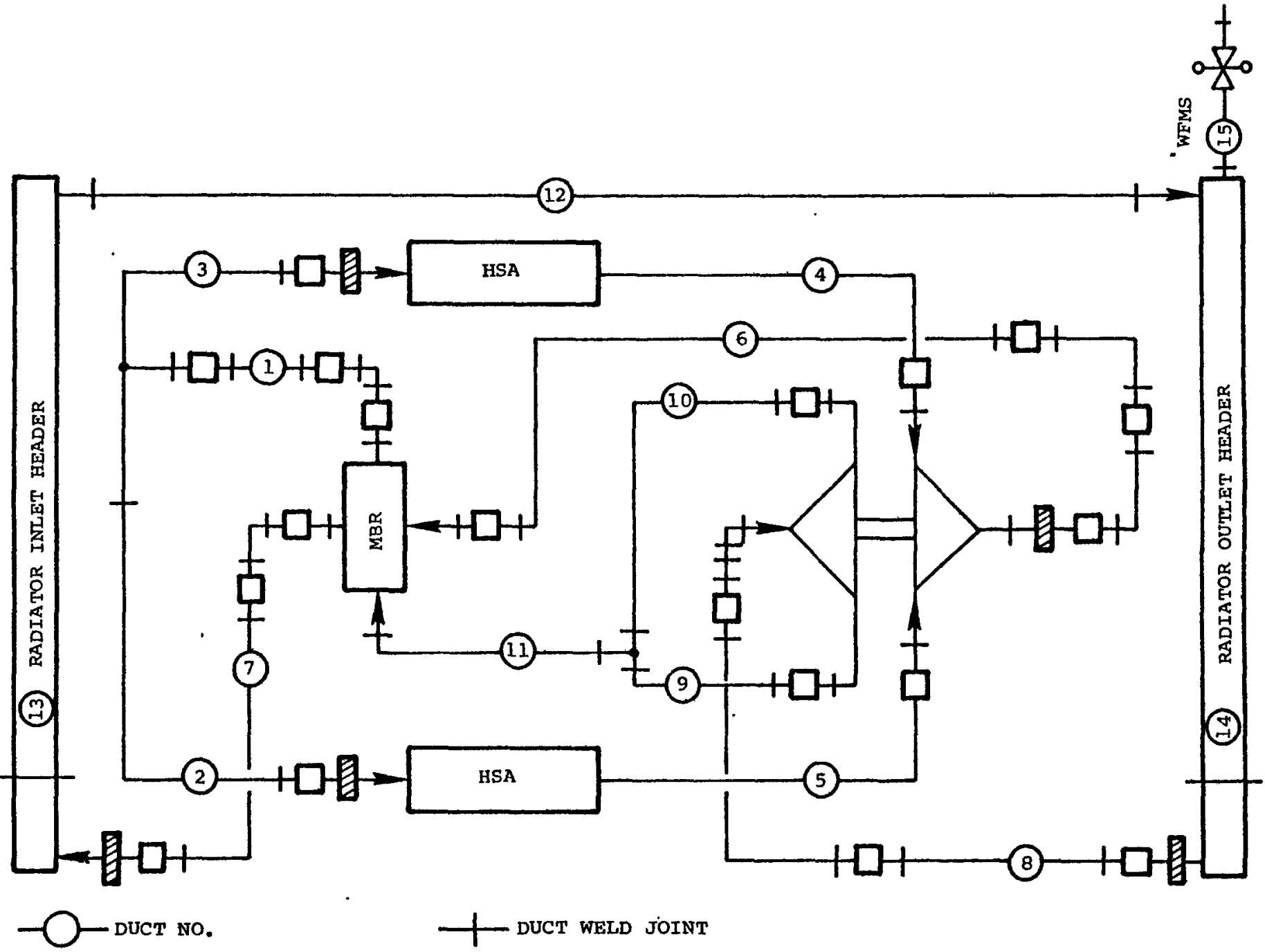

$千$ DUCT WELD JOINT

-

-BI-METALLIC JOINT

BIPS-FS DUCT SCHEMATIC

FIGURE I-3 
AIRESEARCH MANUFACTURING COMPANY DF ARIZDNA

A DIVISIOM OF THE OARRETY CORMORATIOM

PHDENIX, ARIZONA

TABLE I-3

BIPS-FS DUCT SUMMARY

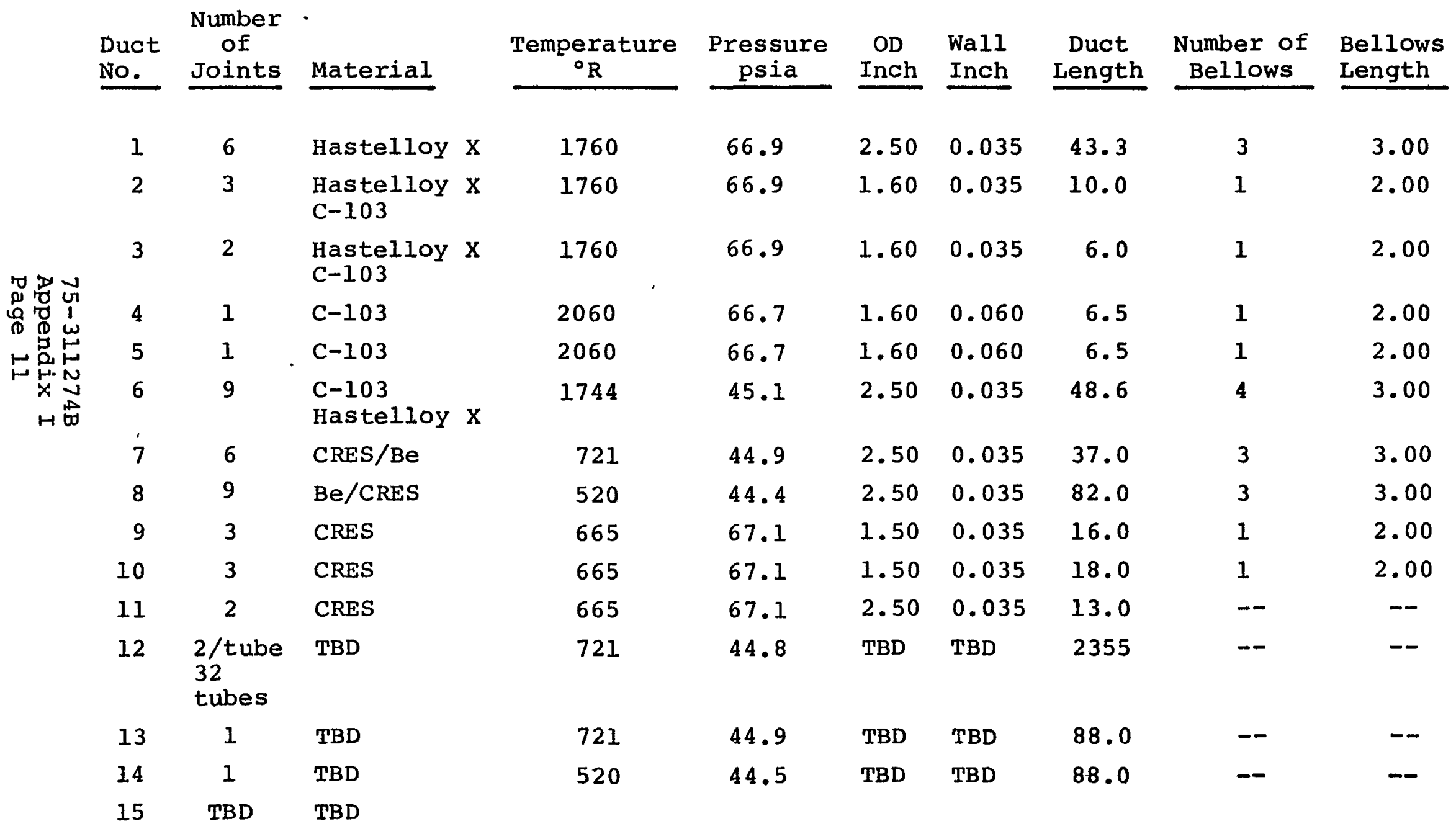




\subsection{PRELIMINARY SHOCK AND VIBRATION DESIGN CRITERIA}

When considering structural dynamics, the BIPS consists of a cylindrical radiator within which four discrete masses are supported by means of interface structure consisting of beams and struts. The four discrete masses are; two heat source assemblies, recuperator, and MiniBRU power package. As presently known, the BIPS will be mounted to the spacecraft, which will be mounted to the interim upper stage (IUS). The IUS will be mounted in a cradle or carrier in the space shuttle orbiter. This series of components comprises the orbiter payload. The Space Shuttle and IUS specifications (References 1 and 2 , respectively) imply that the payload be cantilever-mounted, from the orbiter mount points when in the stowed configuration.

The principal source of structural vibration occurs during space Shuttle powered ascent. Principal vibration levels the BIPS will experience depend on the payload dynamic response to orbiter vibration with the payload in the stowed configuration.

The principal source of shock occurs when using pyrotechnic devices on the IUS vehicle, such as that used for spacecraft separation. Principal shock levels the BIPS will experience depend on the payload dynamic response to pyrotechnic explosions, with the payload in the deployed configuration.

Shock and vibration levels at various interfaces, as estimated for conceptual design by the various referenced sources, are shown below. 
(a) Peak Random Vibration Levels

- Shuttle Vehicle Payload Interface (Reference 1) $0.1 \mathrm{~g}^{2} / \mathrm{Hz}(90$ to $275 \mathrm{~Hz}$ ) estimated response for an unloaded interface structure. Actual response should be lower due to mass of payload.

- IUS-Spacecraft Interface (Reference 2) -0.125 $\mathrm{g}^{2} / \mathrm{Hz}$ (100 to $\left.1000 \mathrm{cps}\right)$ recommended for conceptual design.

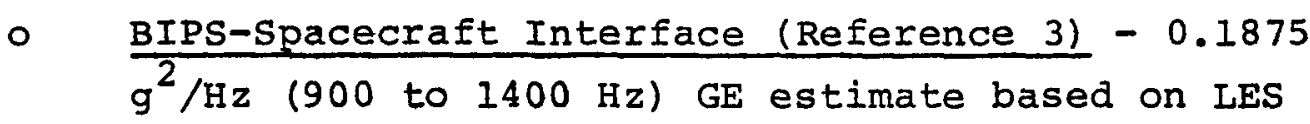

$8 / 9$ and Mariner $\mathrm{J} / \mathrm{S}$ experience.

These vibration levels appear to represent a vibratory amplification through the payload. However, the levels are assumed to be estimates of the three reference sources that were determined independently. It will not be known whether the vibratory input to the payload will be amplified or attentuated until the total payload structure is defined and total payload dynamic analyses are conducted.

(b) Peak Shock Levels

- IUS-Specification (Reference 2, Figure 6) - The shock response spectra gives a dynamic response of $115 \mathrm{~g}$ at the IUS-Spacecraft interface with a " $Q$ " equal to ten for a $100 \mathrm{~Hz}$ system. Although 
the BIPS response to shock at the IUS-Spacecraft interface is undefinable, it will be attenuated due to cantilever mounting and remoteness from the interface.

0

GE Specification Recommendations (Reference 3) 50-g dynamic response for the Isotope Heat Source, and support structure, in the HSA housing and $25-9$ dynamic response for the overall BIPS structure, based on a shock response to a 775-g half sine pulse of $0.2 \mathrm{millisecond}$ duration.

As noted above, actual shock and vibration levels the BIPS will experience depend on payload dynamic responses to the principal sources of excitation.

The Space Shuttle is well defined and the BIPS is conceptually defined. However, the spacecraft, IUS, and IUS support structure to the shuttle craft, are currently undefined except for the decision to utilize a solid rocket motor. It is anticipated that the solid rocket motor and structure will possess a high degree of stiffness. Because of many unknowns, no meaningful dynamic analyses can be made, at this time, for predicting BIPS, vibratory and shock responses. However, criteria does exist that system dynamics must satisfy to maintain BIPS responses within tolerable structural design limits. These are:

(a) The cantilevered payload support structure must be designed to avoid coupling payload and space shuttle fundamental frequencies. To avoid this interaction the cantilevered payload fundamental frequencies should be at least two times greater than space shuttle fundamental frequencies. The shuttlecraft fundamental frequency range is estimated to be within 4 and $12 \mathrm{~Hz}$. Therefore, the fundamental of the cantilevered payload should not be less than $24 \mathrm{~Hz}$. 
(b) Support structures of BIPS discrete masses should be designed to avoid coupling the cantilevered payload fundamental frequencies with the rigid body fundamental frequencies of the BIPS masses. This means that BIPS components fundamental frequencies should be approximately $60 \mathrm{~Hz}$.

(c) Criteria (a) and (b) define cantilevered payload and BIPS components fundamental frequency limits. However, it is desirable to maintain the upper limits of natural frequencies no higher than necessary to satisfy (a) and (b), and to minimize BIPS components dynamic responses to shock and vibration. It is anticipated that the cascade of components, comprising the cantilevered payload, will respond to shock as a succession of simple systems, when each succeeding structure has a low mass relative to the next supporting structure.

\subsection{Design Criteria}

BIPS FS components (i.e., HSA, MBR, Mini-BRU) and mounting pads should be designed to a minimum limit loading of $50 \mathrm{~g}$. BIPS interface structures (i.e., struts, beams, etc.) should be designed to a minimum limit loading of $25 \mathrm{~g}$. The higher acceleration loading requirement provides increased structural integrity for BIPS components and mount pads. This is needed to compensate for the lower degree of mounting redundancy than the interface support structure (i.e., beams and struts). In the case of a statically determinate mounted component such as the MBR, failure of a single mount could result in separation of the component, whereas the interface structure is a many times redundant system capable of tolerating a number of member failures without total failure. The design criteria of providing sufficient stiffness to the BIPS interface structure, to maintain BIPS component 
natural frequencies above $60 \mathrm{cps}$, will inherently result in high strength. It is intended that this built-in strength will exceed $25 \mathrm{~g}$. This limit loading should satisfy requirements for all other loadings such as pre-launch, launch, and operational environments, and in the case of an abort mission, crash landing requirements. This design criteria should be adequate for the BIPS preliminary design phase. After IUS and spacecraft definitions, dynamic analyses should be conducted on the orbiter cantilever-mounted payload, and the payload as deployed from the orbiter. The cantilevered payload and support design should minimize the BIPS dynamic response. Considerable latitude exists in designing the payload structure to minimize BIPS dynamic loading. 


\subsection{ESTIMATED PERFORMANCE}

The estimated FS Mini-BRU performance, for 1, 2, and 3 HSA (2400 $W_{t}$ each), is shown on Table $I-4$. The data was generated assuming the systems were optimized at minimum weight by changing the MBR and radiator sizes. The GFE recuperator was used for the 3-capsule design only and the weight of hypothetical recuperators of 1- and 2-capsule designs was lowered, mainly by shortening lengths. Note that for the 1-capsule case, the optimum system weight was achieved with a radiator larger than for the 2-capsule case. The same performance could be achieved with some weight penalty by using a smaller radiator and larger recuperator. Users of this data are referred to the objectives stated in Table I-l.

Cycle sensitivity to performance parameters that could change because of build technique, aging, intent, or usage, has been evaluated. Table I-5 enumerates those performance variables with linear sensitivity factors. For sink temperatures and turbine inlet temperature non-linear effects, refer to Figures $I-4$ and $I-5$. The partial differentials of cycle efficiency, thus obtained, can be added to estimate the effects of small changes on any of the three system sizes studied.

Parameters for a two-capsule BIPS are shown in Table I-6. To use the sensitivity factors, refer to Table I-4 for the original value, and Table I-5 for sensitivity factor. 
To illustrate sensitivity factors usage, consider the compressor efficiency calculation. A new 0.747 efficiency is assumed, which is 0.01 less than the original, and defines the delta as -0.01 . This is also the 0.55 sensitivity factor multiplier shown on Table I-5. The resulting -0.0055 cycle efficiency change is noted on Table I- 6 . In some cases, the independent variable is a delta to base number ratio (i.e., $\Delta P / P$ ) and the multiplier is the delta of this parameter. As an example of pressure drop effect, if the pressure ratio parameter changes from 0.972 to 0.975 , the increase is $0.003 \Delta \mathrm{P} / \mathrm{P}$. The multiplier is the same number and $(0.003) \times(-0.8)$ results in a -0.0024 cycle efficiency change. As an example of bearing loss effect, if $\mathrm{kw}$ changes from 0.137 to 0.145 , the delta increase is 0.008 , but the multiplier is $0.008 / 0.137$, which is 0.0584 . The cycle efficiency change is then $(0.0584) \times(-0.031)$, equalling -0.0018 . To obtain $\Delta n_{c y}$ for other than design sink temperature (Figure I-4), or turbine inlet design temperature (Figure I-5), refer to the respective figures. 
TABLE I-4

CYCLE DATA OPTIMIZED FOR MINIMUM WEIGHT

\begin{tabular}{|c|c|c|c|}
\hline & $\underset{1}{\text { Capsule }}$ & $\begin{array}{c}\text { Capsule } \\
2\end{array}$ & $\underset{3}{\text { Capsule }}$ \\
\hline Compressor Efficiency & 0.746 & 0.757 & 0.760 \\
\hline Turbine Efficiency & 0.791 & 0.818 & 0.831 \\
\hline Alternator Efficiency & 0.905 & 0.927 & 0.921 \\
\hline Lost Pressure Ratio Parameter & 0.959 & 0.972 & 0.9755 \\
\hline Recuperator Effectiveness & 0.970 & 0.975 & 0.9758 \\
\hline Bearing Loss (kw) & 0.124 & 0.137 & 0.151 \\
\hline Windage. $(\mathrm{kw})$ & 0.030 & 0.053 & 0.073 \\
\hline Turbine Inlet Temperature $\left({ }^{\circ} \mathrm{R}\right)$ & 2060.0 & 2060.0 & 2060.0 \\
\hline Compressor Inlet Temperature $\left({ }^{\circ} R\right)$ & 440.0 & 500.0 & 520.0 \\
\hline Compressor Pressure Ratio & 1.615 & 1.537 & 1.514 \\
\hline Turbine Pressure Ratio & 1.549 & 1.493 & 1.477 \\
\hline Compressor Inlet Pressure (psia) & 18.2 & 42.3 & 66.2 \\
\hline Radiator Area $\left(f t^{2}\right)$ & 112.0 & 110.6 & 134.2 \\
\hline Recuperator Length (inch) & 15.7 & 20.4 & 24.0 \\
\hline Fractional Heat Loss* & 0.13 & 0.13 & 0.13 \\
\hline Net Output Power (kw) & 0.619 & 1.356 & 2.067 \\
\hline Net Cycle Efficiency & 0.2578 & 0.2825 & 0.2872 \\
\hline Radiator Emissivity & 0.83 & 0.83 & 0.83 \\
\hline Radiator Sink Temperature $\left({ }^{\circ} \mathrm{R}\right)$ & 390.0 & 390.0 & 390.0 \\
\hline Compressor Flow Rate (Ib/sec) & 0.1064 & 0.2262 & 0.3442 \\
\hline Turbine Flow Rate $(1 \mathrm{~b} / \mathrm{sec})$ & 0.1043 & 0.2217 & 0.3347 \\
\hline Heater Inlet Pressure (psia) & 29.11 & 64.60 & 99.74 \\
\hline Heater Inlet Temperature $\left({ }^{\circ} \mathrm{R}\right)$ & 1738.9 & 1758.4 & 1762.5 \\
\hline
\end{tabular}

*Thermal Loss/Gross Heat Release 
AIRESEARCH MANUFACTURINE CDMPANY GF ARIZDNA

A OIVISIOW OF THE OARAETr COABOMATIOE

PHOENIX, ARIZINA

TABLE $I-5$

BIPS FS CYCLE EFFICIENCY SENSITIVITY FACTORS*

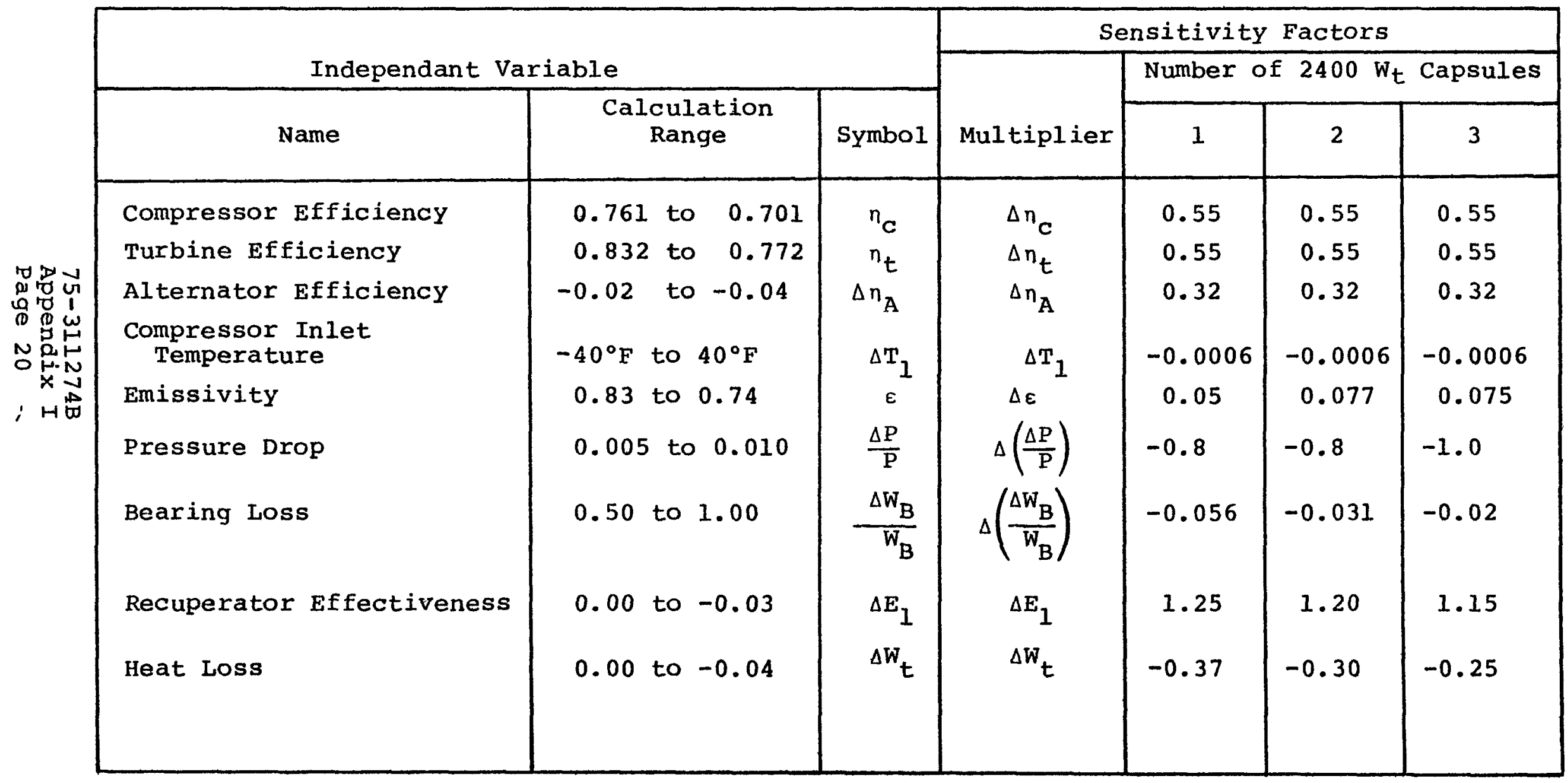

$* \Delta n_{C Y}=$ (Sensitivity Factor) x Multiplier 
AIRESEARCH MANUFACTURING CDMPANY OF ARIZQNA

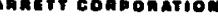

PHOENIX, ARIZONA
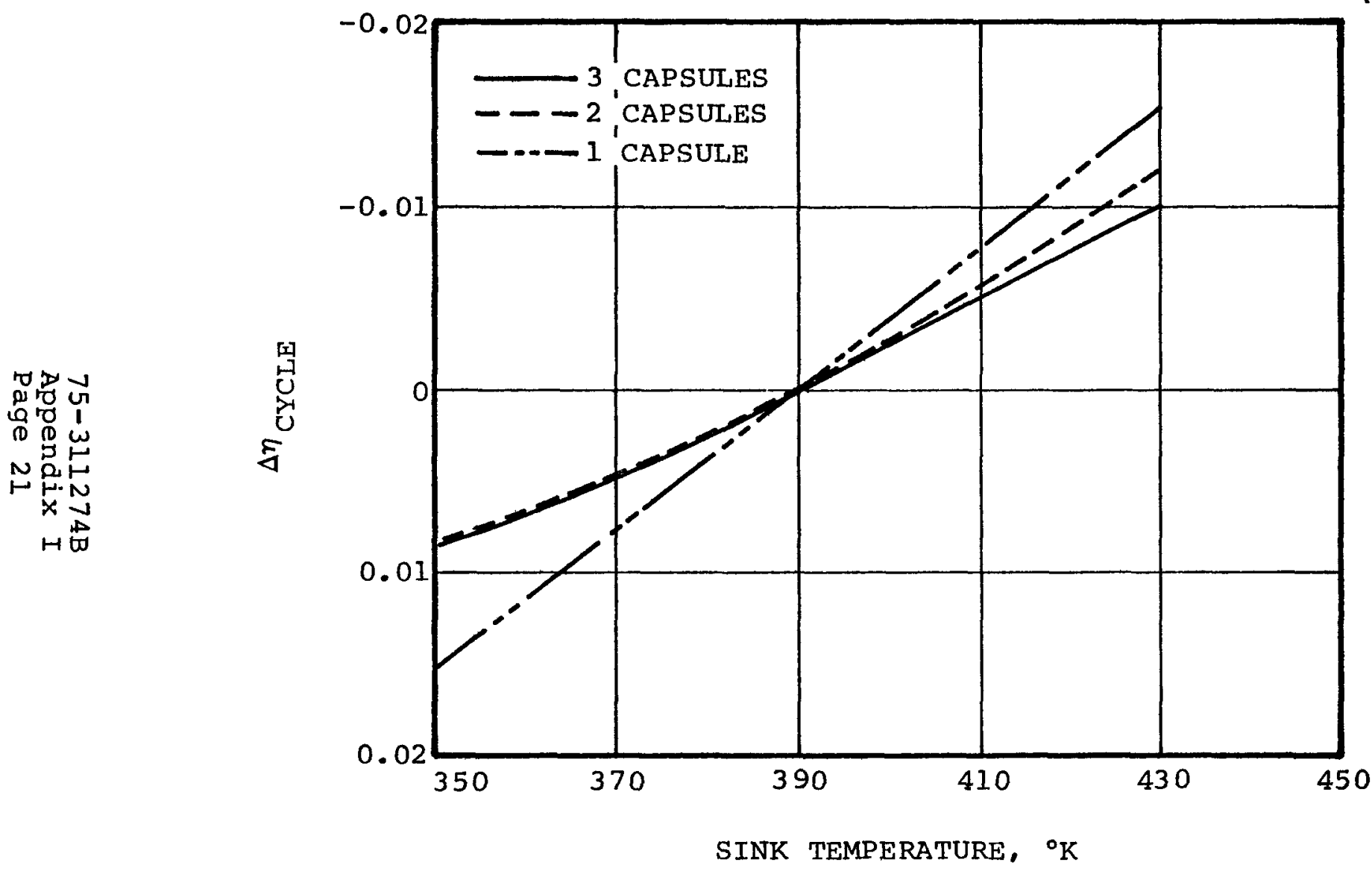

SINK TEMPERATURE EFFECTS

FIGURE I-4 


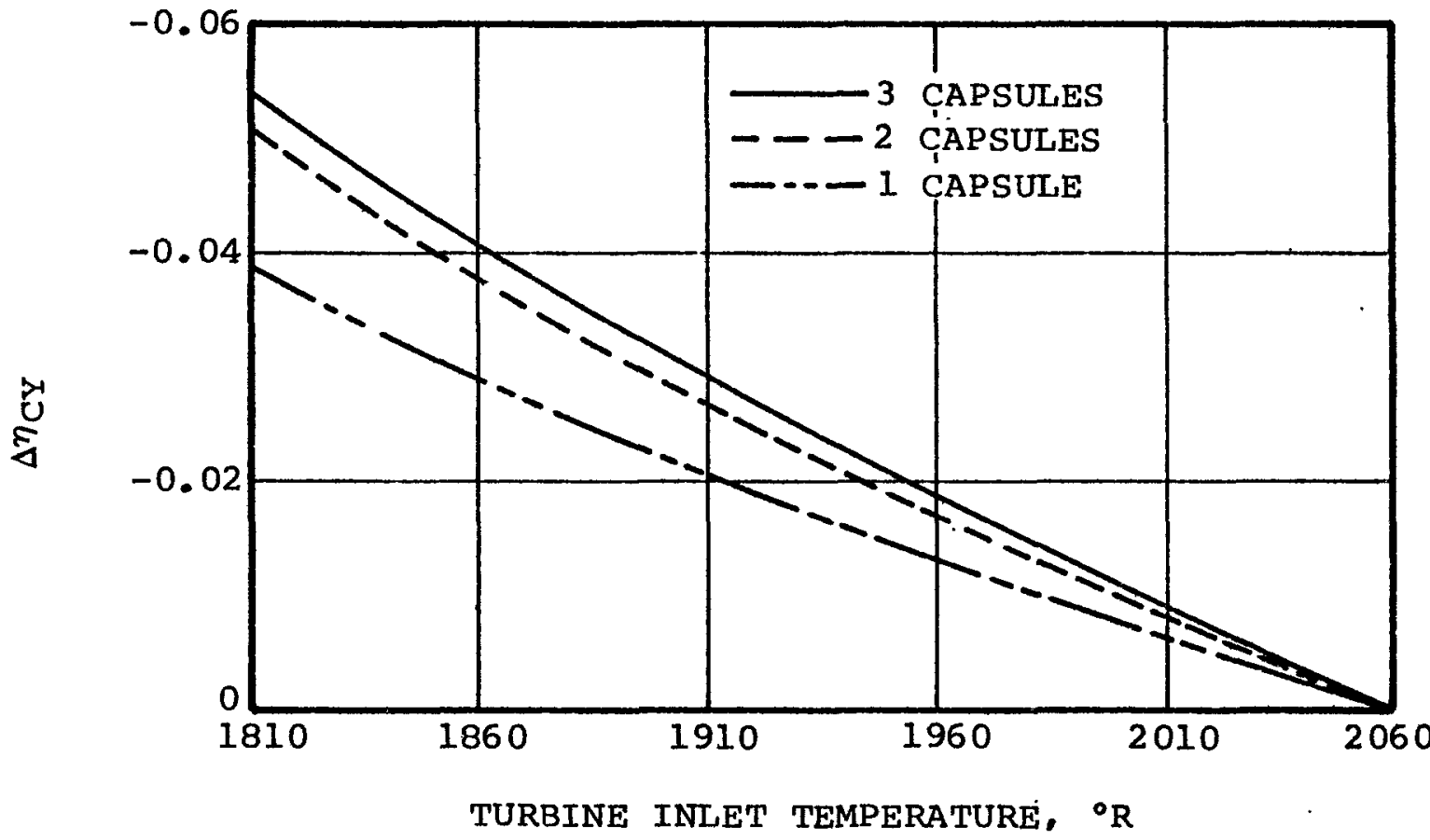

EFFECT OF TURBINE INLET TEMPERATURE ON OVERALL PERFORMANCE

FIGURE I-5 
TABLE I-6

OFF-DESIGN PERFORMANCE

Parameter

Compressor Efficiency

Turbine Efficiency

Alternator Efficiency

Compressor Inlet Temperature

Emissivity

Pressure Drop

Bearing Loss

Recuperator Effectiveness

Heat Loss

Sink Temperature

Turbine Inlet Temperature
New Value Delta Multiplier $\underline{\Delta \eta} c_{y}$

$\begin{array}{llll}0.747 & -0.01 & -0.01 & -0.0055\end{array}$

$\begin{array}{llll}0.808 & -0.01 & -0.01 & -0.0055\end{array}$

$\begin{array}{llll}0.917 & -0.01 & -0.01 & -0.0032\end{array}$

$\begin{array}{llll}510 & 10 & 10.0 & -0.0060\end{array}$

$\begin{array}{llll}0.80 & -0.03 & -0.03 & -0.0023\end{array}$

$\begin{array}{llll}0.975 & 0.003 & 0.003 & -0.0024\end{array}$

$\begin{array}{llll}0.145 & 0.008 & 0.0584 & -0.0018\end{array}$

$\begin{array}{llll}0.950 & -0.025 & -0.02 & -0.0300\end{array}$

$\begin{array}{llll}0.160 & 0.03 & 0.03 & -0.0090\end{array}$

$420+30 \quad--\quad-0.0088$

$2010 \quad-50 \quad--\quad \underline{-0.0080}$

Total $\quad-0.0825$

$($ or $-8.25 \%)$ 
In more practical cases, only a few performance variables would generally be considered at one time. Assuming that compressor efficiency, radiator emissivity, and bearing loss have new values as indicated in Table I-6, cycle efficiency would then be reduced 0.96 percent.

To bring the cycle efficiency back to the original value, the compressor inlet temperature sensitivity factor is used to determine the required increased temperature:

$$
\mathrm{T}_{1_{\text {new }}}=500+0.0096 /(-0.0006)=484^{\circ} \mathrm{R}
$$

From Figure $I-7,(\Delta$ area $) /\left(\Delta \mathrm{T}_{1}\right)=-1.03$ and the required radiator area increase is therefore:

$$
\Delta \text { Area }=-16 \times(-1.03)=16.48 \mathrm{ft}^{2}
$$

for a total of $127.08 \mathrm{ft}^{2}$, which represents a 14.5 percent increase.

This simplified approach to performance parameters effects on cycle efficiency, loses accuracy as parameters increase. Also, when the radiator size is changed, the performance of other components are changed slightly. Therefore, sensitivity factors, etc., should be used with caution.

To aid in assessing performance of a given system, with varying radioisotope quantities, off-design performance of the three systems is presented in Figure I-6. Since surface temperatures would be nearly constant, in each case it was assumed that the change in thermal loss would be insignificant. 
AIRESEARCH MANUFACTURING CDMPANY OF ARIZDNA

A OIVISION OR TME OAMRETr EOAMORATIOE

PHOENIX, ARIZONA

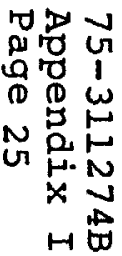

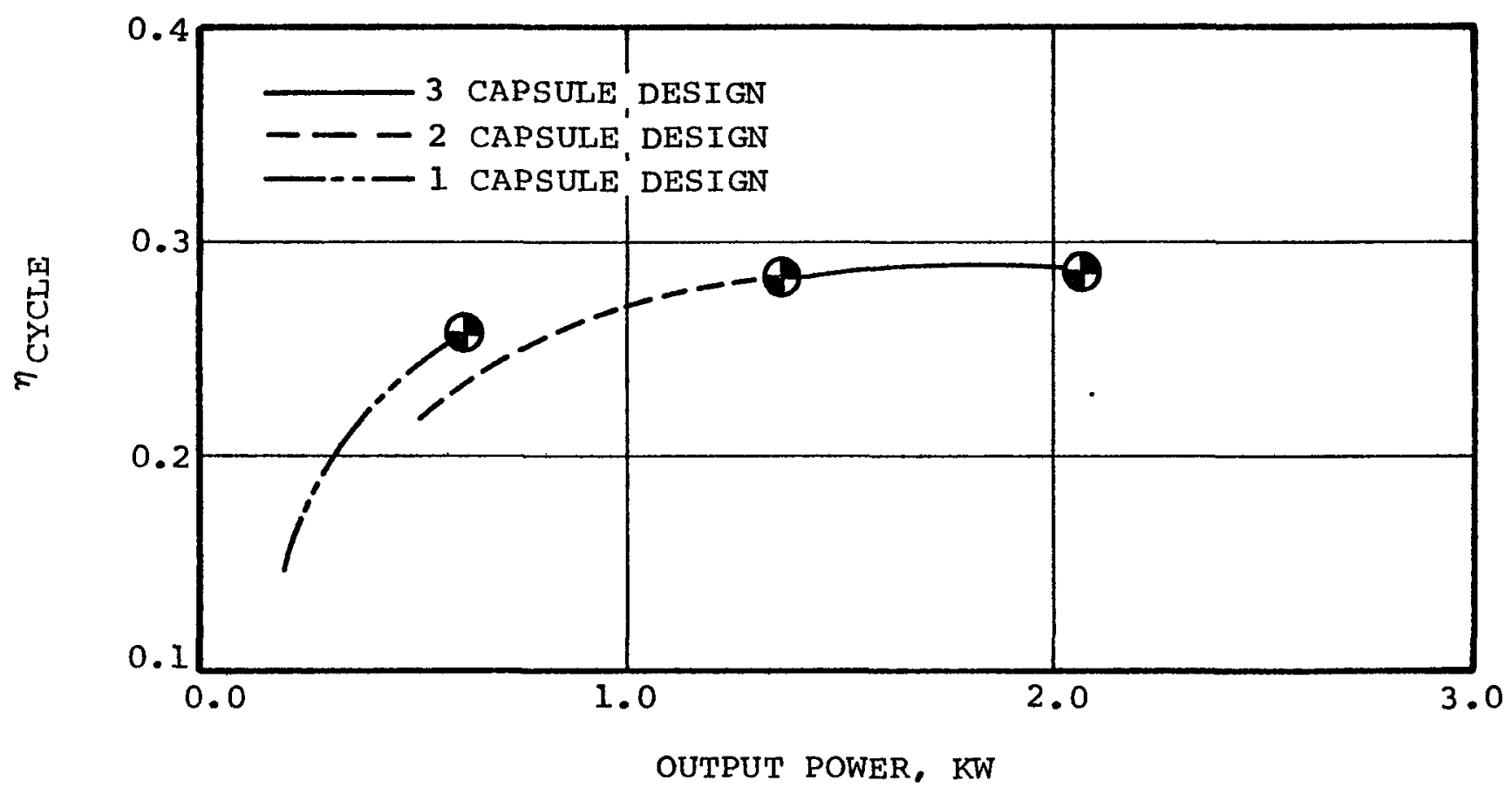

PERFORMANCE SPECTRUM OF 3 MINI-BRAYTON SYSTEMS

FIGURE I-6 
为为为

它

逢亩

(1)

O‥

$x y$

$\rightarrow \stackrel{\leftrightarrow}{b}$

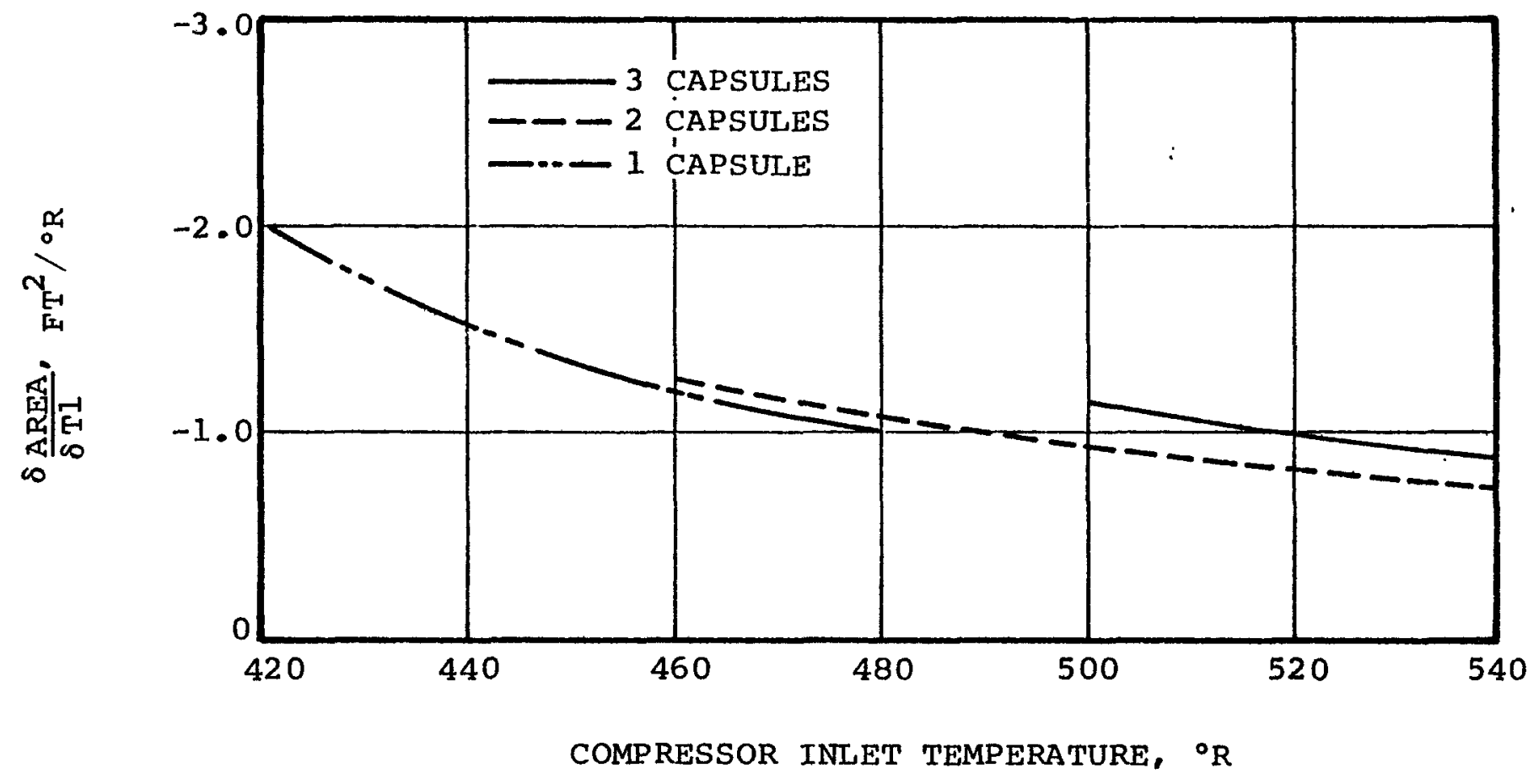

RADIATOR AREA EFFECTS

FIGURE I-7 


\subsection{LEAKAGE RATES}

Estimated leakage rates of GDS components and joints are discussed in Section 3.3.5. FS hardware can be expected to meet or exceed existing estimates of leak tightness. However, assuming that all Fs components and joints leak at the maximum rates estimated for GDS components, the total loss rate is calculated as:

\section{Component}

Mini-BRU

MBR

2 HSA at $1 \times 10^{-9}$

Space Radiator

Duct Welds (46)

Bellows ( 19 with 2 welds each)
Rate (Standard CC He/Sec)

$2.73 \times 10^{-8}$

$1 \times 10^{-7}$

$2 \times 10^{-9}$

$1 \times 10^{-9}$

$4.6 \times 10^{-9}$

$3.8 \times 10^{-9}$

Based on these rates the system total leakage rate is $1.387 \times 10^{-7}$ standard cc He/sec. Since the allowable MBR leakage rate is 72 percent of the total, it may prove feasible to allow only a $1 \times 10^{-9}$ standard $\mathrm{cc} / \mathrm{sec}$ of He leakage rate in the FS MBR.

A constant maximum leakage rate for five years will result in 21.87 standard cc total 1oss. This loss equates to only 0.0146 percent of inventory, since the FS contains 1.16 pounds $(150,079$ standard cc) of $\mathrm{Xe} / \mathrm{He}(\mathrm{MW}=83.8)$ gas at standard conditions. The resultant effects of this loss are negligible.

It is recognized that leakage rates do not normally remain constant, but rather, tend to grow with time. However, this is not considered a problem because the FS can tolerate leakage rates exceeding two orders of magnitude greater than the above noted maximum rate. For example assume the total working fluid loss percentage after 5 years will be as high as the thermal input reduction resulting from 
radioisotope decay. This is the ideal and desired condition because the turbine inlet temperature and system efficiency remain constant.

It is estimated that thermal input will degrade to 96.13 percent after 5-years. An equivalent reduction in working fluid is $0.0387 \mathrm{x}$ $150,079 \mathrm{cc}$, which equates to $5808 \mathrm{standard} \mathrm{cc}$. This computes to a constant system loss of $3.68 \times 10^{-5}$ standard $\mathrm{cc} \mathrm{He} / \mathrm{sec}$, which is 265 times greater than the assumed $1.387 \times 10^{-7}$ maximum rate. From this, it is obvious that the FS can tolerate an average maximum leakage rate exceeding $3 \times 10^{-5}$ standard $\mathrm{cc} \mathrm{He} / \mathrm{sec}$.

The FS control. system will compensate for thermal input, and working fluid decreases. This is accomplished by altering engine speed to maintain a constant turbine inlet temperature $\left(T_{6}\right)$. 


\section{LIST OF REFERENCES}

1. JCS 07700 Volume XIV Revision D, "Space Shuttle System Payload Accommodations."

2. SS-STS-100 Volume 3 Code Identification $07868^{\text {"Interim Upper }}$ Stage system Segment Basic Requirements for January 76.

3. GE-BIPS-20-001. "Mission Environments for The Isotope Brayton Flight System (Preliminary), August 8, 1975", Memo No. BIPS-GDSG0017, 10-22-75. 

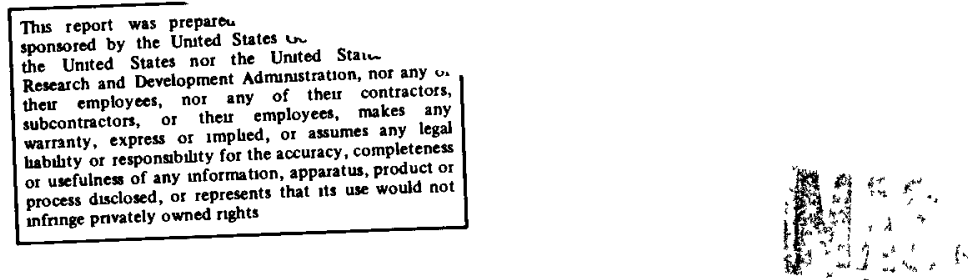

DISTRIBUTION OF THIS DOCUMENT IS UNMIMITEN 
The NoTICE

Thes report was prepared as an account of work the United States nor the United States Energy Research and Development Admunustration noz any of their employees nor any of their contractors subcontractors or their employees makes any

warranty express or impled or assumes any legal

pr uneful respon any

process disclosed or represents that is use would or

infunge privately owned rights

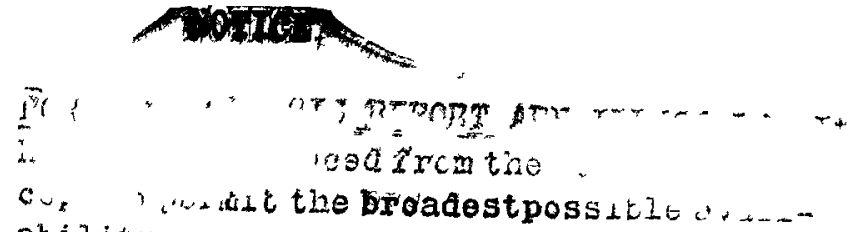
ability.

BRAYTON ISOTOPE POWER SYSTEM

PHASE I

(GROUND DEMONSTRATION SYSTEM)

CONFIGURATION CONTROL

DOCUMENT (CCD)

- $75-311274 \mathrm{~B}$

March 15, 1976

Prepared by: Engineering Staff/BAP

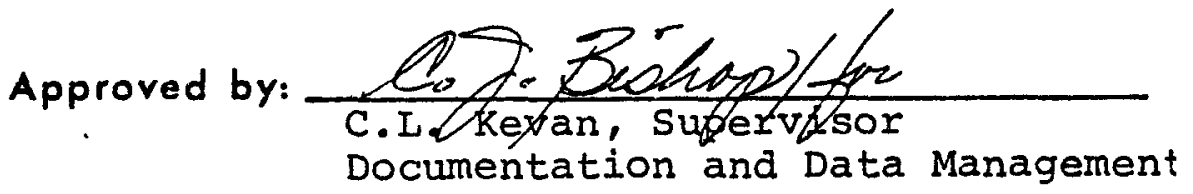

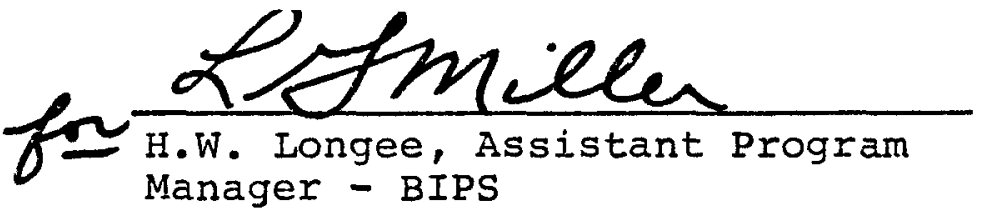

AIRESEARCH MANUFACTURING COMPANY DF ARIZQNA

A OIVIGION OF THE GARRETT CGRPOAATION 
REPORT NO. $75-311274 \mathrm{~B}$

TOTAL PAGES

88

ATTACHMENTS: Appendix I - 26 Pages

Appendix II - 9 Pages

Appendix III - 24 Pages

\begin{tabular}{|l|c|l|c|c|}
\hline REV & BY & APPROVED & DATE & PAGES AND/OR PARAGRAPHS AFFECTED \\
\hline NC & BAH & $\begin{array}{l}\text { See Title } \\
\text { Page } \\
\text { See Title } \\
\text { Page } \\
\text { See Title } \\
\text { Page }\end{array}$ & $5-9-75$ & Initial Issue \\
CJBD & $3-15-76$ & Complete Revision \\
Complete Revision & & \\
\hline
\end{tabular}




\section{TABLE OF CONTENTS}

$\underline{\text { Page }}$

$1-1$

1.1 Purpose

$1-1$

1.2 Organization of Material

$1-2$

2.0 CONFIGURATION CONTROL PROCEDURES 2-1

2.1 Scope $2-1$

2.2 Specific AiResearch Configuration Control system 2-1

2.2.1 Specifications $2-2$

2.2 .2 Drawings $2-2$

2.2.3 Release Record 2-2

2.2.4 Subcontractor $2-2$

3.0 SYSTEM DEFINITION $3-1$

3.1 System Objectives $3-2$

3.1.1 Performance Objectives $3-2$

3.1.2 Design Criteria 3-4

3.2 Applicable Documents 3-4

3.3.1 Thermodynamic Cycle 3-4

3.3.2 Reference Cycle 3-6

3.3.3 Operating Environment 3-6

3.3.4 System Assembly 3-9

3.3.5 System Leakage Rates 3-9

3.3.6 Operational Transient Characteristics 3-10

3.3.6.I System Characteristics 3-10

3.3.6.2 MBR Characteristics 3-10

3.3.6.3 HSA Characteristics 3-10

3. 4 BIPS-GDS Components

3.4.1 Mini-Brayton Rotating Unit (Mini-BRU) 3-13

3.4.1.1 Compressor 3-16

3.4.1.2 Alternator 3-16

3.4.1.3 Turbine 3-19

3.4.1.4 Cooling Cyctem 3-25

3.4.1.5 Gas Bearing System 3-25

3.4.1.6 Instrumentation $3-32$

3.4.1.7 Physical Data 3-33 
TABILE OF CONTENTS (Contd)

3.4.1.7.1 Weight Analysis

3.4.1.7.2 Interface Data - Static

3.4.1.7.3 Interface Data - Dynamics

3.4.1.8 Electrical Data

3.4.1.8.1 External Magnetic Field

3.4.1.9 Radiation Tolerance

3.4.1.10 Handling and Storage

3.4.1.11 Cleaning

3.4.1.12 Nuclear

3.4.2 Mini-Brayton Recuperator (MBR)

3.4.2.1 Physical Data

3.4.2.1.1 Materials

3.4.2.1.2 Structural Design Criteria

3.4.2.2 Detail Design Data

3.4.2.3 Installation Data

3.4.2.4 Environmental Conditions

3.4.2.5 Maximum Allowable Leakage

3.4.2.6 Nuclear

3.4.3 Heat Source Assembly (HSA)

3.4.3.1 Auxiliary Cooling system (ACS)

3.4.3.2 Emergency Cooling System (ECS)

3.4.3.3 HSHX

3.4.3.4 Development Status

3.4.3.5 Interface Data

3.4.4 Heat Rejection Heat Exchanger (HRHX)

3.4.4.1 Steady-State Performance

3.4.4.2 Dynamic Simulation

3.4.4.3 Structural Analysis

3.4.4.4 Structural Integrity

3.4.4.5 Performance Verification

3.4.4 Controls
Page

$3-33$

$3-33$

$3-35$

$3-35$

$3-36$

$3-36$

$3-36$

$3-36$

$3-36$

$3-37$

$3-57$

$3-37$

$3-43$

$3-44$

$3-44$

$3-46$

$3-46$

3-46

$3-47$

$3-48$

3-52

3-53

3-53

3-53

$3-55$

$3-55$

3-55

3-57

3-57

3-57

$3-59$ 
TABLE OF CONTENTS (Contd)

$\underline{\text { Page }}$

3.4.5.1 Development Status

3-59

3.4.5.2 Reliability

$3-60$

3.4.5.3 Physical Data

$3-60$

3.4.5.4 Description of Operation

$3-60$

3.4.5.5 Drawings and Parts List

$3-64$

3.4.5.6 Interface Data

$3-64$

3.4.6 Ancillaries

$3-65$

3.4.6.1 Bi-Metallic Joints

$3-65$

3.4.6.2 Ducting

3.4.6.3 Structure

$3-65$

3.4.6.4 Insulation system

$3-69$

$3-70$

3.4.7 GDS Tests

$3-73$

\subsection{FACILITY}

4.1 Facility Energies Requirements

$4-1$

4.2 Clean Room Requirements

$4-3$

4.3 Vacuum System Requirements

$4-3$

4.3.1 Vacuum Chamber

$4-3$

4.3.2 Pumping Requirements

4-3

Appendix I - Brayton Isotope Power System Flight system (BIPS FS)

Appendix II - Background Information

Appendix III - BIPS FS Design Information 
BIPS PROGRAM

ABBREVIATIONS AND ACRONYMS

\section{(ㄱ)}

AEC RR

AIRPHX

AIRLA

AFSCF

AM

AOA

ASE

ARS

ATO

ATcs

BCL

BOM

BIPS

BRC

c

cCAFS

CCD

CCTV

CFM

e.g. or

$\mathrm{CO} 2$

CRT

CSI

DAS

$\mathrm{db}$

DC

DCS

Delta-V

or $\Delta V$

DOD

DOD STS
Auxiliary Battery System Auxillary cooling System IEOr HSA

Attitude Control System Atomic Energy Commission (nOW ERDA)

Atomic Energy Commission Procurement Regulation

AiResearch, Phoenix

AiResearch, Los Angeles

Air Force Sateliite Control

Amplitude Modulation

Abort-once-Around

Airborne Support Equipment Subsystem

Abort-To-orbit

Active Thermal Control

Subsystem

\section{(B)}

Battelle Columbus Laboratory Beginning of Mission

Brayton Isotope power system Brayton Rotating Unit

\section{(c)}

Celsius (Centigrade) Degrees Cape Canaveral Air Force station

Configuration Control Document

Closed Circuit Television

Cubic Feet per Minute

Center of Gravity

Carbon Dioxide

Cathode Ray Tube

Control Servo Input

\section{(D)}

Data Acquisition System

Decibel

Direct current

Demonstrator Cooling System

Velocity Change in Feet

per second

Department of Defense

Department of Defense Space Transportation Syster

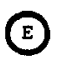

EAT

EAFB

EPFS

ECLS

ECs

EHS-D

EHS-s

ELS

EMS

EOM

ESD

ET

EPS

ERDA

EVA

Engineering Assembly

Instructions

Edwards Air Force Base

Electrically zowered Flight

Systera (PCS + EHS-D)

Environmental Control and Life support

Emergency Cooling System

(for HSA)

Eastern Launch Site

Material Specification

(AiResearch Term)

- End of Mission

Electronic System Division

(of Air Force Systems Command)

External Expendable Tank

Electrical Power Systen

Extravehicular Activity
Atmospheric Revitalization

Electrical Heat Source - Dynamic

Electrical Heat Source - Static

Energy Research and Development

Administration (Formerly AEC)
FIB

FM

FMA

FMEA

FMECA

FPR

fps

Fs

FSA

FSAR

FSE

Fuo

FT

FWW

GDS

GE

GET

GFE

GMS

GN2

GN LC

GSE

GTC

HS

HSA

HRHX

HSHX

HSIS

HSS

IBFS

IBGDS

Fahrenheit Degrees

Filght Battery System Required

for start in orbit

Fuel Impact Body

Frequency Modulation

Faslure Mode Analysis

Failure Modeg and Effects Analysis

Fafjure Modes, Effects and

Criticality Analysis

Federal Procurement Regulation

Feet per second

Flight System

Fuel Sphere Assembly

Final Safety Analysis Report

Flight Support Equipment

Follow-up Output

Feet, Foot.

Food, Water and Wast

Management

(G)

Acceleration Due to Gravity Ground Demonstration System PCS + EHS-S

General Electrie, Valley Forge

Ground Elapsed Tine

Government Furnished Equipment

Gas Management System

Greenwich Mean Time

Gaseous Nitrogen

Guidance, Navigation and Control

Ground Support Equipment

Ground Test Console (a STE/ GSE item)

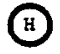

Heat Source (Same as and replaced by IHS)

tieat Source Assembly (Does not include Ins of kSS. Does inalude Hsth, gtruss.

Heat Rejection Heat Exchanger
(Radiator simulator for GUS)

Heat Source Heat Exchanger

Heac Source Insulation System

Heat Source Simulator (Same

as and replaced by EHS)

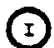

Isotope Brayton Flight System

Isotope Brayton Ground Demonstration System (PCS + EHS-s)

IHE

IHS

IMU

IUS

Handling Equipment

Isotope Heat Source

Inertial Measurement unit

Interius upper Stage

Intra Vehicular Activity

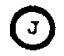

JPL

Jet Propulsion Laboratory

(Rasadena, California)

JFC

Johnson Space Center (Houston)

$\mathrm{KB}$

Kbaud

xbps

RSC

$\mathrm{KW}$

$\mathrm{KW}_{t}$

\section{(B)}

Keyboard

Code Elements per second in 1,000 's

Bits per second in 1,000's

Kennedy space Center

Kilowatts Electrical

Kilowatts The rmal 


\section{ABBREVIATIONS AND ACRONYMS \\ (CONTD)}

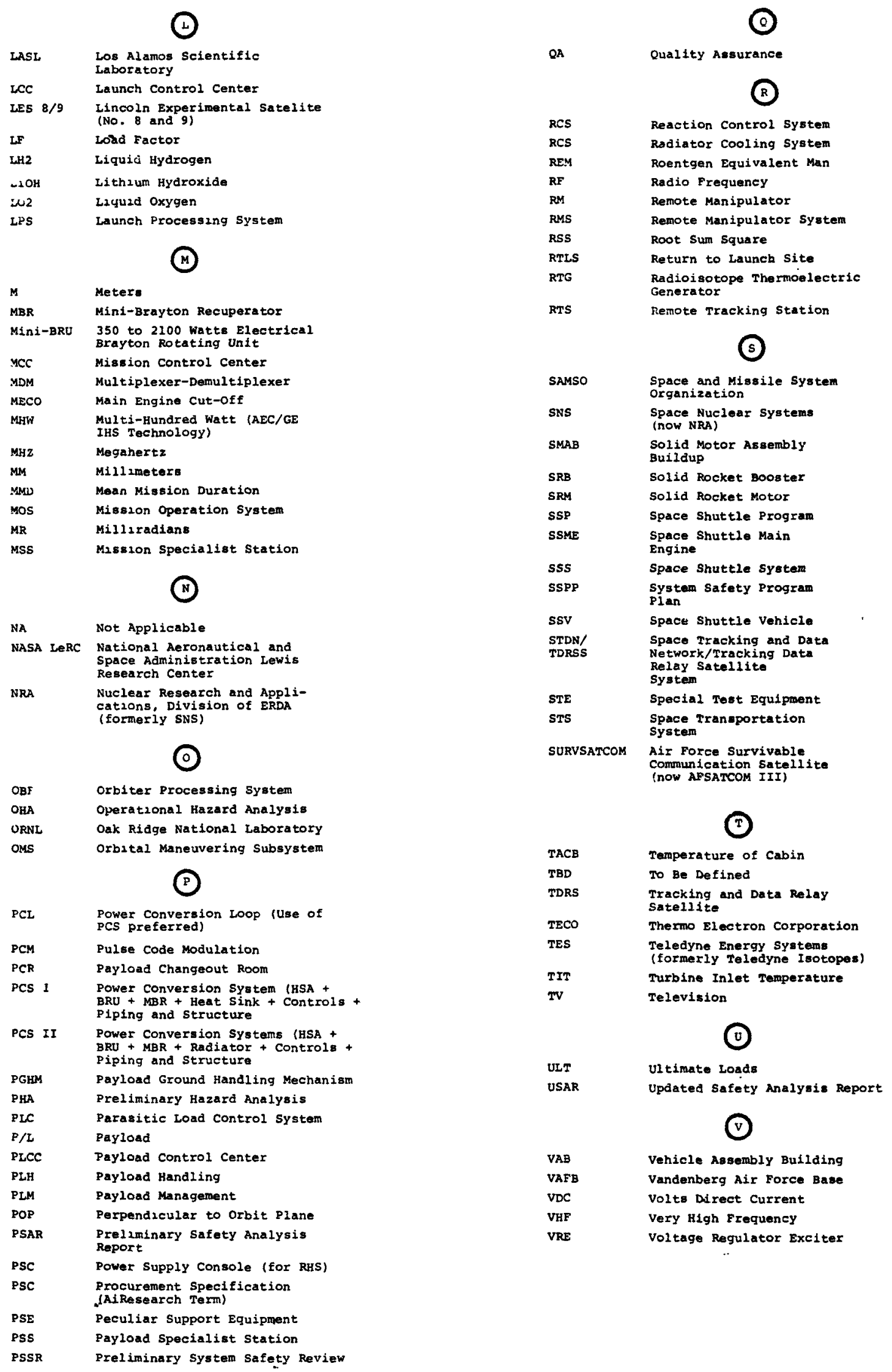




\section{BRAYTON ISOTOPE POWER SYSTEM \\ PHASE I \\ (GROUND DEMONSTRATION SYSTEM) \\ CONFIGURATION CONTROL \\ DOCUMENT (CCD)}

\subsection{INTRODUCTION}

This CCD was prepared by AiResearch Manufacturing Company of Arizona, a Division of The Garrett Corporation, under NASA Contract NAS3-18517 (NASA Mini-BRU Program). Revisions to this CCD are published, as system design progresses, under ERDA BIPS Contract E(04-3)1123.

\subsection{Purpose}

This CCD defines the BIPS-GDS configuration. The GDS configuration is similar to a conceptual flight system design, referred to herein as the BIPS-FS, and which is discussed in Appendix I. The BIPS is being developed by ERDA as a 500 to $2000 \mathrm{~W}_{\mathrm{e}}$, 7-year Iife, space power system utilizing a closed Brayton cycle gas turbine engine to convert thermal energy (from an isotope heat source) to electrical energy at a net efficiency exceeding 25 percent.

This CCD relates to Phase I of an ERDA Program to qualify a dynamic system for launch in the early $1980^{\prime} \mathrm{s}$. Phase I is a 35-month effort to provide an FS conceptual design and GDS design, fabrication, and test. The baseline is a 7-year life, 450-pound, $4800 \mathrm{~W}_{t^{\prime}} 1300 \mathrm{~W}_{\mathrm{e}}$ system which will use two multihundred watt (MHW) isotope heat sources being developed by GE under ERDA contract AT (29-2)-2831. The baseline FS will also utilize components and technology being developed by NASA under Contracts NAS3-18517, NAS3-18029, and NAS3-18541 for the: Mini-Brayton rotating unit (AIRPHX); recuperator (AIRLA); and heat source assembly (GE); respectively. 
It is intended that the GDS simulate the FS as closely as possible. Testing includes detailed performance and 1000-hours endurance.

Information presented herein is intended to ensure proper integration of system components into a complete system. It is intended as a ready reference for all organizations such as ERDA, NASA, and industry contractors participating in BIPS development. This CCD provides the reader sufficient information and direction to obtain drawings and documents such that a system description can be obtained to any level desired. The CCD also serves as a working document, and index, to supporting detail documentation. Appendix III presents a listing of BIPS related documents and drawings.

\subsection{Organization of Material}

This document includes reference material, a related documents listing, and pertinent system and components design data. Also included is a preliminary BIPS-FS design description (Appendix I) and certain appropriate background information that may be useful to potential users (Appendix II). All drawings referenced in the text herein are included, in numerical order, in Appendix III.

As a working document, this $\operatorname{CCD}$ will be revised as necessary to maintain current descriptions of the components and system. After completing Phase I, the CCD will provide a GDS "as-built" description and record. When sufficient information is available, either new or changed, this $C C D$ will be revised and updated to reflect these changes. Between these major revisions, Addenda and Errata will be issued to provide the most current information to all CCD holders.

Due to the current preliminary status of the GDS, some paragraphs herein are noted with a TBD (to be determined). When the status of TBDs become known or defined, this information will be included in Addenda and Errata, or updated editions of this CCD, as appropriate. 


\subsection{CONFIGURATION CONTROL PROCEDURES}

\subsection{Scope}

Configuration practices described herein will assure technical and administrative direction and surveillance to: ( 1 ) identify and document functional and physical characteristics of a configuration item; (2) control changes to these characteristics; and (3) record and report change processing and implementation status. Specifically, configuration management will accomplish the following:

- Control and Documentation - Provide product configuration control and documentation through assemblies, subassemblies, and parts.

- Interfacing - Assure interface compatibility with customer installation.

- Change Control - Utilize established AIRPHX procedures for evaluation, coordination, and approval/disapproval of baseline equipment configuration changes.

- Vendor Control - Impose and monitor configuration control disciplines on AIRPHX vendors.

AIRPHX intends to utilize present organization and management practices, as applicable, in performing the ERDA/BIPS GDS program, and all subsequent phases (i.e., BIPS-FS).

\subsection{Specific AiResearch Configuration Control System}

An original baseline configuration, as defined on AIRPHX drawings, will be established. Changes to existing drawings and/or new drawings will be integrated into the baseline, until a qualification baseline is established. 


\subsubsection{Specifications}

Equipment specifications applicable to the level of equipment to be procured will be prepared to define recommended technical requirements and acceptance criteria for the product. Specifications will conform to MII-STD-490 format. Lists of Materials and Processing Specifications, in existence, or to be prepared, are included in Tables I and II of AIRPHX Report 76-311737 (Specification Requirements Summary for the BIPS).

\subsubsection{Drawings}

A complete set of engineering drawings will be prepared to define each procured item. Drawings will be prepared to the format defined in the AiResearch Drafting Room Manual, which satisfies MIL-STD-100A and MIL-D-1000 requirements.

\subsubsection{Release Record}

Drawings, related data, and associated changes, are released by Engineering Project in accordance with the AiResearch Drafting Room Manual and Operating Procedures.

\subsubsection{Subcontractor}

Major subcontractors will be required to comply with MIL-D-1000 and MIL-STD-100A requirements. 


\subsection{SYSTEM DEFINITION}

This CCD defines the GDS, but as previously stated, the GDS design represents typical flight hardware. Therefore, for information, the FS used as a model is described in Appendix I.

Basic Phase I objectives are to:

(a) Conduct a two-phase flight system conceptual design, to establish typical flight system requirements, as the basis for GDS design.

(1) The first phase summarizes requirements known on October 1, 1975.

(2) A finalized conceptual design will be prepared in the last quarter of 1976.

(b) Design, fabricate, and assemble the GDS and accomplish performance and endurance testing.

(c) Conduct any long lead development necessary to effect first production FS delivery by April 30, 1981.

Testing will be conducted in an AIRPHX facility equipped to provide the clean room, assembly, and test support systems required to meet these basic objectives. The overall test system configuration is defined on Drawing 306960.

System testing will provide valuable data contributions that will assist in confirming the following design considerations: 
- Component Performance

- Synergistic Effects

- System Performance

- Control System Definition

- Startup and shutdown

- Electrical Power Quality

- Material Compatibility

- Material Contamination

- Thermal Gradients

- Reactive Torques and Component Loading

- Electromagnetic Fields

- Insulation Effectivity and structural Heat Loss

- Configuration Flexibility

- Preflight Checkout

- Maintainability

- Instrumentation/Test Equipment

- Endurance Test Cost/Hr

- FMECA Substantiation

- System Confidence

\subsection{System Objectives}

It is intended that the GDS satisfy performance objectives and design criteria specified below.

\subsubsection{Performance Objectives}

GDS design objectives are, to the greatest extent possible, identical with FS performance objectives shown on Table I-I, Appendix I. Some noteworthy GDS differences are:

(a) The MBR and HSA are designed to meet Requirement (4). The radiator simulator (HRHX) is not. 
(b) The heat rejection method will utilize a liquid-cooled heat exchanger to simulate the working-fluid side of a space radiator.

(c) The weight goal, Requirement (6), will not be met since (1) the actual radiator will not be used, and (2) beryllium will not be used for the GDS support structure and HSA housing as contemplated for the FS.

(d) An electrically heated simulated isotope heat source will be used, which limits output power to $1300 \mathrm{w}_{\mathrm{e}}$ A slave heater has been proposed, which allows operation over the entire 500 to $2000 \mathrm{w}_{e}$ range.

(e) Controls will consist of breadboard circuits using military grade components.

(f) $120 \pm 2$ percent vac will be the reference output voltage after alternator output rectification. Refer to Monthly Progress Report 75-311457(02), Appendix B, "Output Voltage study".

Several potential requirements may materialize at a later date. Examples of these are:

(a) Provision for operation through launch

(b) Provision for fueling on the pad or in orbit

(c) Partial or complete power system spacecraft integration

System layout is based on objectives listed on Table I-I, Appendix I. Any new performance and configuration data resulting from Phase I efforts, will be incorporated in Appendix I. 


\subsubsection{Design Criteria}

System design criteria are defined in AIRPHX Report 76-311737, entitled, "BIPS/GDS System Design Specification".

\subsection{Applicable Documents}

Included in Appendix III are lists of applicable documents involving:

(a) BIPS-FS related documents (i.e., study final reports, technical reports, development program plans, and drawings).

(b) Incorporation of Government documents and specifications.

\subsection{System Characteristics}

Subparagraphs 3.3 .1 through 3.3 .6 present specific features and characteristics that are applicable to the GDS.

\subsubsection{Thermodynamic Cycle}

The closed-cycle gas turbine (Brayton cycle) theory of operation is similar to open cycles (Figure 3-1) used in turbojet and turboprop aircraft propulsion engines as well as many electrical, shaft, and compressor-air power generation systems. Closed cycle applications are suited for shaft power generation and electrical power generation with the generator integral to the turbocompressor shaft. The closed-cycle engine is generally recuperated, as shown in Figure 3-1, to obtain a high level of efficiency. The heat source may be any of several energy release systems such as fossil-fuel combustion, chemical reactants, solar, geothermal, and various forms of nuclear power. 

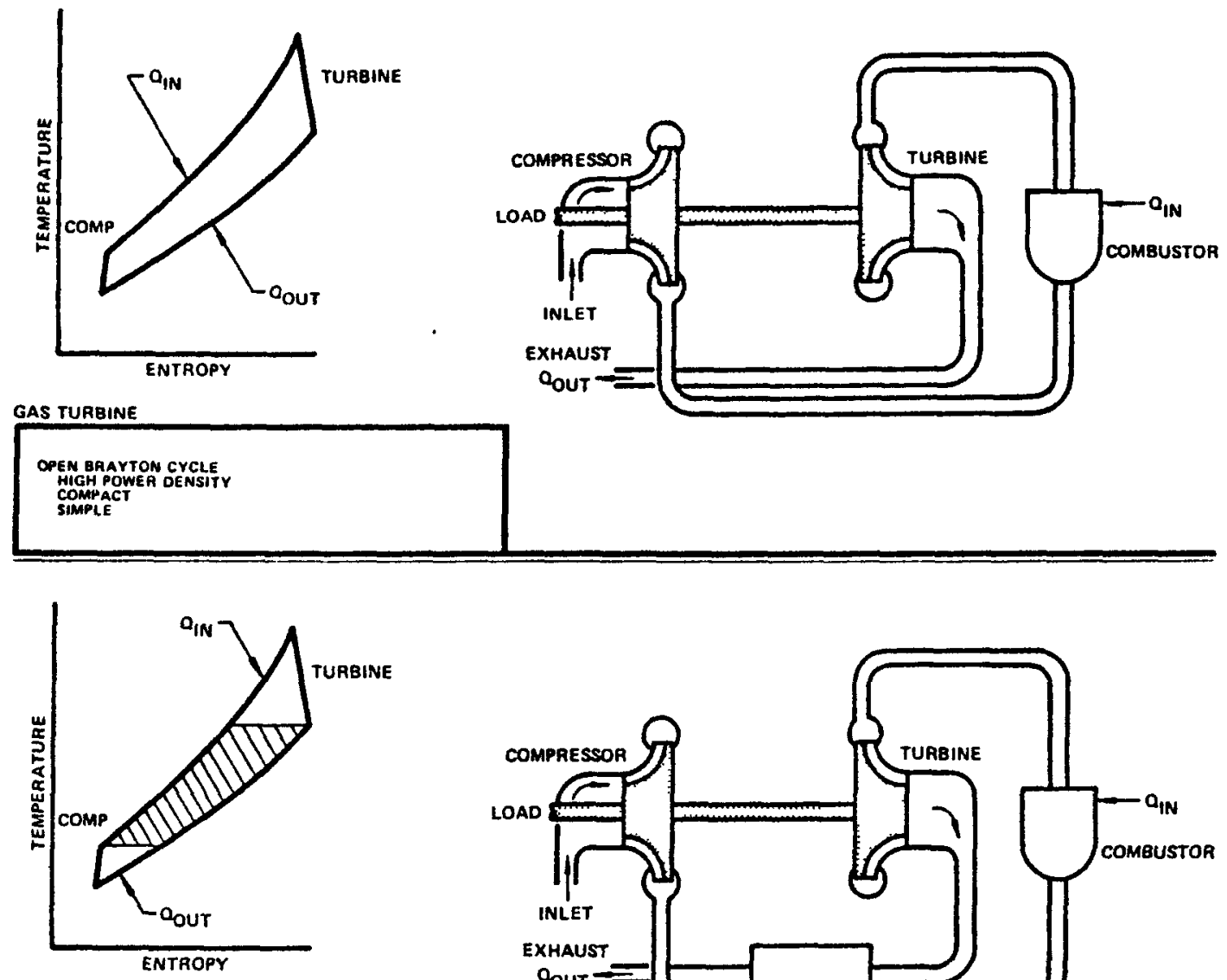

GAS TURBINE

RECUPERATED OPEN BRAYTON CYCLE
REDUCED HEAT NPUT

LOW OPTHMUM PAESSURE RATIO

HIGH AERODYNAMIC EFFICIENCY
HIGH CYCLE EFFICIENCY AT RATEO POWES

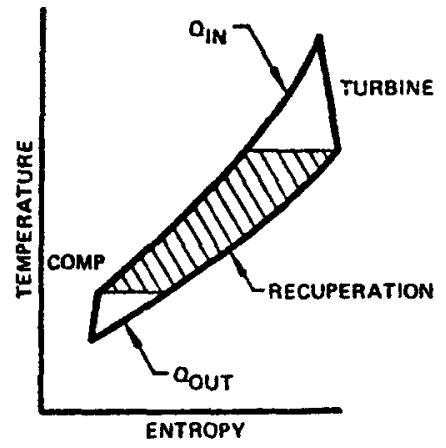

GAS TURBINE

RECUPERATED CLOSED BRAYTON CYCLE

SELECTION OF HEAT SOUACES

getrchron or Working flulos

GEALS

OUIETLLENT OFF DESIGN PERFORMANCE

\section{OPEN VS CLOSED CYCLE GAS TURBINE \\ FIGURE 3-1}




\subsubsection{Reference Cycle}

The reference cycle showing all state-point conditions is presented in Figure 3-2. The GDS reference design energy balance is shown in Figure $3-3$.

Predicted GDS performance is based on predicted performance of the rotating unit, recuperator, and HSA, which will be GFE from NASA contracts, and on an assumed thermal loss of 20 percent rather than the 12 percent predicted for the BIPS-FS (refer to Appendix I). Higher GDS thermal loss was assumed because the instrumentation penetrations and insulation removability give heat losses not found in the BIPS-FS. System performance is shown for the same heat input and power output of the FS. Independent variables available to attain this performance are; coolant flow rate, coolant temperatures, and gas inventory.

\subsubsection{Operating Environment}

The environment of the GDS is as follows:

- External Environment

- $<10^{-4}$ Torr for Multi-Foil insulation to be effective

- TBD to prevent excessive contamination of refractory material (allowable levels of $\mathrm{O}_{2}, \mathrm{~N}_{2}, \mathrm{CO}, \mathrm{CO}_{2}$, $\mathrm{H}_{2}$, and other contaminants to be determined).

- Ambient Temperature

- Approximates the expected space radiator internal temperature 


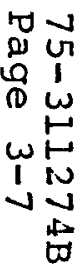

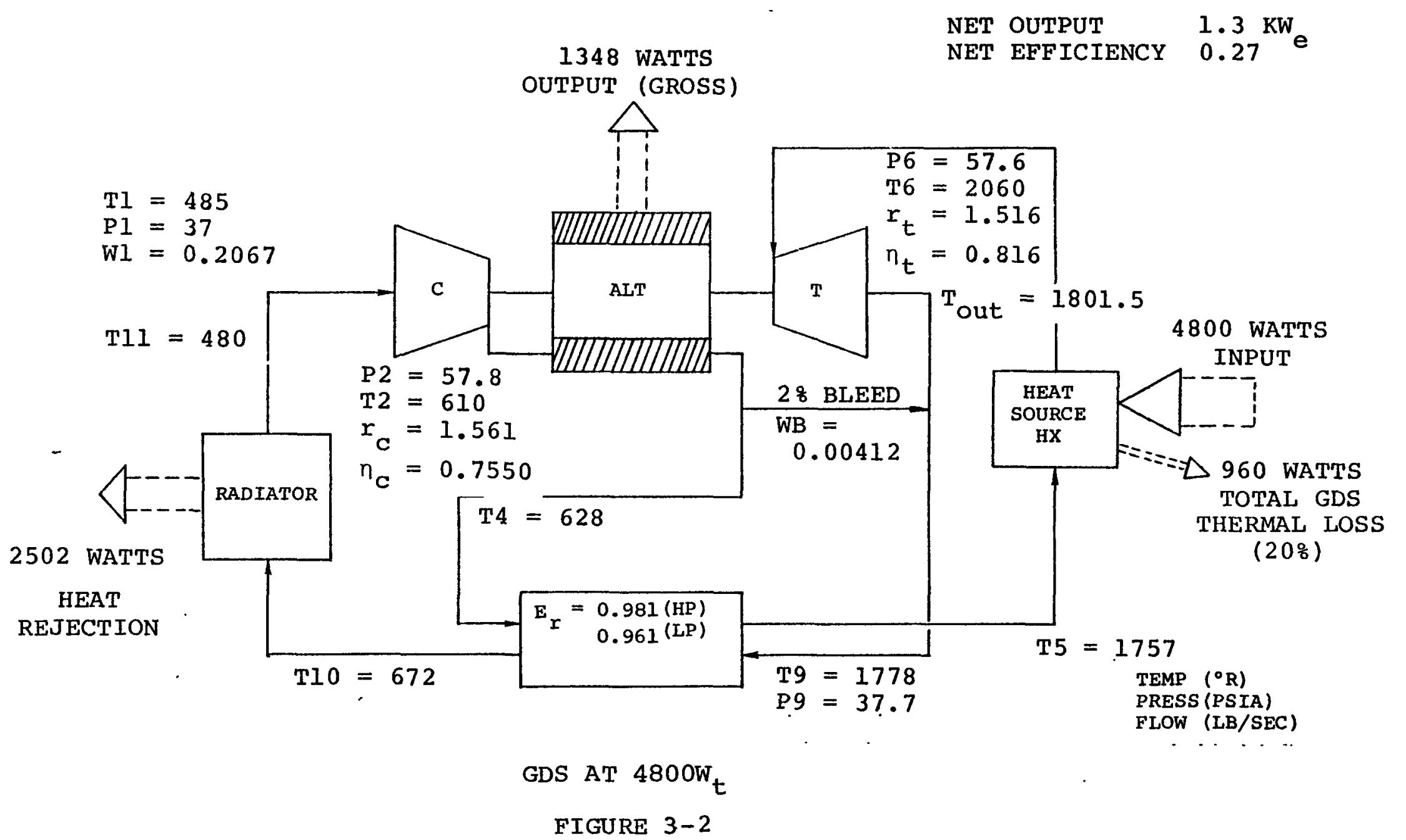



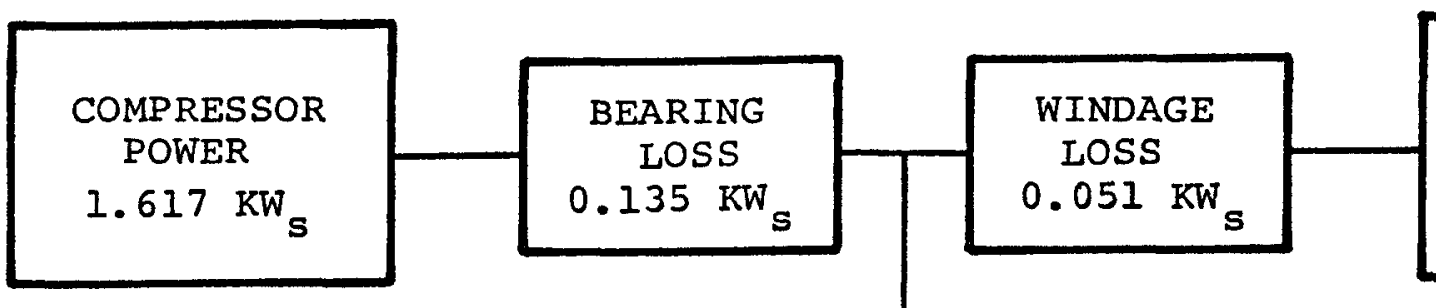

TURBINE

OUTPUT

$3.256 \mathrm{KW}_{\mathrm{s}}$

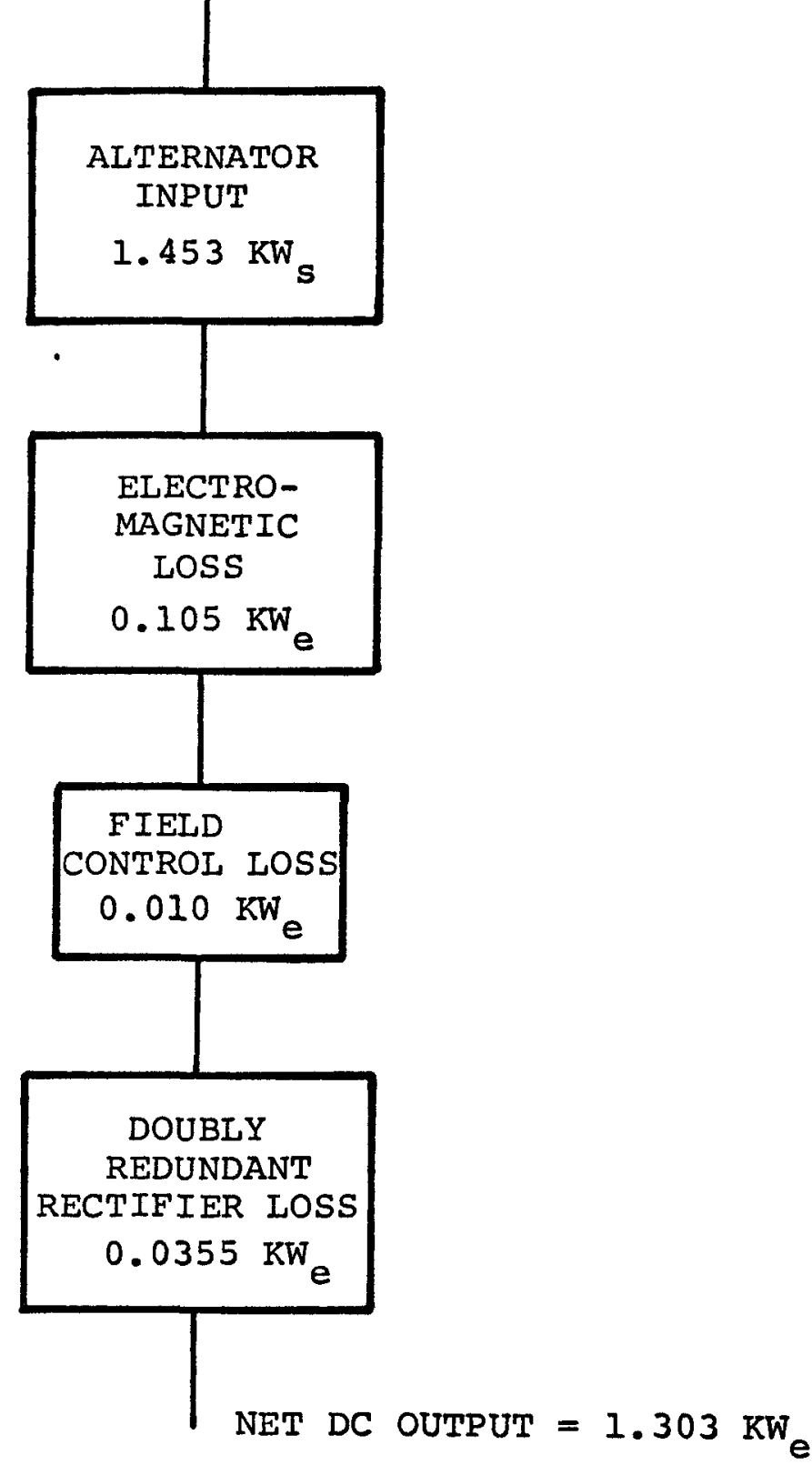

ENERGY BALANCE

FI GURE 3-3

Page 3-8 
- Working Fluid - Xe/He mixture

- Molecular weight 83.8

- Trace amounts of other monatomic gases $<2$ percent

- Allowable contamination levels of $\mathrm{O}_{2}, \mathrm{~N}_{2}, \mathrm{CO}, \mathrm{CO}_{2}$ ' $\mathrm{H}_{2} \mathrm{O}, \mathrm{H}_{2}$, and other contaminates to be determined.

\subsubsection{System Assembly}

The integrated GDS is shown in the drawings listed below:

(a) L3621580, GDS Assembly

(b) L3621583 Sheets 2 and 3, GDS Installed in Test Facility

(c) 306960, GDS Piping and Instrumentation Schematic

\subsubsection{System Leakage Rates}

NASA LeRC-developed components, used in the GDS, have specific maximum contractual leakage rates as follows:

Component

*Mini-BRU, each joint

MBR

HSA
Rate (Standard CC He/Sec)

$1 \times 10^{-10}$

$1 \times 10^{-7}$

$1 \times 10^{-9}$

*Since the Mini-BRU has 33 joints that could lose working fluid to space vacuum, the total maximum leakage rate through joint welds is $3.3 \times 10^{-9}$. In addition, the Mini-BRU contains 12 hermetic connectors used for feed through of electrical and monitoring leads. Each connector may leak at the rate of $2 \times 10^{-9}$ resulting in a total leakage rate through the connectors of $2.4 \times 10^{-8}$. This, added to the joint leakage, results in a Mini-BRU total maximum leakage rate of $2.73 \times 10^{-8}$ 
Preliminary maximum leakage rates for other components comprising the GDS are estimated as follows:

\section{Component}

HRHX

Bellows/interconnecting ducting weld joints (each)
Rate (Standard CC He/Sec)

$1 \times 10^{-9}$

$1 \times 10^{-10}$

\subsubsection{Operational Transient Characteristics}

System and specific components transient performance characteristics are defined below.

\subsubsection{System Characteristics}

System performance characteristics are defined in AIRPHX Report 75-311279A, relative to predicted; voltage, power, speed, pressure, temperatures, and working fluid flows for startup, load changes, and shutdown. Figures III-1, III-2, and III-3 included in Appendix III, are taken from the latest analysis report and represent start transients used for MBR and HSA transient analyses and test definitions.

\subsubsection{MBR Characteristics}

TBD and to be included in an updated edition of this CCD.

\subsubsection{HSA Characteristics}

TBD and to be included in an updated edition of this CCD. 


\subsection{BIPS-GDS Components}

An outline of GDS components is presented on Table 3-1. Component characteristics (i.e., operational limitations, design points, safety factor, acceptance testing parameters, and environmental hazards) will be defined during Phase I and included in future editions of this CCD. Component descriptions, presently defined related data, and related (referenced) detail design reports are presented in paragraphs 3.4.1 through 3.4 .5 below. System sensitivity data, to evaluate the effects of variations in predicted component performance, is provided in Appendix III. 
TABLE 3-1

BIPS-GDS COMPONENT OUTLINE

Mini-BRU

- $1600^{\circ} \mathrm{F}$ turbine inlet temperature (working fluid is Xe-He, $M=83.8$ )

- Single shaft turbine, Rice alternator, and compressor supported on foil bearings with compressor bleed cooling

- Alternator cooled by compressor discharge, output voltage is for a 3-phase 120 vdc rectifier

- Refractory metal turbine plenum (Columbium Alloy C-103)

\section{Recuperator}

- Hastelloy $x$ construction with gold alloy braze

- Fin/plate counterflow design

\section{Radiator Simulator (Heat Rejection Heat Exchanger-HRHX)}

- Inlet and outlet conditions equivalent to a space radiator with 390 degree equivalent sink temperature

\section{Heat Source}

- Electrically heated heat source simulator (EHS)

Heat Source Assembly (HSA)

- Columbium Alloy $\mathrm{C}-103$ heat source heat exchanger (HSHX)

- Auxiliary Cooling System - Helium short circuit of HSHX Multi-Foil insulation

- Emergency Cooling system - Melting of HSHX Multi-Foil insulation (alternatives have been identified).

\section{Insulation}

- High temperature Multi-Foil insulation

- Twenty percent heat loss from HSA, turbine, and hot interconnecting ducting to allow for instrumentation penetration through the insulation, etc.

\section{Controls}

- Motor start inverter

- Parasitic load

- Speed control

- Voltage regulator

- Power Supply

- Rectifier/filter

\section{Piping and Structure}

- Ducting
- Bellows
- Support structure




\subsubsection{Mini-Brayton Rotating Unit (Mini-BRU)}

The Mini-BRU, shown on Figure 3-4, functions to convert $\mathrm{Pu}-238$ radioisotope heat source thermal energy into electricity. The Mini$B R U$ is designed to produce from 0.35 to $2.1 \mathrm{~kW}$ electrical power for space satellite applications. Mini-BRU detail design is completed, with parts fabrication in process. First delivery is anticipated for late 1976 .

The Mini-BRU consists of a radial-flow turbine, radial-flow compressor, and alternator. These components, which are mounted on a common shaft rotating nominally at $52,000 \mathrm{rpm}$ and supported on gas lubricated hydrodynamic journal and thrust bearings, will produce up

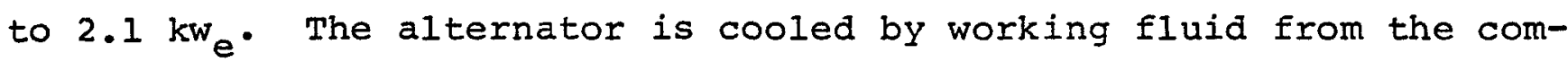
pressor discharge. The Mini-BRU includes a flight-type housing, and turbine and compressor inlet and exit ducting. Mounting pads are provided to permit installation in a space power system. Machined bosses or pads are provided for required instrumentation.

To facilitate alteration and major components replacement, the Mini-BRU is designed for ease of assembly and disassembly. Although specific operating characteristics are dependent on many variables, Mini-BRU components are designed to maintain high efficiency over the specified rated power output range. GDS performance data for $1.3 \mathrm{kw} \mathrm{e}^{\prime}$ 2-capsule heat source operation (1-capsule equates to $2.4 \mathrm{kw}_{t}$ ) are provided on Figure 3-2. However, Mini-BRU versatility is shown on Figure I-6, Appendix I, which relates to operating performance with 1,2 , and 3 heat source capsules.

Mini-BRU characteristics are as follows:

(a) Type of rotating unit: single shaft

(b) Cycle working gas: He-Xe, molecular weight 83.8 


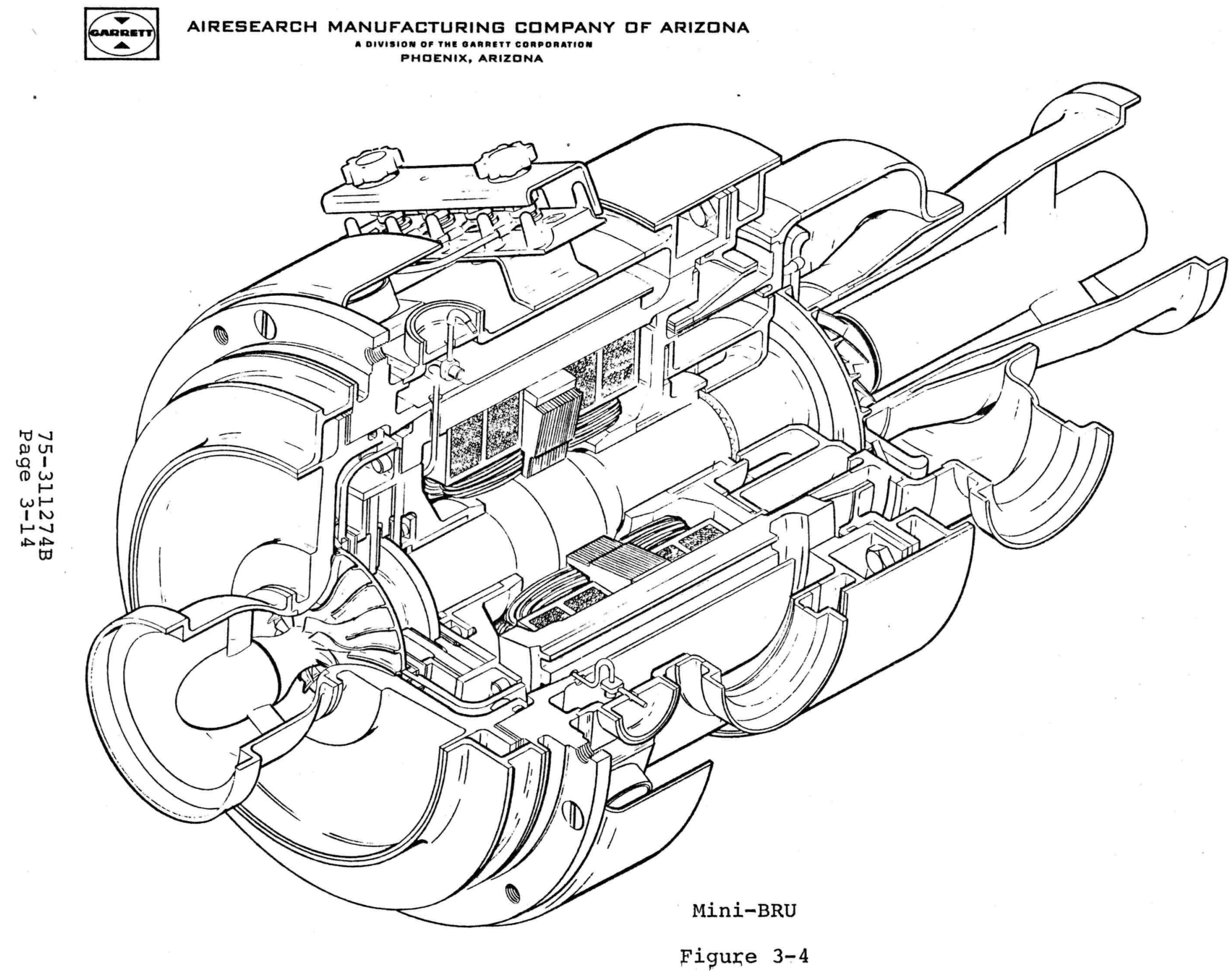

Figure 3-4 
(c) Rated power output range: $\left(350-2146 \mathrm{w}_{e}\right)$. The alternator is designed for a three phase full-wave 120 vac rectifier load.

(d) Turbine:

Type - radial flow

Optimized for 3-capsule configuration - Table I-4, Appendix I

(e) Compressor:

Type - radial flow

Optimized for 3-capsule configuration - Table I-4, Appendix I

(f) Alternator:

Type - stationary excitation coil, brushless, Rice type Lundell. Optimized for performance over the range of 1 to 3 heat source capsules

(g) Overspeed capability - 62,400 rpm (120 percent of nominal $52,000 \mathrm{rpm}$ design speed)

(h) Environmental conditions: Exhibit "E", NASA RFP 3-456906-Q, except as noted in Item (i) below

(i) Design operating life: 10 years at maximum rated power, and turbine inlet temperature, in space vacuum $\left(<10^{-4}\right.$ Torr).

(j) Final balance is consistent with objectives of minimum bearing deflections for 10-year design life.

(k) Design provides the capability for 1000 startupshutdown thermal cycles, minimum. 
(1) Design to assure super alloy and refractory metal scrolls interchangeability with minimum rework.

Pertinent Mini-BRU component data and design features/ characteristics are presented below.

\subsubsection{Compressor}

The compressor is a 2.12 inch diameter radial outflow, backward curved impeller (see Figure 3-5) with vane diffuser and plenum. Compressor design efficiency (76 percent) is lower than larger designs. This is attributed to low specific speed, which results from the low physical speed (tip speed is $480 \mathrm{fps}$ ) required to optimize the entire system. Size effects appear in the form of clearance and tolerance losses. During the design phase, attention was given to increasing the exit absolute flow angle, which increases exit width and reduces the clearance loss. In an effort. to achieve better performance, a tandem diffuser was incorporated. However, because of compressor deficiencies disclosed during testing, and limited development funding, this effort was stopped and a proven single-stage diffuser design was incorporated.

Table 3-2 iterates compressor design parameters from Mini-BRU Final Design Report, 75-311241.

\section{4 .1 .2 Alternator}

The selected alternator is a four-pole Rice machine designed for high efficiency when operated with a 3-phase, full-wave rectifier furnishing $120 \mathrm{vdc}$ to a 350 to 2100-watt load. Preliminary studies for two, four, six and eight poles alternator designs indicated that a four-pole machine had the smallest, lightest rotor. Although total alternator weight was slightly less for six and eight poles designs, efficiencies of these machines were reduced by higher windage losses, 

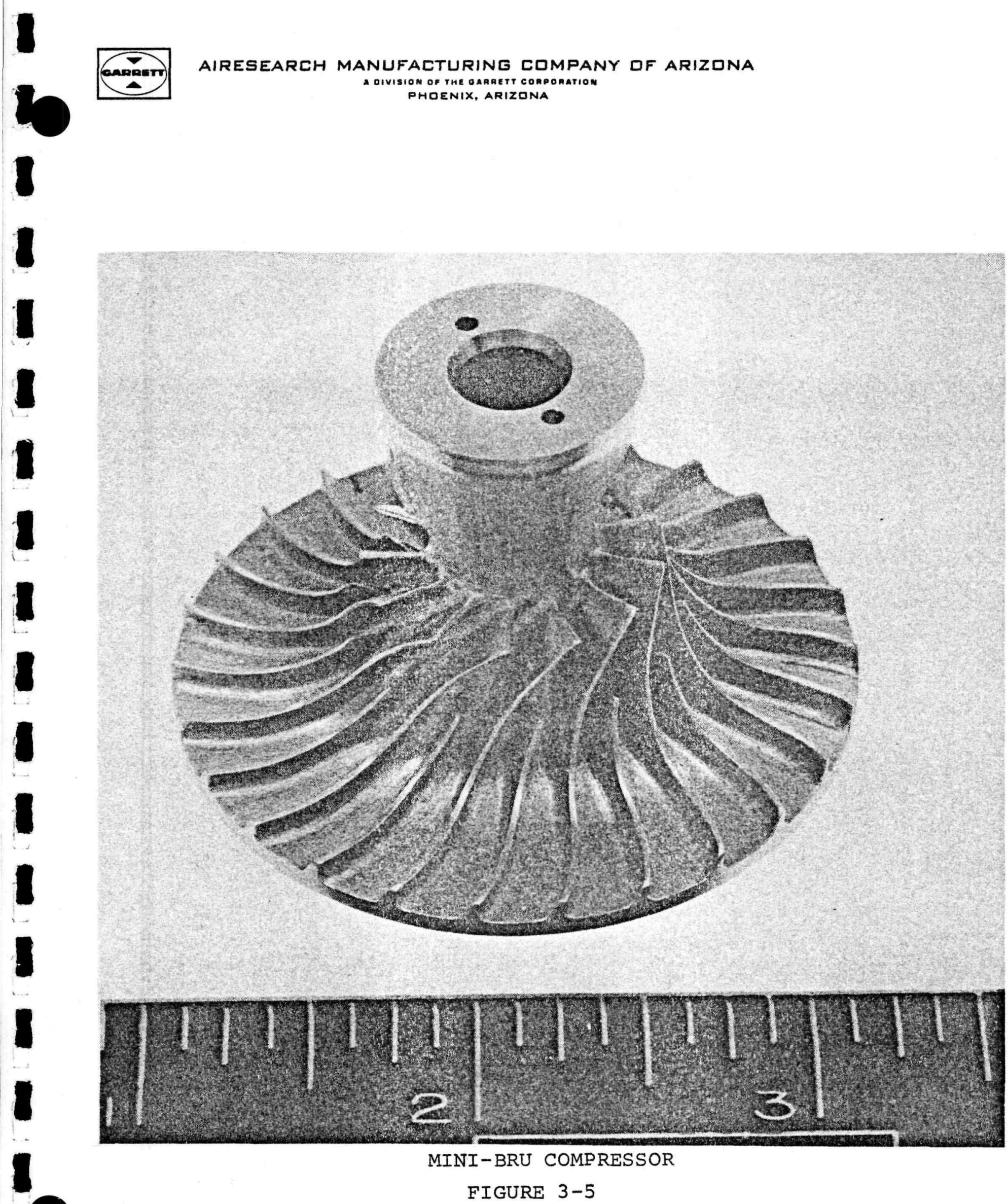

75-311274B

Page 3-17 
MINI-BRU RADIAL COMPRESSOR DESIGN PARAMETERS

(SEE NOTE)

Impeller

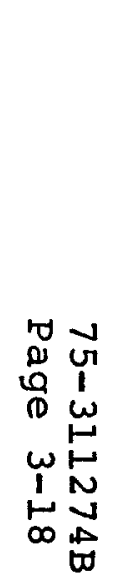

$=\mathrm{Xe}-\mathrm{He} ; \mathrm{MW}=83.8$

$=0.0753 \mathrm{lb} / \mathrm{sec}$

$=51,153 \mathrm{rpm}$

$=0.876$

$=1.579$

$=0.2289$

$=47.4-$ Defined

$=13$ full blades 13 splitters

$=0.931$

$=536^{\circ} \mathrm{R}$

$=70.8$ psia

$=52,000 \mathrm{rpm}$

$=2.12$ inch

$=0.509$ inch

$=0.931$ inch
Stage

$$
\begin{aligned}
n & =0.758 \\
\mathrm{P}_{\mathrm{T} 3} / \mathrm{P}_{\mathrm{Tl}} & =1.500 \\
\Delta \mathrm{T} / \mathrm{T}_{\mathrm{OA}} & =0.2313
\end{aligned}
$$

$\mathrm{N}_{\text {PHYS }}$

Diameter Tip

Inducer Hub Diam

Inducer Tip Diam
$N_{S}=\frac{N \sqrt{Q_{A V G}}}{H_{A C T}^{3 / 4}} \quad$ where $\begin{aligned} N & =R P M \\ Q_{A V G} & =\left(Q_{1} Q_{2}\right)^{1 / 2}, \mathrm{ft}^{3} / \mathrm{sec}\end{aligned}$

$$
\begin{aligned}
& Q_{A V G}=\left(Q_{1} Q_{2}\right)^{1 / 2}, \mathrm{ft}^{3} / \mathrm{sec} \\
& \mathrm{H}_{\mathrm{ACT}}=\text { Head, Ft }
\end{aligned}
$$

NOTE: Impeller efficiency, pressure ratio, and Euler work values calculated during preliminary design analyses. 
caused by larger diameter rotors. The four pole machine was further optimized by increasing field and stator core sizes to fully utilize available space in the alternator heat exchanger ID. Figure 3-6 depicts the alternator, and Table 3-3 provides design data. Additional detailed information is provided in the Mini-Brayton Alternator Final Design Report 75-311211.

Various materials used in alternator construction, such as resins, adhesives, and potting compounds, are listed in Table 3-4.

Behavior of these materials, under required operating temperatures and long. life requirements, will be determined, as accurately as possible, to ensure desired reliability. The exact degree and nature of materials decomposition are not readily available, and in some instances do not exist. Tests to obtain outgassing rates and composition are planned for early 1976.

Alternator instrumentation is illustrated on Figure 3-7. Precise locating dimensions for thermocouples, and the flux search coil located in the stator assembly, are shown on Drawing 2045426, included in Report 75-311211.

\subsubsection{Turbine}

The Mini-BRU radially designed turbine impeller (see Figure 3-8A) has ten full blades, ten splitters, and an overall diameter of 2.858 inches. Considerable attention was given to the 52,000 rpm nominal design speed, and the $0.357 \mathrm{lb} / \mathrm{sec}$ maximum weight flow requirement. This turbine design is much smaller than any previous AiResearch design, thus, direct attention was given the various design details to assure a good performance level.

During a preliminary study, the turbine inlet configuration was a scrall. However, by using a scroll inlet, it was necessary that 


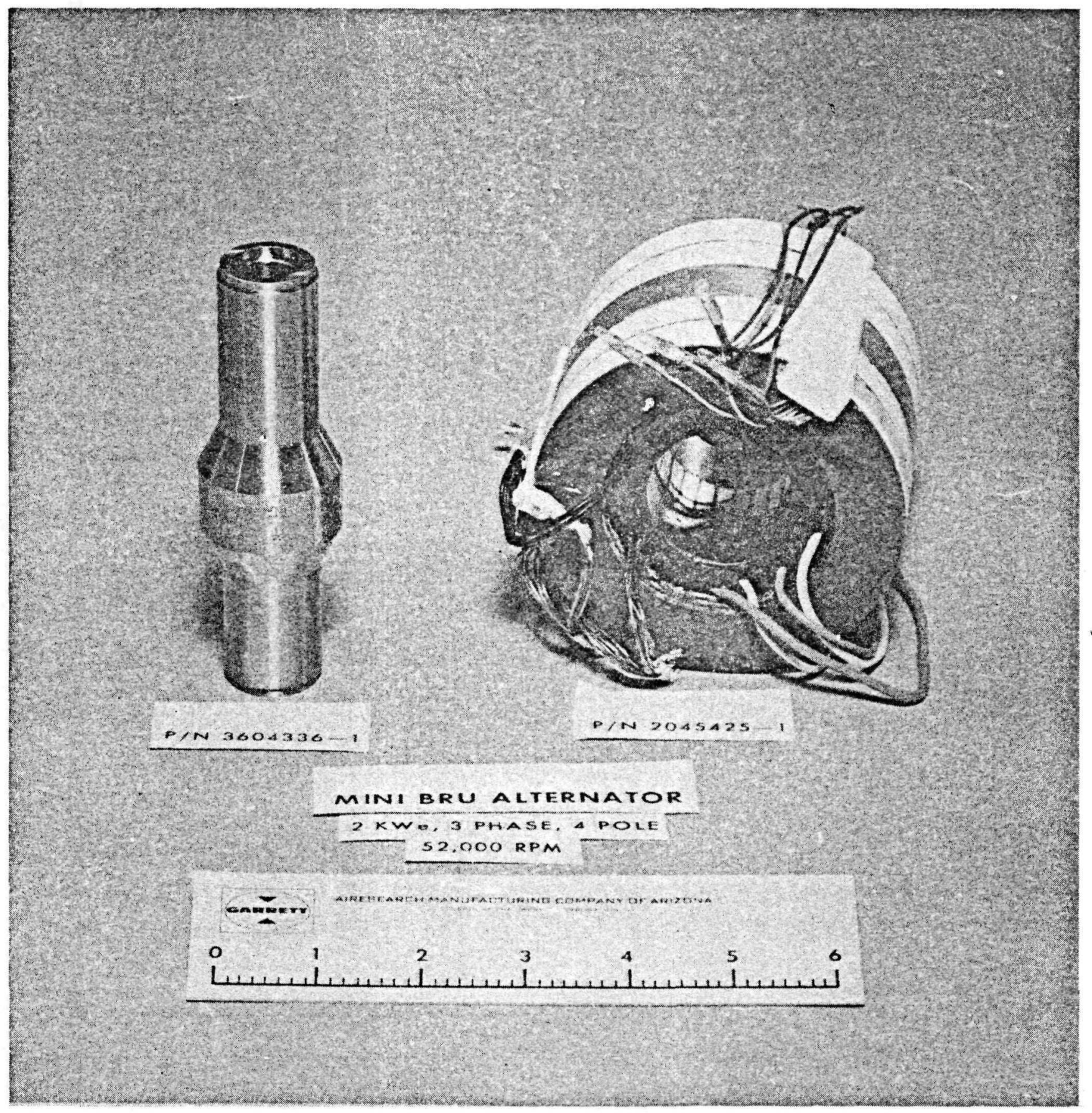

MINI-BRU ALTERNATOR ASSEMBLY

FIGURE 3-6

$75-311274 \mathrm{~B}$

Page 3-20 
TABLE 3-3

\section{ALTERNATOR DESIGN SUMMARY}

\begin{tabular}{|c|c|}
\hline Type: & $\begin{array}{l}\text { Four-Pole Rice } \\
\text { Gas Cooled } \\
\text { 3-Phase "Y" Connected } \\
4 \text { Parallel shunt Field Coils }\end{array}$ \\
\hline Design Rating: & $\begin{array}{l}2 \mathrm{KW} \mathrm{e}^{\prime} \text { Rectifier Load } \\
12.27 \text { amps per phase } \\
65.90 \text { volts Iine to Neutral* } \\
1733 \mathrm{~Hz}\end{array}$ \\
\hline Materials: & $\begin{array}{l}\text { Rotor - HP 9-4-20/INCO } 713 \text { LC } \\
\text { Stack - AL } 4750,0.006 \text { in. Laminations } \\
\text { Frame and End Bells - SAE } 1018 \\
\text { Field and Stator Windings - Copper }\end{array}$ \\
\hline Geometry: & $\begin{array}{l}24 \text { Slots } \\
2 \text { Parallel Circuits } \\
5 / 6 \text { Coil Pitch } \\
2 / 3 \text { Rotor Pole Pitch } \\
1.51 \text { in. Diam Rotor } \\
0.020 \text { Air Gap } \\
0.72 \text { in. Stack Width }\end{array}$ \\
\hline
\end{tabular}

*Intrinsic voltage behind $\mathrm{x}_{\text {com }}$ in rectified mode 
TABLE 3-4

CONSTRUCTION MATERIAL USED IN MINI-BRU ALTERNATOR

\section{Application \\ Material}

Adhesive One component RTV Silicone

Adhesive Nitrile-Phenolic

Adhesive Epoxy one part

\section{Potting}

Varnish

Tape

Tape

Nylon creped (Nomex Type 410)

Lacing Tape Polyimide (Nomex) Microcrystalline Fungicide wax

Insulation

Wire

Insulation ML Polyimide Resin Sleeving coated fiberglas Sleeving

Fluorinated Ethylene Propylene

EncapsuEpoxy Resin Type $V$ Fin
105-070-9001

$\begin{gathered}\text { Garrett } \\ \text { Identification }\end{gathered}$
105-097-9001
RS184C01
MIL-A-46106
105-050-9001

RS185E08 MIL-C-81306 HIIL-I-24204

MIL-T-43435 Size 3

58936,58937

MIL-W-168780

\section{0}

MIL-I-3190

\section{Bentley-Harris Manu-}

facturing Company

Conshohocken,

Pennsylvania,

S9051

Brand-Rex Company Box 498

Willimantic,

Connecticut

219-116-9001
Emerson \& Cuming Inc., Dielectric Mtl. Div.

Stycast 2850 G.T.
Amount Used and

Temperature

$450^{\circ} \mathrm{F}$ maximum oper- Approximately 0.00017 los ating temperature thermocouple bond 9 places field and stato

$400^{\circ} \mathrm{F}$ operating

temperature

0.0714 lbs lamination and damper $r$ ing bond

$400^{\circ} \mathrm{F}$ maximum

Field to stator bond

0.1833 lbs field and stator encapsulation

0.10361 lbs field wire coating

0.01005 lbs stator insulation

$0.020 \mathrm{lb}$ field bobbin corner insulation

Stator winding trace

$400^{\circ} \mathrm{F}$ operatin temperature

$-130^{\circ}$ to $482^{\circ} \mathrm{F}$

$482^{\circ} \mathrm{F}$ maximum

insulatio connecting wi insulation, stator and

stator wire insulation trace

$275^{\circ}-400^{\circ} \mathrm{F}$

Field and stator assembly

$400^{\circ} \mathrm{F}$ maximum

stator end turn encapsulation 


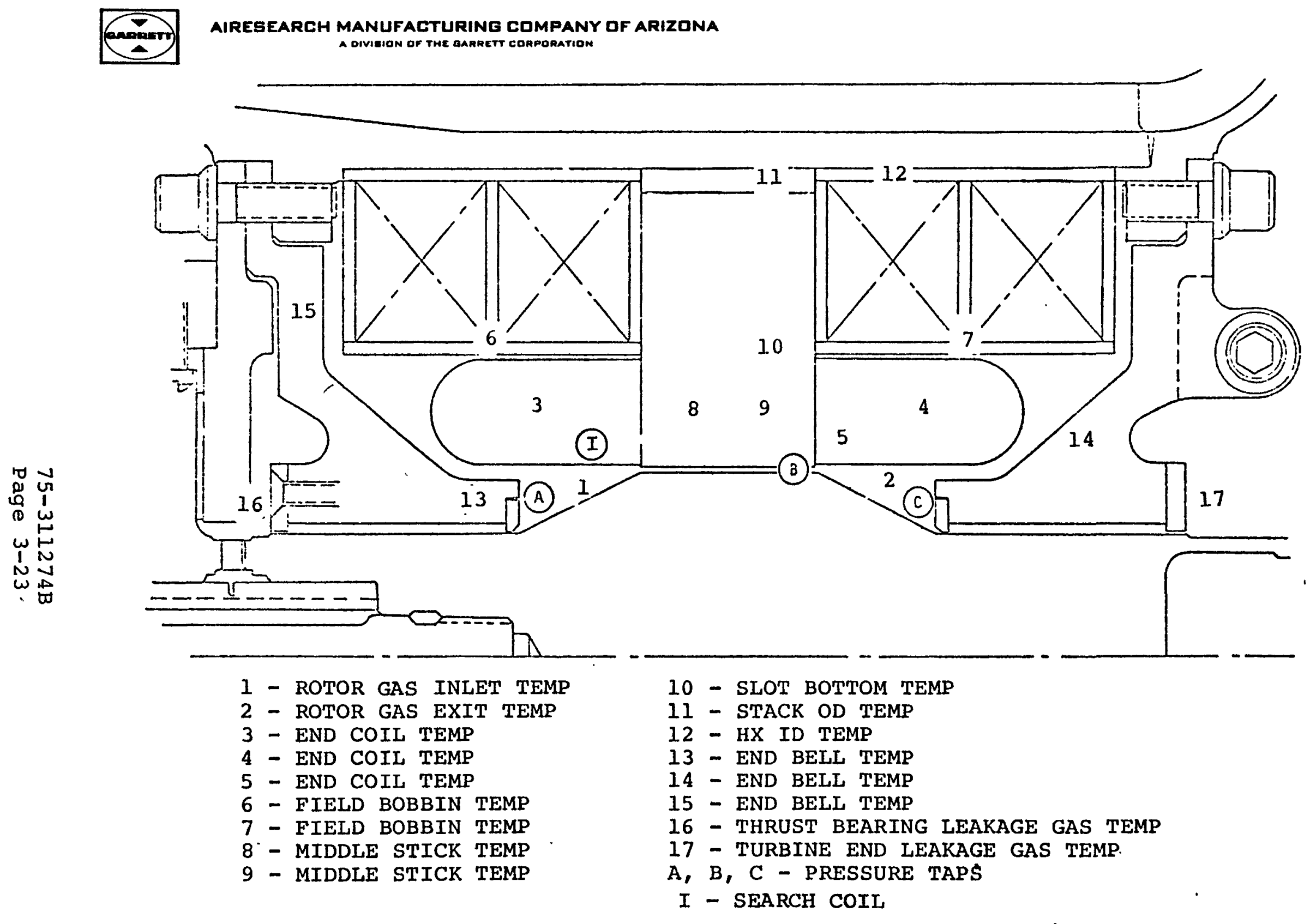

ALTERNATOR INSTRUMENTATION

FIGURE 3-7 


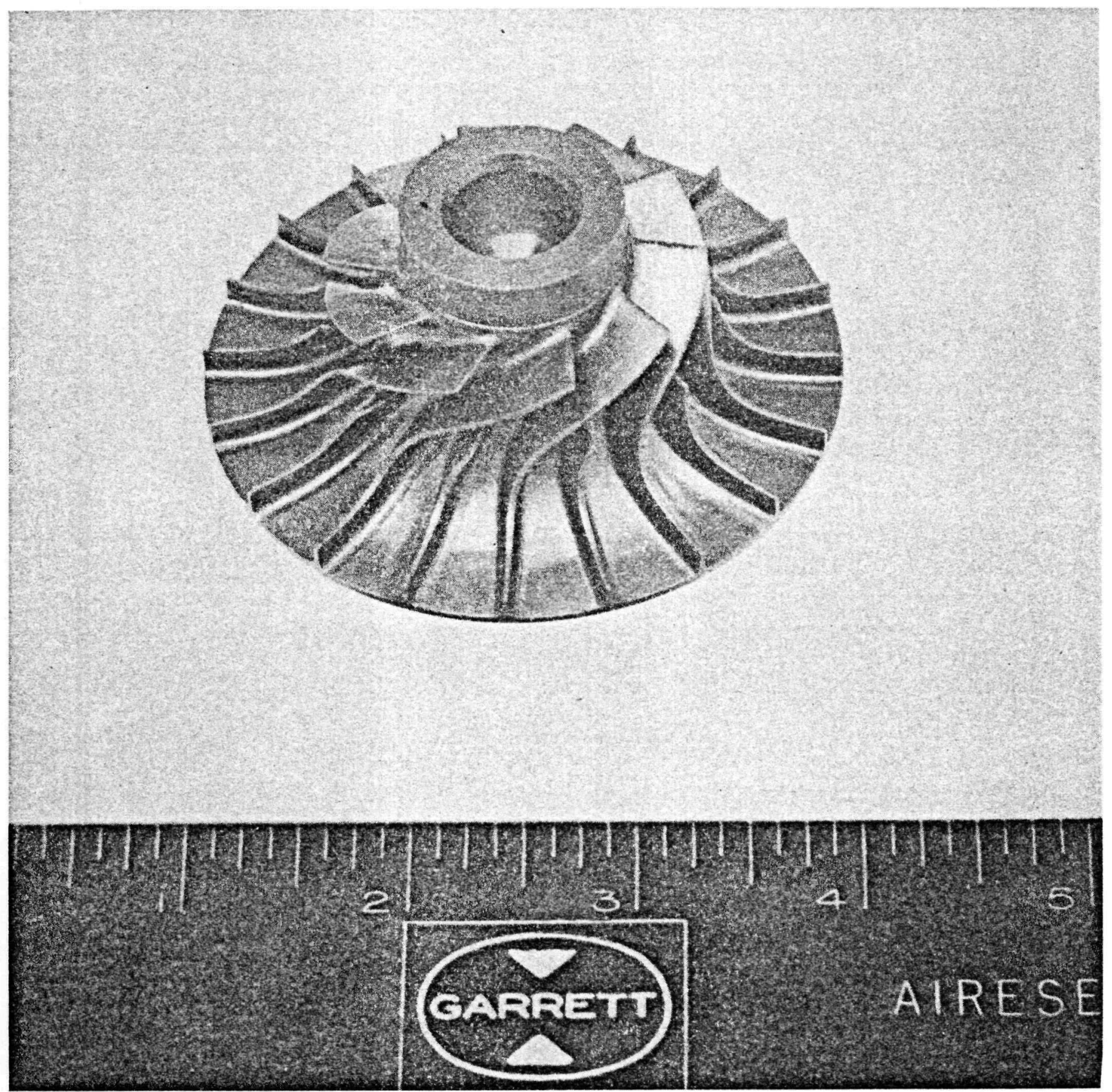

MINI-BRU TURBINE WHEEL

FIGURE 3-8A

$75-311274 \mathrm{~B}$

Page 3-24 
stators be designed to carry high stress loads. This resulted in thick blade sections and a relatively large trailing edge thickness. With a subsequent decision to go to a plenum configured turbine inlet, stator blade thicknesses were decreased because of lower stress loads.

Table 3-5 iterates turbine design parameters from AIRPHX Report $74-311068$.

\subsubsection{Cooling System}

The Mini-BRU is self-cooled. Compressor discharge gas is used to cool the alternator and bearings. This is accomplished by directing two percent bleed flow through the bearing and alternator cavities, with the remaining flow (from the diffuser exit) directed through a 0.1 percent pressure drop heat exchanger surrounding the alternator stator and field coils. This is shown schematically in Figure 3-2. Predicted operating temperature for 1 - and 3-capsule heat source operation are shown on Figures 3-8B through 3-12. These two conditions define component, and system, design extremes.

\subsubsection{Gas Bearing System}

The Mini-BRU utilizes "dry starting" (without hydrostatic jacking gas) hydrodynamic gas journal and thrust bearings capable of operating over the specified power range with minimum losses, particularly in the zero-"G" mode. Bearing load capacity permits operation in any attitude, within one-"G", with the bearing cavity pressure that exists when compressor inlet pressure is at 10 psia minimum. Thrust bearing load capacity is sufficient to continuously support, hydrodynamically, maximum anticipated cycle thrust loads in any Mini-BRU attitude, including loads that might occur during start-up and shutdown.

Journal and thrust bearings are capable of starting and stopping, under conditions previously specified, without external pressurization. 
TABLE 3-5

DESIGN PARAMETERS FOR MINI-BRU RADIAI TURBIINE

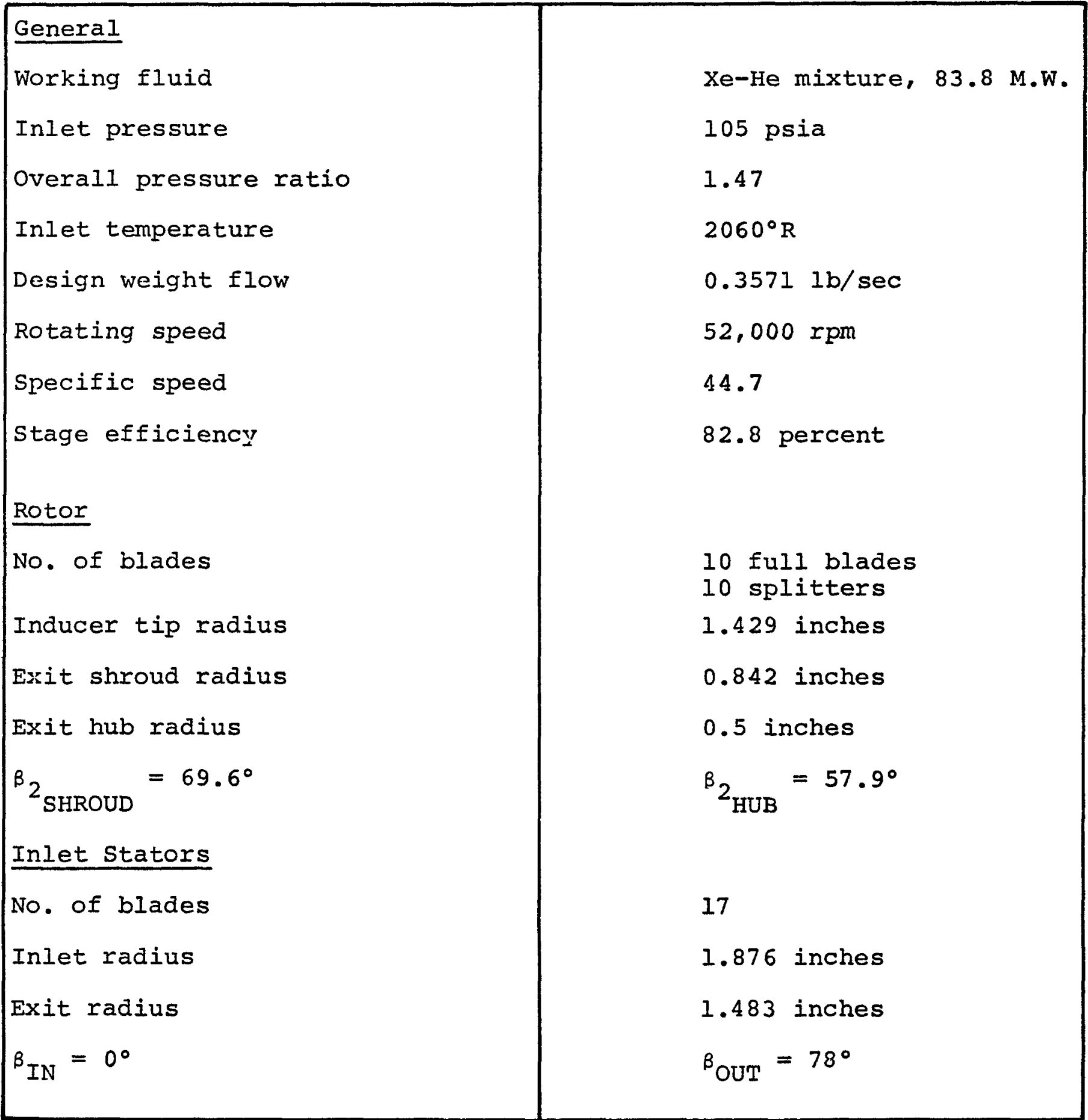




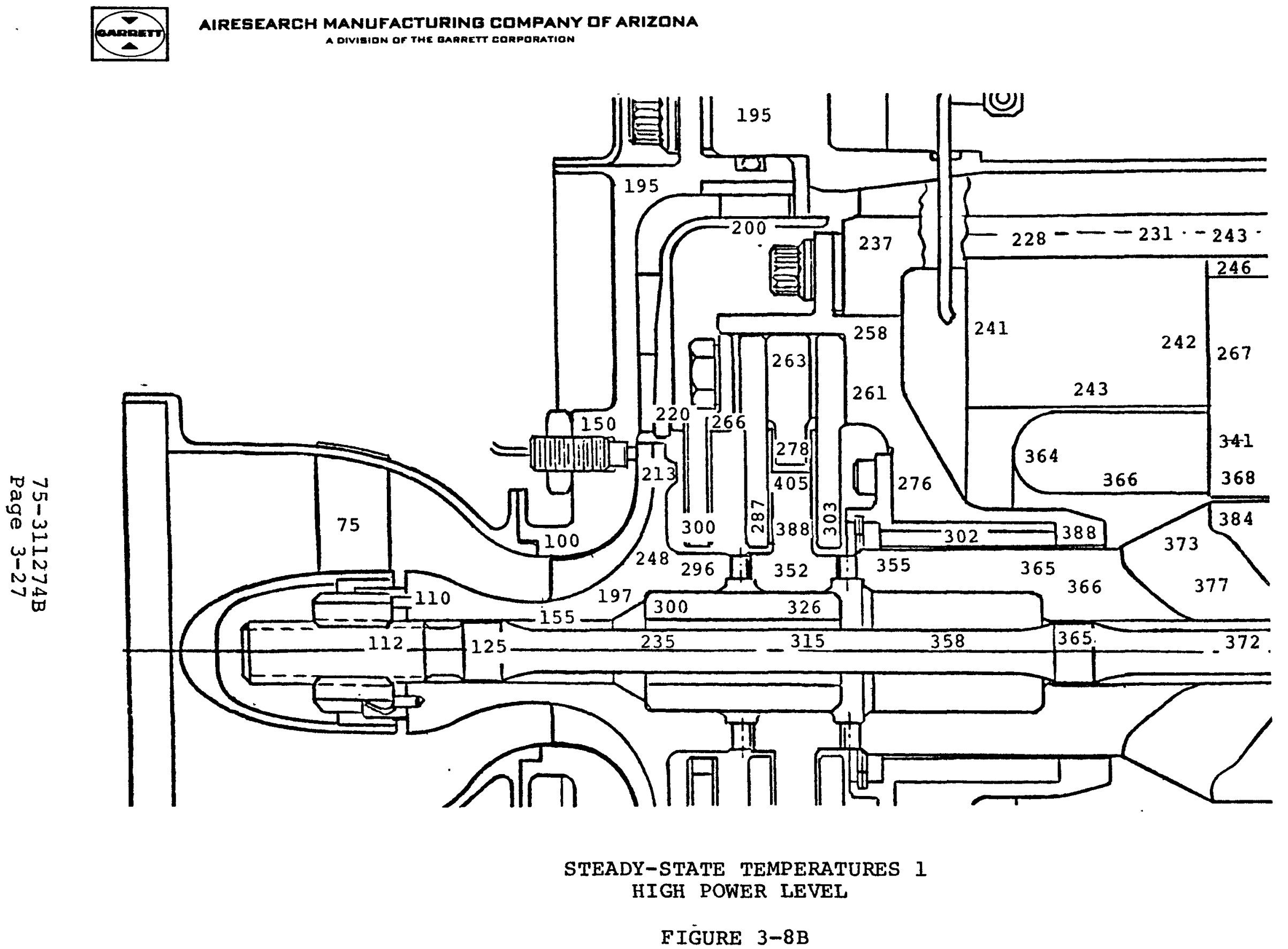




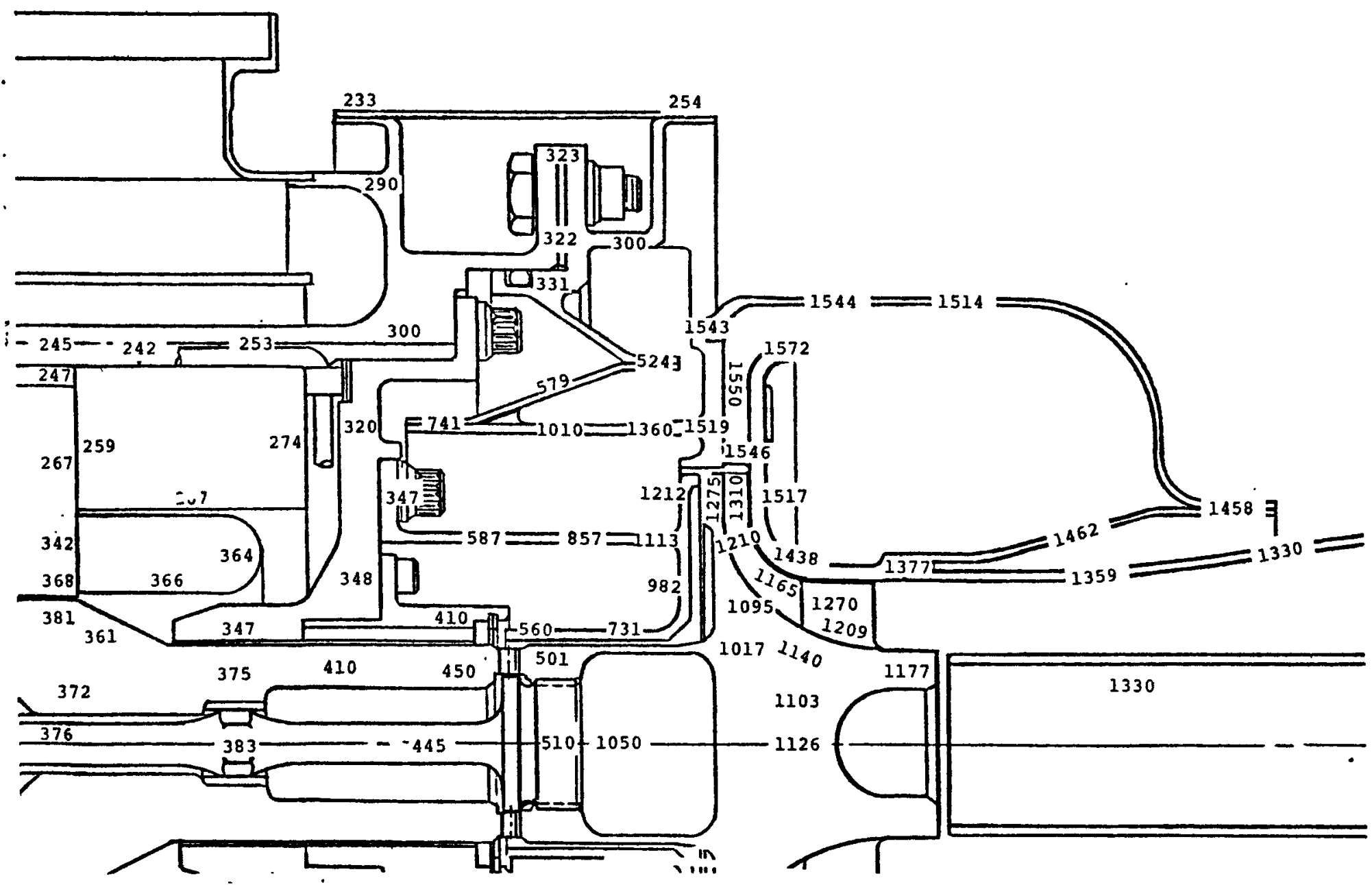

STEADY-STATE TEMPERATURES II HIGH POWER LEVEL 


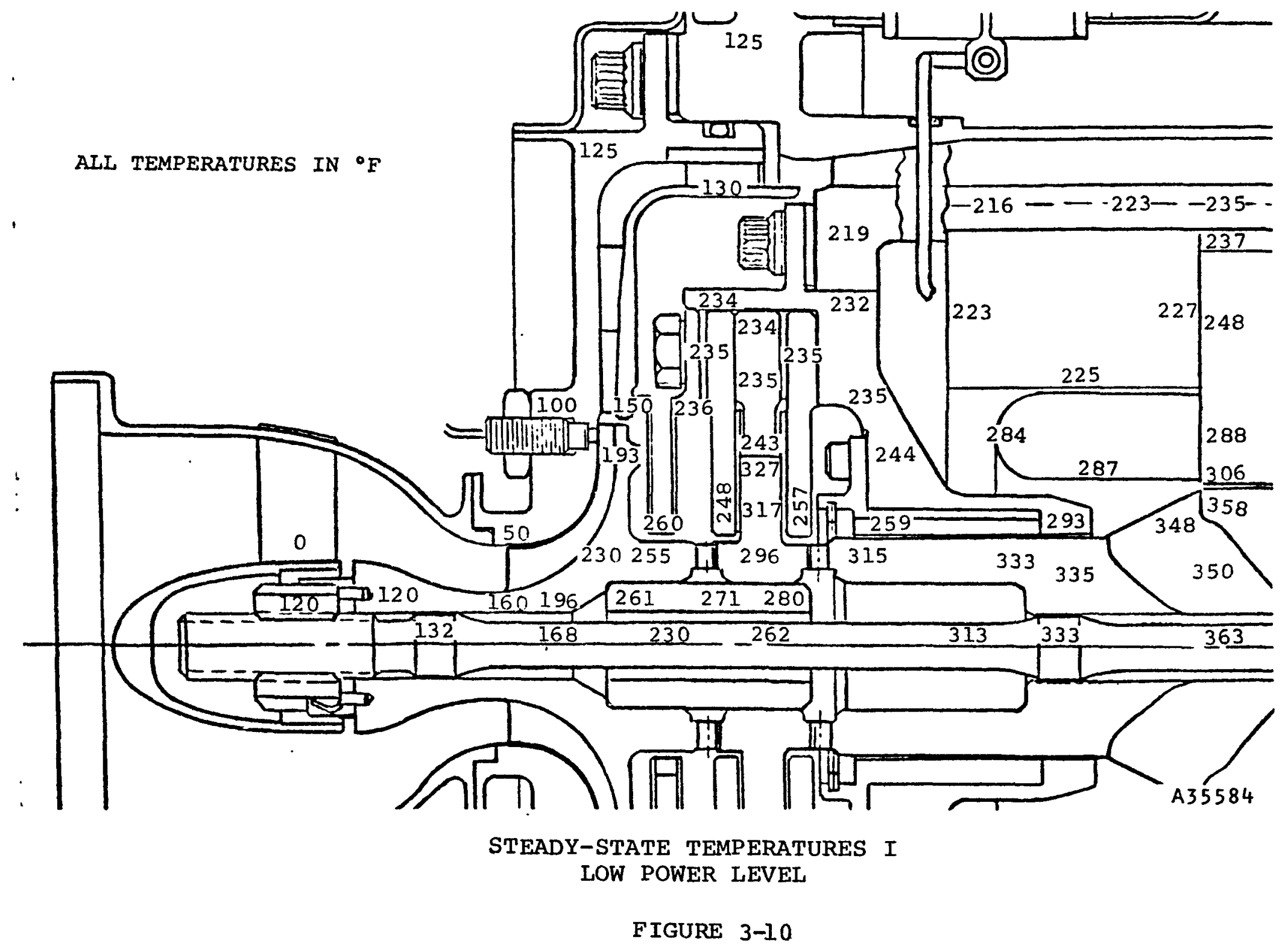




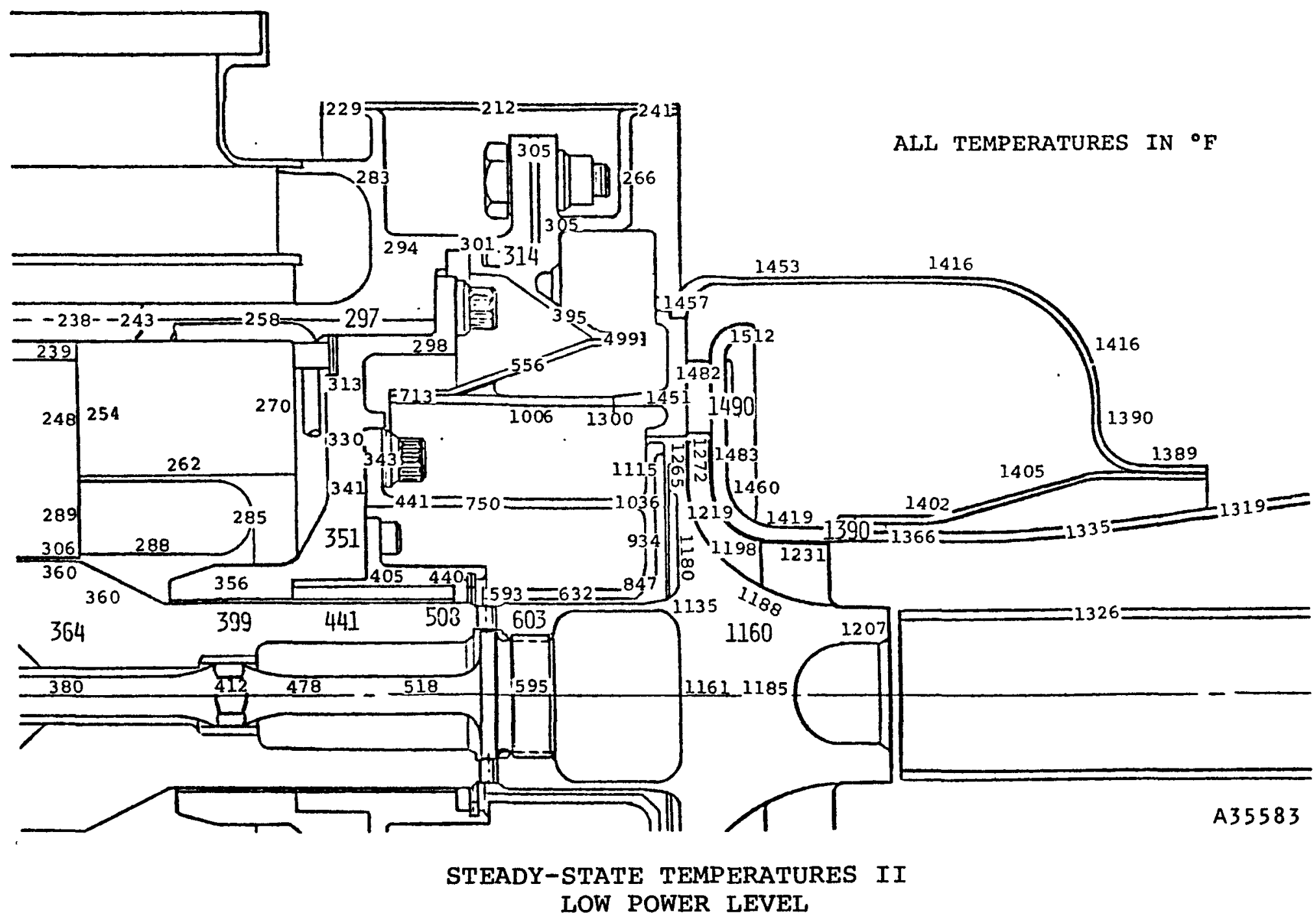

FIGURE 3-11 
صu

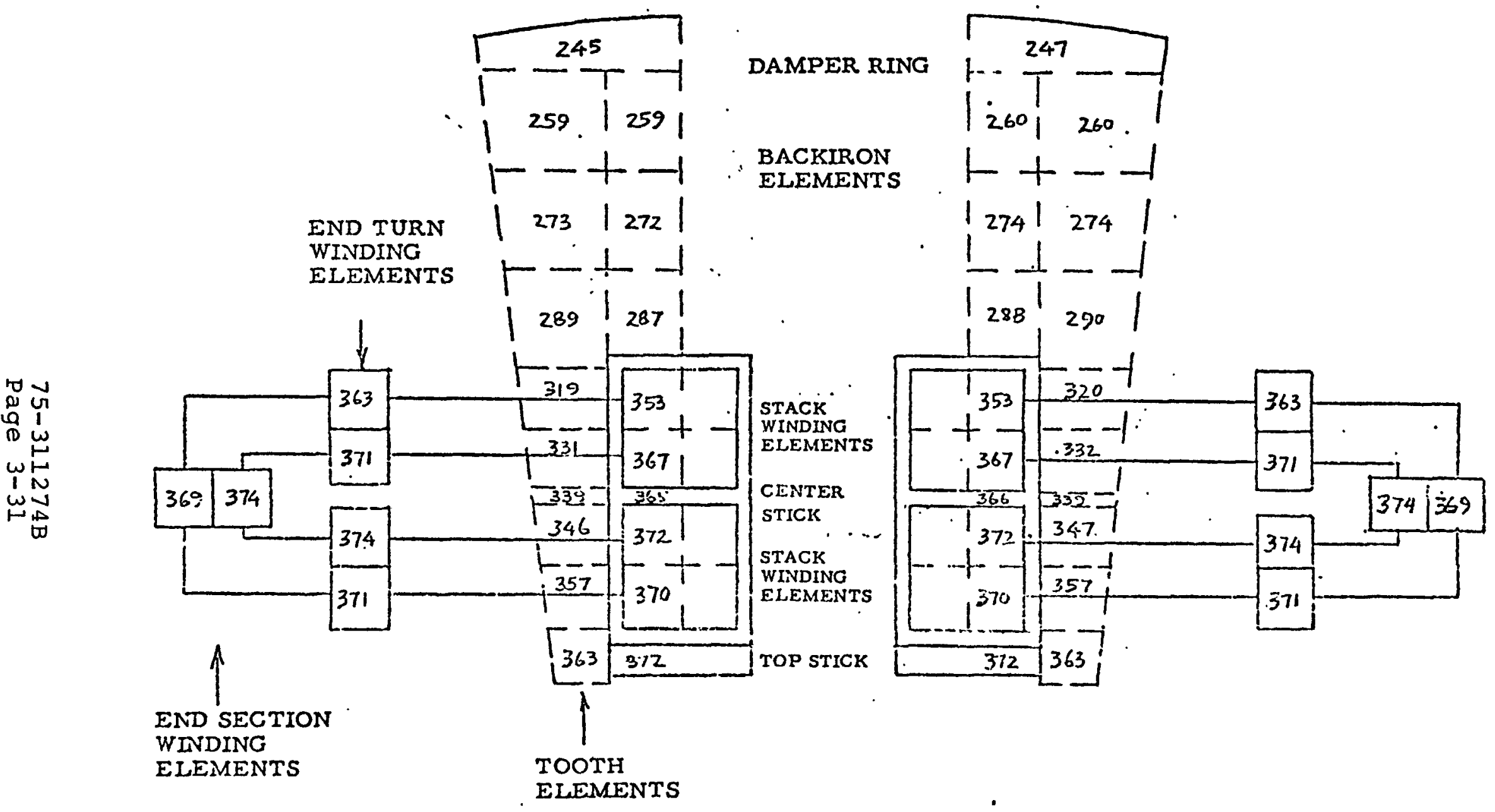

TEMPERATURES ARE SHOWN IN $\cdot F$

\section{ALTERNATOR STATOR TEMPERATURES} AT HIGH-POWER OPERATION

FIGURE $3-12$ 
To assure motor start capability, the bearings' total resisting breakaway torque is expected to be less than 60 percent of alternator motoring torque, at three times rated alternator output current. If high-g bearings (for operation through launch) are used, breakaway torque will increase approximately 25 percent. Breakaway torque is based on one"G" loading on thrust and journal bearings. Torque data is presented in AIRPHX Mini-BRU Progress Report, 74-310631(16).

Gas bearing materials selection, and application of coatings, provide a minimum of 1000 start-stop cycles.

\section{4 .1 .6 Instrumentation}

Mini-BRU design incorporates the following instrumentation (see Drawing SKP32488):

(a) Chromel-alumel thermocouples to measure critical static component and local gas temperatures within the Mini-BRU. Placement is shown on SKP 32488 .

Gas-sealed hermetic through bulkhead-type receptacles are used for thermocouple connections. Friction contact sleeves similar to those in mating external sockets are used on thermocouple leads. All thermocouples are electrically insulated from alternator windings.

(b) Three magnetic pickup shaft-speed sensors.

(c) Static pressure measurement line with filters to sense pressure in each rotor and bearing cavity pressure zone shown on SKP 32488 .

(d) A coil of one full pole pitch is installed in the stator for magnetic flux measurements. 


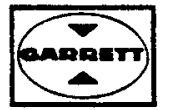

\section{AIRESEARCH MANUFACTURING COMPANY DF ARIZDNA \\ A DIVISION OF THE GAARETT CORDORATION \\ PHQENIX, ARIZONA}

\subsubsection{Physical Data}

Mini-BRU physical dimensions and configuration are presented on the following AIRPHX drawings and parts list:
- Engine Layout I3621255
- Engine Assembly 240610-1
- Parts Iist PL 240610-1
- Engine Installation 240611-1

Drawing 3604385 and Table 3-6 show materials to be used for MiniBRU component parts.

\subsection{Weight Analysis}

Mini-BRU assembly weight was determined by calculating and estimating component part weights. The weight breakdown is presented on Parts List PL 240610-1. Total weight, including the refractory plenum, is estimated at 36.1 pounds.

\subsection{Interface Data - Static}

Appropriate Mini-BRU static interface data is defined below:

(a) Flange Loading - Turbine and compressor maximum allowable flange loads are calculated to be:

\begin{tabular}{|c|c|c|c|}
\hline Flange & $\begin{array}{c}\text { Moment } \\
(\text { in }-1 b) \\
\end{array}$ & $\begin{array}{l}\text { Shear } \\
\text { (Ib) }\end{array}$ & $\begin{array}{l}\text { Axial Load } \\
(1 \mathrm{~b})\end{array}$ \\
\hline Turbine Exhaust & 400 & 300 & 300 \\
\hline Turbine Inlet & 360 & 825 & 375 \\
\hline Compressor Inlet & 500 & 400 & 450 \\
\hline Compressor Exhaust & TBD & TBD & TBD \\
\hline
\end{tabular}




\section{TABLE $3-6$}

MINI-BRU MATERIALS

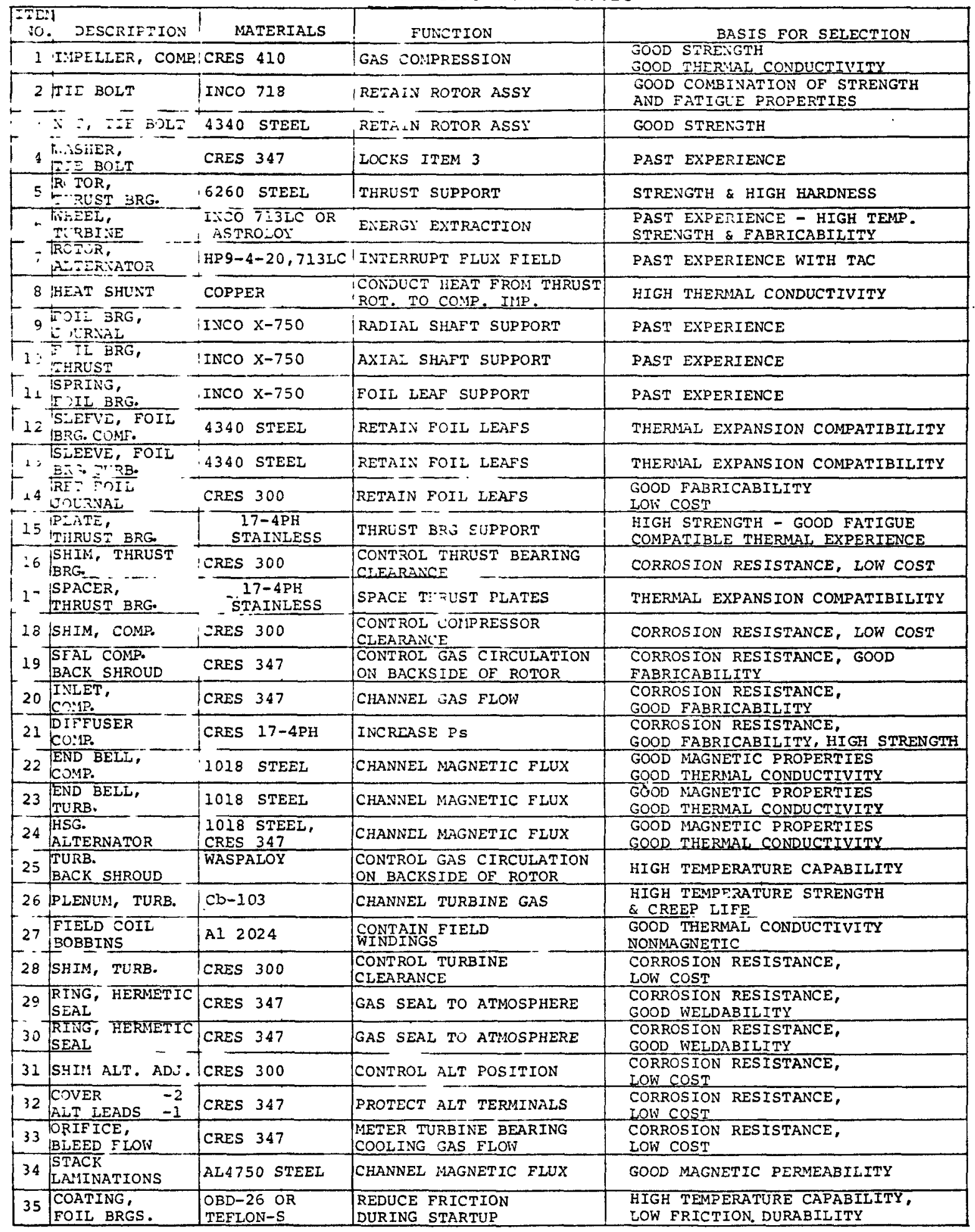


(b) Center of Gravity - Estimated at 5.75 inches from the compressor inlet flange, and 0.02 inch from the centerline in the direction of the alternator terminals.

(c) Orientation - Any attitude.

(d) Mounting - An 8-bolt hole patterned, large oD flange, at the compressor-end, which may be adapted to a variety of mounting arrangements (see Drawing 240611-1).

\subsection{Interface Data - Dynamics}

Appropriate Mini-BRU dynamic interface data is defined below:

(a) Rotating group polar moment of inertia ( $\left.I_{p}\right)$ : Calculated to be 0.00149 in. $-1 b-\sec ^{2}$.

(b) Rotating group diametral moment of inertia $\left(I_{d}\right)$ : Calculated to be 0.0359 in. $-1 b-\sec ^{2}$.

(c) Bearing span: Center of journal to center of journal = 3.63 inch.

(d) Unit rotating speed: $52,000 \mathrm{rpm}$

(e) Critical speeds:

- First rigid body critical $=10,560 \mathrm{rpm}$

- Second rigid body critical $=17,129 \mathrm{rpm}$

- Third bending critical $=127,000 \mathrm{rpm}$

\subsubsection{Electrical Data}

Location of electrical connections is shown on Installation Drawing 240611-1. Electrical connector types are TBD. 


\subsection{External Magnetic Field}

Magnetic field intensity, external to the Mini-BRU and generated by the Rice alternator, will be determined during GDS testing.

\subsubsection{Radiation Tolerance}

Alternator materials and system electronics radiation tolerances will be determined and appropriate shielding provided, if necessary.

\subsubsection{Handling and Storage}

Mini-BRU handling and storage procedures are defined as follows:

(a) At all times, protect the Mini-BRU from moisture during handling and storage. Specific procedures are TBD, although vacuum packing with desiccant is under consideration.

(b) Maintain Mini-BRU temperature, during storage, below $200^{\circ} \mathrm{F}$.

(c) Keep all refractory alloy parts in a vacuum, or inert environment, if exposed to temperatures above $400^{\circ} \mathrm{F}$.

(d) Special handling procedures are TBD for Multi-Foil insulation protection.

3.4.1.11 Cleaning

Cleaning procedures are TBD.

\section{4 .1 .12 Nuclear}

Nuclear characteristics are TBD. 


\subsubsection{Mini-Brayton Recuperator (MBR)}

The MBR functions to transfer turbine discharge working fluid thermal energy to the compressor discharge working fluid. This thermal energy recovery increases cycle efficiency by reducing required heat source output for a given power level.

MBR design requirements, for the reference $2.08 \mathrm{kw}$ system, are presented on Table 3-7. Heat transfer performance is based on no heat loss to the surroundings. MBR detail design is complete, with parts fabrication in process. First delivery is anticipated for late 1976.

\subsubsection{Physical Data}

MBR design is shown on Figure 3-13, Table 3-8, and Drawing 190930. Envelope dimensions are 32.1 inches by 16.3 inches by 9.4 inches. Internal construction, illustrated in Figure 3-14, is typical of that used on counterflow heat exchangers. Heat transfer takes place predominately in the rectangular counterflow section where highperformance rectangular offset fins are used. Triangular end sections are used to distribute and collect gas flow to, and from, the counterflow section. End sections incorporate plain rectangular fins to uniformly distribute gas flow, with minimum pressure drop. In the core pure counterflow section, fins in the hot and cold passages are 20R0.10-1/8-0.004 (20 fins per inch, rectangular, $0.10 \mathrm{inch} \mathrm{high,} 1 / 8$ inch offset, and 0.004-inch thick). In transition sections, plain rectangular fins (16 fins per inch) are utilized. Additional core features are shown in Figure 3-15.

\subsection{Materials}

The MBR is fabricated entirely from Hastelloy $x$. The core assembly is brazed, using gold-base braze alloys applied in foil form. 
TABLE 3-7

MBR DESIGN REQUIREMENTS

\begin{tabular}{|c|c|}
\hline Item & Requirement \\
\hline $\begin{array}{l}\text { System net power output, } \mathrm{kw} \text {, } \\
\text { Working fluid } \\
\text { Hot side (low pressure) } \\
\text { Flow rate, lb/sec } \\
\text { Inlet temperature, }{ }^{\circ} \mathrm{R} \\
\text { Inlet pressure, psia } \\
\text { Cold side (high pressure) } \\
\text { Flow rate, lb/sec } \\
\text { Inlet temperature, o } \mathrm{R} \\
\text { Inlet pressure, psia } \\
\text { Effectiveness (cold side) } \\
\text { Pressure drop, total of } \\
\text { both sides, percent } \\
\text { Operating life, years } \\
\text { Number of startup/shutdown } \\
\text { cycles }\end{array}$ & $\begin{array}{l}2.08 \text { (ref } 3 \text { heat source } \\
\text { capsule design) } \\
\text { Xe-He (M.W. = } 83.8) \\
0.357 \\
1792 \\
71.7 \\
0.350 \\
685 \\
106.2 \\
0.975 \\
0.70 \\
10 \\
1000\end{array}$ \\
\hline \multicolumn{2}{|c|}{$\begin{array}{l}\text { NOTE } \\
\times \text { I, Figure I- } 1 \text { for } \\
\text { cle data. }\end{array}$} \\
\hline
\end{tabular}


PMOENIX, ARIZONA

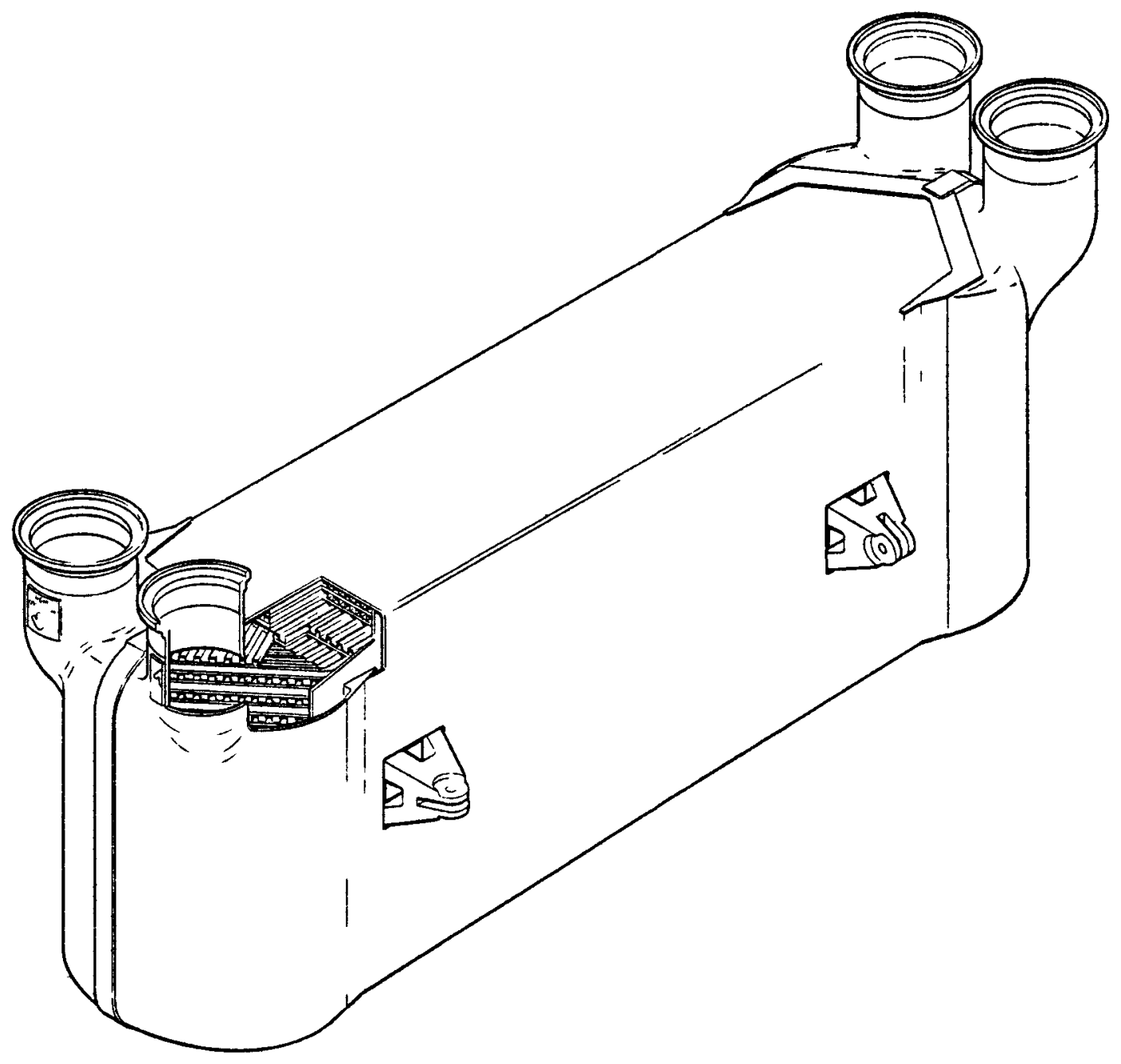

MINI-BRU RECUPERATOR

FIGURE 3-13

$75-311274 \mathrm{~B}$

Page 3-39 


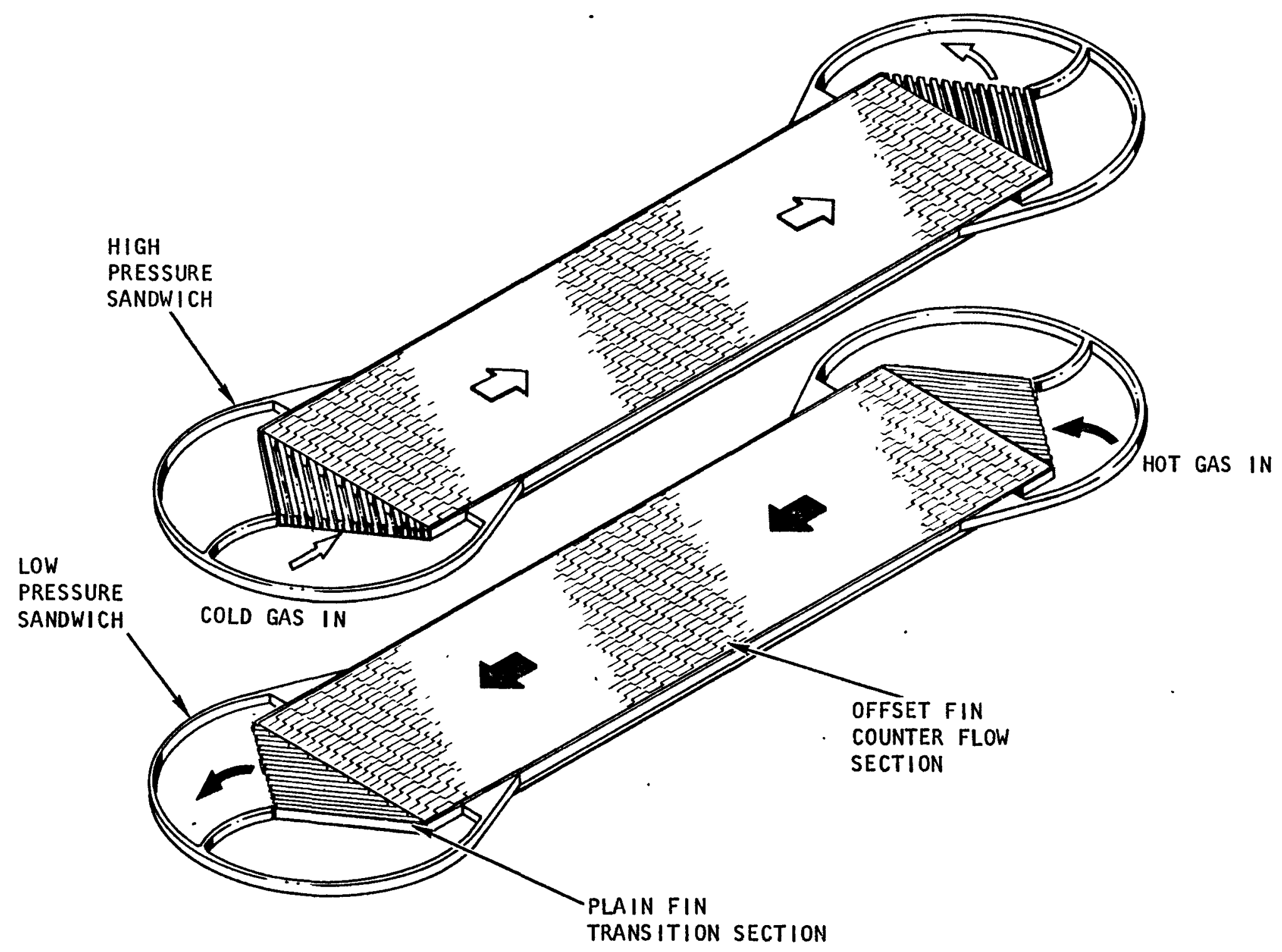

MBR CORE DETAIL

FIGURE 3-14 


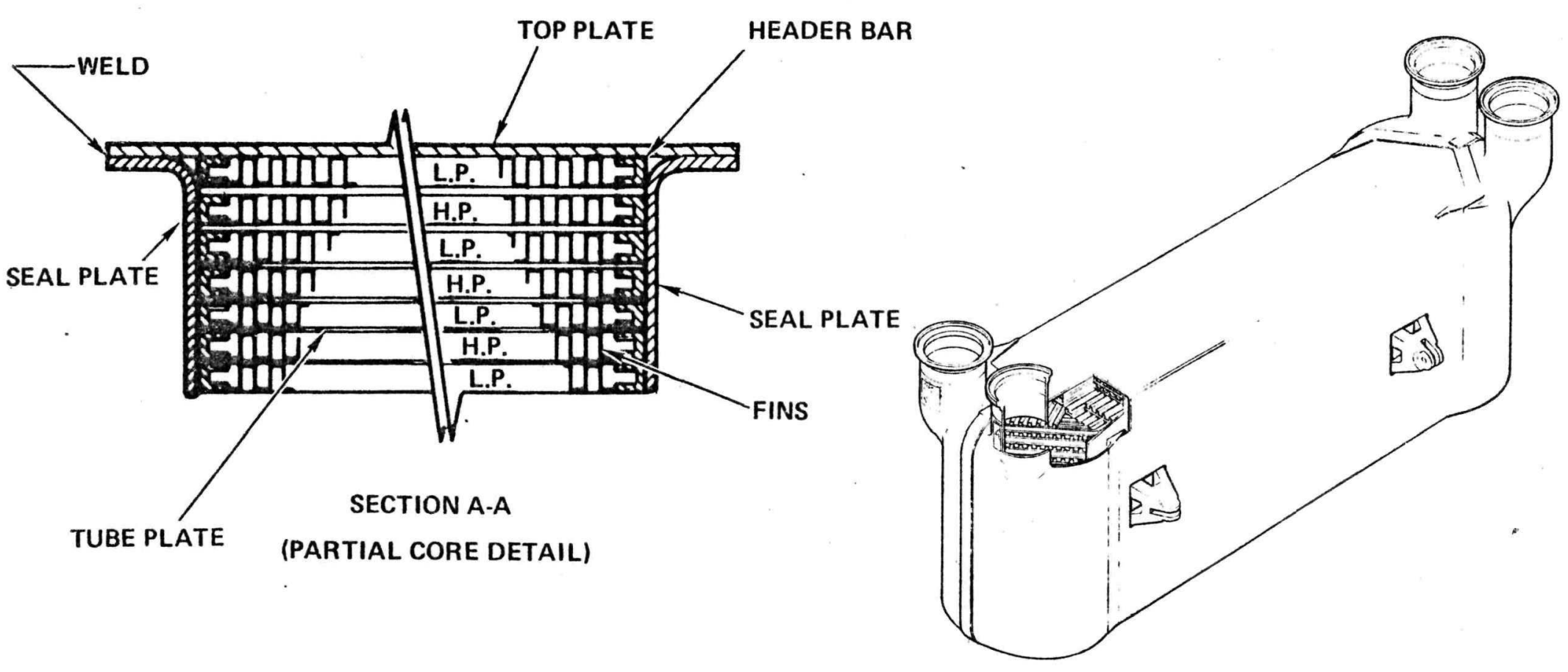

MBR CORE DESIGN

FIGURE 3-15 
MINI BRAYTON RECUPERATOR (MBR) MATERIALS

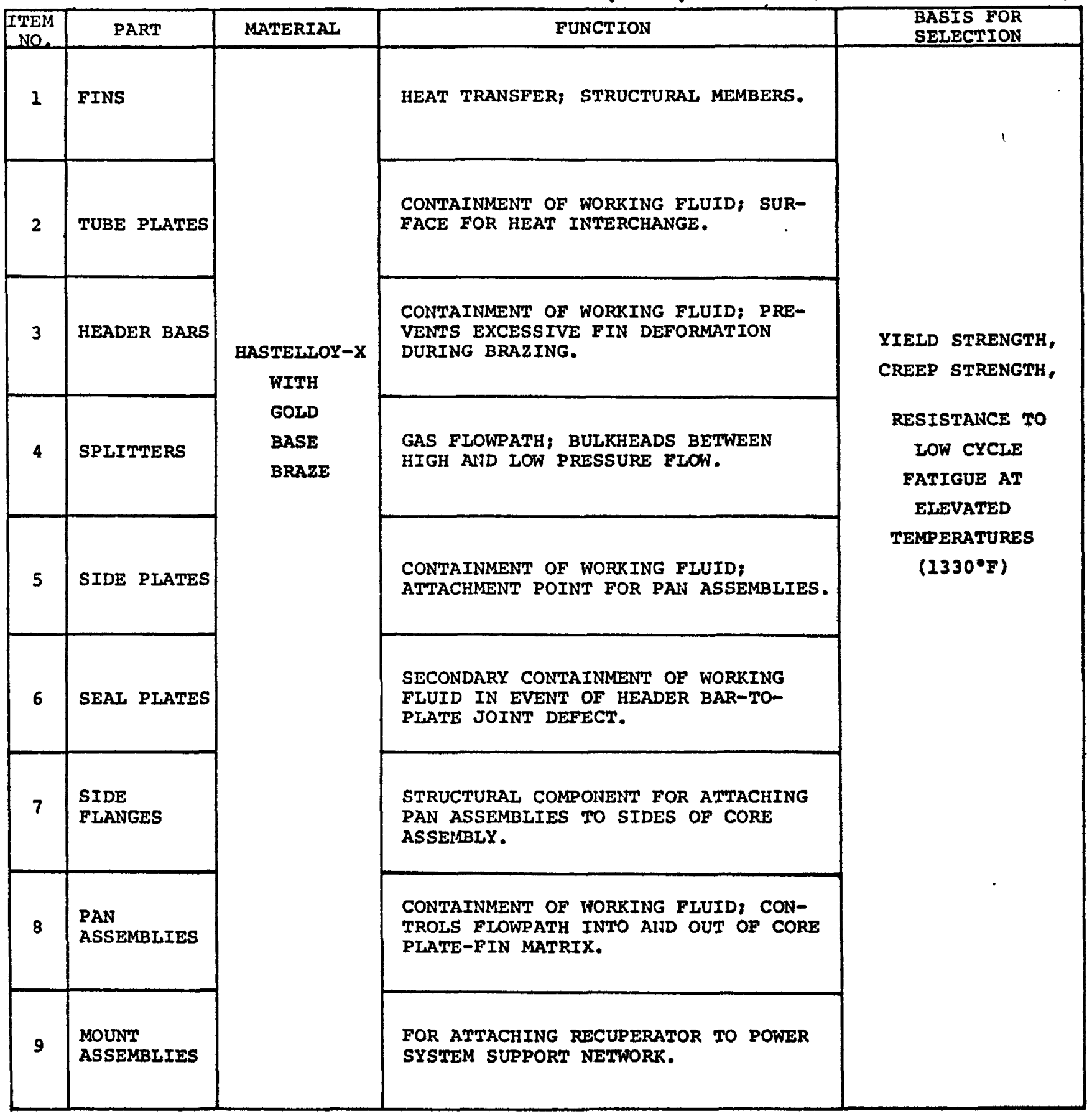




\subsection{Structural Design Criteria}

MBR design criteria are summarized as follows:

(a) Design Operating Life - 100,000 hr (approximately 10 years) at $1330^{\circ} \mathrm{F}$ maximum operating temperature.

(b) Cyclic Life - 1000 operating cycles without failure for contractual transients. Revised transient startup conditions, which form the basis for new analysis and development testing, are shown in Plots $A$ and $B$ in Appendix III. Additional transient performance details are included in AIRPHX Report 75-311279, dated May 19, 1975.

(c) Short-Time Pressure Containment - At operating conditions and 2.5 times the working pressure. Roomtemperature proof pressure testing will be accomplished to verify these pressure capabilities.

\section{NOTE}

High-pressure-side pressure must be greater than lowpressure-side pressure, with a maximum allowable pressure differential of 85 psi across the manifold splitter plate.

(d) Inertial and Vibratory Loads - Conditions are as specified in Contract NAS3-18029, Exhibit E. Design allowable stress for inertial loads is determined from short-term material properties using the following equation:

$$
\sigma_{a 11}=\left(f_{t_{u}}\right) / 2.5
$$


Where:

$$
\begin{aligned}
& \sigma_{a l l}=\text { Allowabie stress } \\
& f_{t_{u}}=\text { material ultimate tensile stress }
\end{aligned}
$$

Allowable indicated elastic stress, due to bending loads, is established at 1.5 times the allowable value computed using the above equation.

3.4.2.2 Detail Design Data

A list of drawings with an estimated weight breakdown of components comprising the MBR is presented in Table 3-9. Additional design data is presented below: (a) Estimated Weight
for $1300 \mathrm{~W}$ system)
so $\mathrm{lb}$ (could be reduced to $106 \mathrm{lb}$

(b) Center of Gravity - TBD

(c) Dimensions - Refer to Outline Drawing 190930.

\subsubsection{Installation Data}

Specific installation items include the following:

(a) Mounting Provisions - Designed for mounting at four locations, with allowable mount loads and thermal growth provisions as defined on Drawing 190930.

(b) Interface Connections - Flange location and style, position tolerance, and allowable interface loads are defined on Drawing 190930. 
TABLE 3-9

IIST OF DRAWINGS AND WEIGHT BREAKDOWN

OF MINI-BRAYTON RECUPERATOR

P/N 190930-1-1

\begin{tabular}{|c|c|c|}
\hline $\begin{array}{l}\text { AiResearch } \\
\text { Drawing } \\
\text { lJumber }\end{array}$ & Description & $\begin{array}{l}\text { Estimated } \\
\text { Weight }\end{array}$ \\
\hline 190930 & Recuperator outline & -- \\
\hline 190931 & Recuperator assembly & 132.5 \\
\hline 189614 & Core assembly & 115.42 \\
\hline 189627 & Pan assembly & 3.42 \\
\hline 189936 & Pan assembly & 3.48 \\
\hline 189629 & Identification plate & 0.10 \\
\hline 189809 & Flow direction plate & -- \\
\hline $197-505-9004$ & Protective cap & -- \\
\hline 189615 & Tube plate & 36.30 \\
\hline 189616 & side plate & 4.16 \\
\hline 189622 & Channel header & 0.03 \\
\hline 189623 & Header bar & 1.90 \\
\hline 189677 & Header bar & 1.98 \\
\hline 189617 & Offset fin & 20.09 \\
\hline 189618 & Turning fin & 0.52 \\
\hline 189619 & Turning fin & 1.51 \\
\hline 189624 & Pan splitter & 0.93 \\
\hline 189625 & Pan splitter & 3.60 \\
\hline 189626 & side flange & 3.64 \\
\hline 189628 & Mount & 1.29 \\
\hline
\end{tabular}


(c) Duct Arrangement - Working fluid flow through the MBR must be as shown on Drawing 190930. Flow direction arrows are permanently attached to each of the four ducts.

(d) Contamination - The recuperator assembly is cleaned in accordance with AIRPHX Specification C-38, using trichlorotrifluoroethane followed by a nitrogen purge to achieve Class II, Level III cleanliness.

(e) Allowable Pressure Differential - Test operations shall be conducted to assure that a maximum pressure differential of 85 psi, across the high- and low-pressure sides of the recuperator, at operating temperatures is not exceeded.

\subsubsection{Environmental Conditions}

The MBR is designed to withstand environmental conditions listed in Contract NAS3-18029, Exhibit E, without malfunction or performance degradation.

\subsubsection{Maximum Allowable Leakage}

After completing all manufacturing operations, the MBR is subjected to a proof-pressure test and is leak tested using a helium mass spectrometer. MBR leakage is required to be less than $10^{-7}$ standard cc He/sec, to surroundings, and less than $10^{-7}$ standard cc/sec between streams.

\section{4 .2 .6 Nuclear}

Nuclear characteristics are TBD. 


\subsubsection{Heat Source Assembly (HSA)}

The HSA functions to receive radiated heat, from a heat source, and impart this heat into the working fluid. This heat impartation is accomplished by forced convection, utilizing a Heat Source Heat Exchanger (HSHX). While the FS heat source will be radioisotopic," it is intended that the GDS heat source be an electrical resistance heater.'

The HSA, which does not include a heat source, is designed to accommodate the ERDA Multi-Hundred Watt (MHW) isotope heat source, as described in NASA CR 121223 (Volumes $I$ and II), and is capable of transferring $2400 \mathrm{w}_{t}$ to the power conversion system working fluid. The HSA is also designed to accommodate the GDS Electrical Heat Source (EHS).

Specific design parameters are:

(a) Design Life - 7 years

(b) Thermal Cycles - Capability to sustain 100 startupshutdowns

(c) Power Source - Capability of operating with $24 \mathrm{w}_{t}$ MHW heat source of electric heat source simulator for ground test demonstration

(d) Working Fluid - Xe-He (M.W. = 83.8)

(e) Weight Goal - 90 1b

(f) Environmental - Capability to operate in a space vacuum and meet conditions specified in Exhibit $C$ of NAS3-18541 and as TBD 
AIRESEARCH MANUFACTURING COMPANY DF ARIZINA

A DIVISION OF THE ORARETT COMHOAATION

PHOENIX, ARIZONA

(g) State Points - Inlet temperature $1307^{\circ} \mathrm{F}$

Outlet temperature $1600^{\circ} \mathrm{F}$

Flow

$0.12 \mathrm{lb} / \mathrm{sec}$

The HSA includes the following items:

(a) HSHX

(b) A Multi-Foil insulation blanket

(c) An outer housing with mounting points and instrumentation leads

(d) Auxiliary Cooling System (ACS)

(e) Emergency Cooling System (ECS)

The HSA is defined on Drawing SK No. MB-30-4-75-1. Figure 3-16 is an exploded view of the HSA, showing component parts, and Table 3-10 provides a materials list.

\subsubsection{Auxiliary Cooling System (ACS)}

ACS design must encompass the following temperature limitations:

(a) Maximum temperature of exposed surfaces: $380^{\circ} \mathrm{F}$ - assumes forced cooling (ground support furnished) on exposed surfaces, or cooling and inert gas flow in the ACS.

(b) Maximum temperature of refractory alloys exposed to air: $400^{\circ} \mathrm{F}$ 


\section{EXPLODED VIEW REFERENCE BASELINE HSA HSA REFERENCE DESIGN}

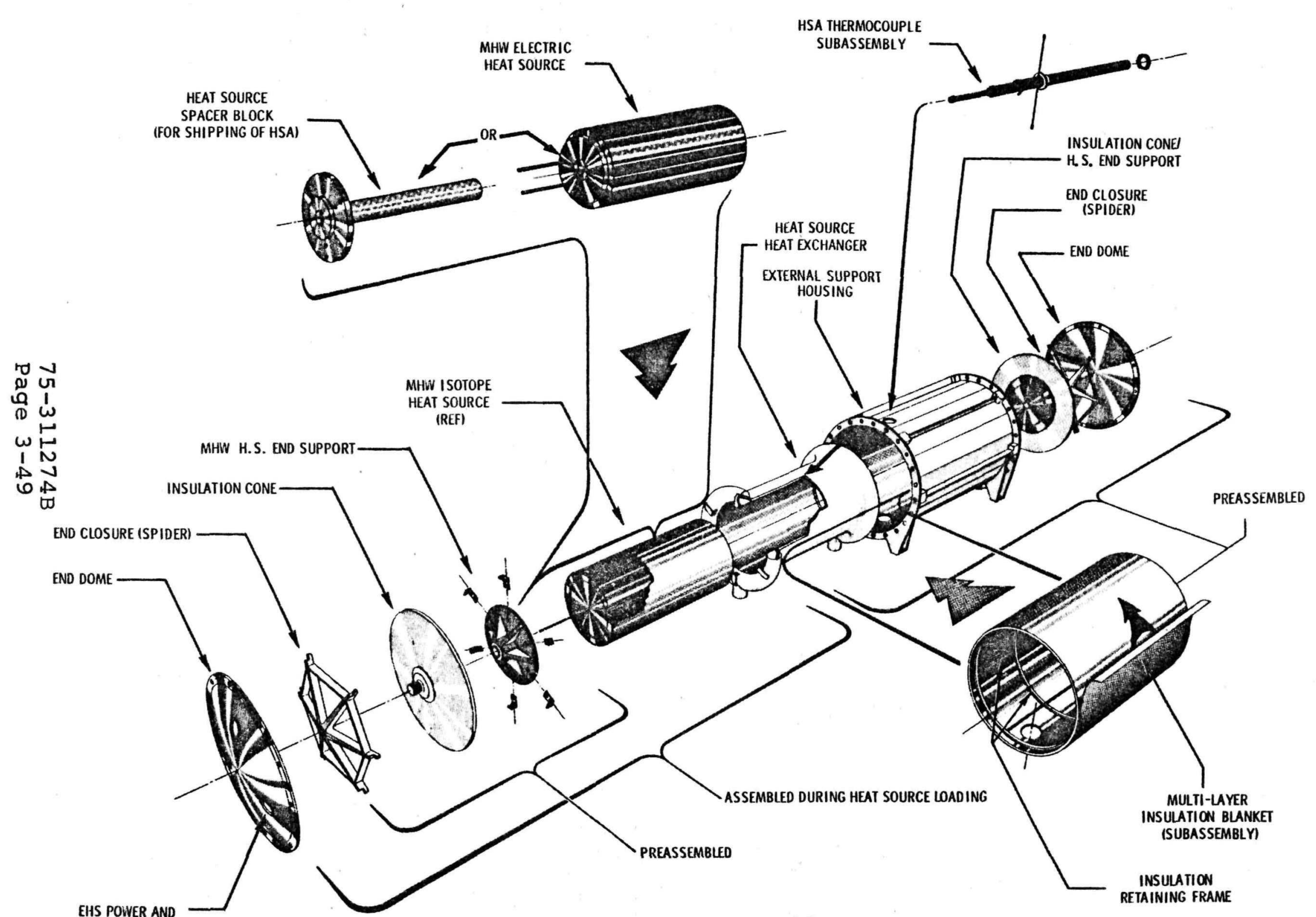

FIGURE 3-16 
TABLE 3-10

HEAT SOURCE ASSEMBLY (HSA) MATERIALS

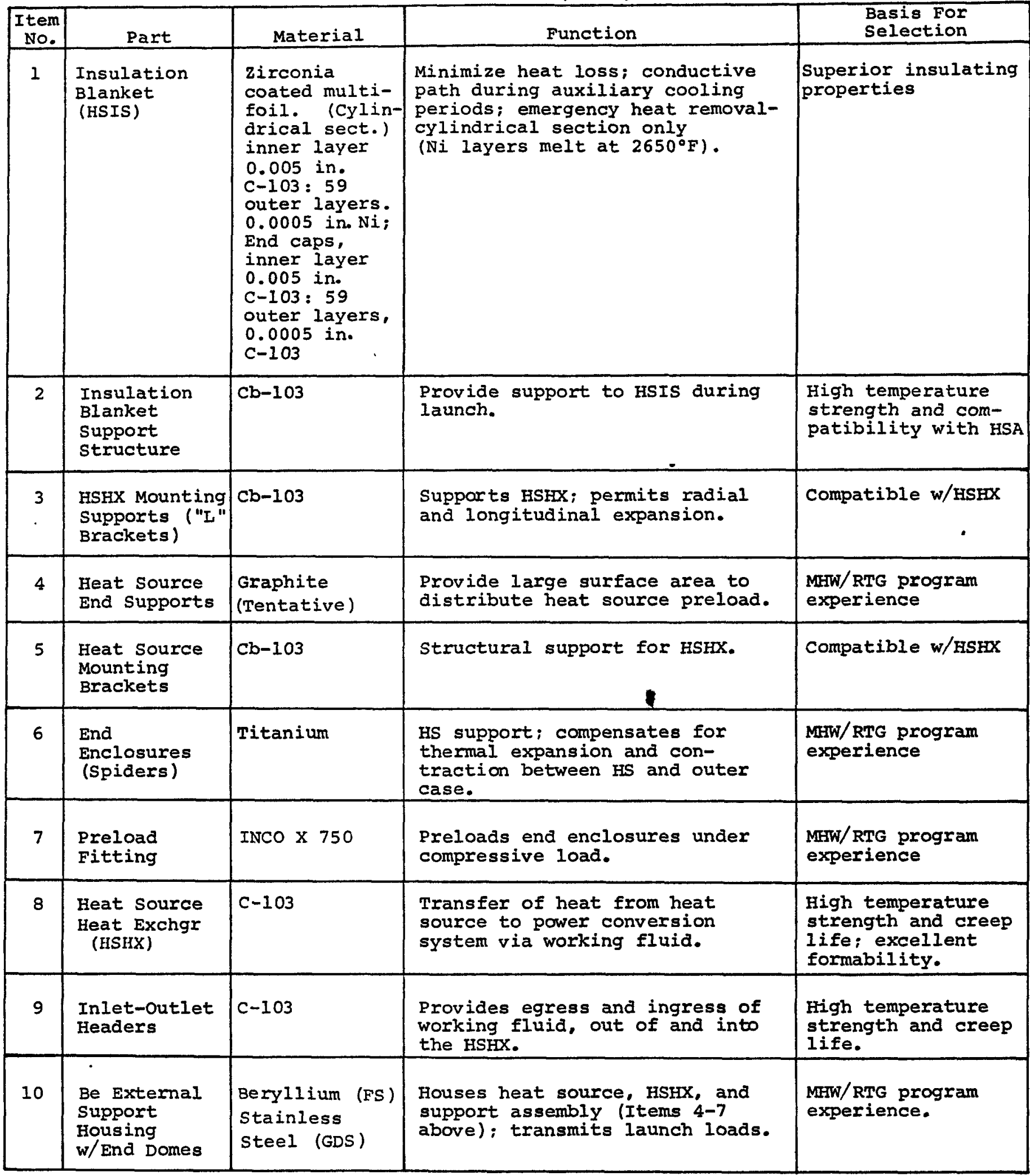


To accomplish this, HSA design includes a Multi-Foil insulation system that will function as an effective insulation in a space hard vacuum environment. Auxiliary HSA cooling is required immediately after isotope heat source loading, if the BIPS remains idle for mare than a short (TBD) period of time. The ACS utilizes a method of filling the HSA outer surface. This results in a radial temperature gradient reduction, across the HSA, such that fuel sphere assemblies within the heat source are at acceptable temperatures. The HSA retains this inert gas by the sealed housing. (The GDS HSA will utilize a stainless steel housing in lieu of the more expensive FS HSA beryllium housing.) Conversely, this sealed design prevents air from entering the refractory and graphitic parts of the HSA. To ensure that HSA exterior surfaces are maintained below $380^{\circ} \mathrm{F}$ on the launch pad, forced convection cooling over the surface may be necessary. Tests conducted on the MHW-RTG indicate that temperatures below this limitation can be provided with moderate nitrogen gas flow rates. An alternate approach for maintaining exterior surfaces below $380^{\circ} \mathrm{F}$ would be to use a cooled, flowing, inert gas in the ACs.

Operation with the space shuttle may require a revision in ACS utilization. A preliminary evaluation indicates that, during prelaunch operation, cooling gas must be circulated through the HSA housing to reject prelaunch generated heat, and to subcool the system prior to launch. Detailed temperature profile analyses, for normal and abnormal operating conditions, will be accomplished during the second phase of Task 2 .

Gas venting from the HSA is effected by ground command, which fires a squib to rupture a vent disc. Eliminating this gas from the HSA allows the Multi-Foil insulation system to again perform as an effective insulation.

Advantages of this design approach are: 
$20-1$

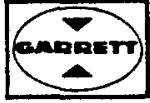

AIRESEARCH MANUFACTURING CDMPANY DF ARIZONA

A DIVIEION OE THE OARMETT CORPOAMTION

PHOENIX, ARIZONA

(a) High reliability is provided by the helium filled, and sealed, HSA and by using cooling gas flow (on-pad).

(b) Low weight due to minimum additional (vent system) hardware

(c) Minimal heat leaks by eliminating insulation penetrations (i.e., piping connections)

(d) Low development risk since no new technologies are involved

(e) Capability of being ground tested

\subsubsection{Emergency Cooling System (ECS)}

The emergency cooling concept is based on a HSA insulation system, with a relatively low melting point, to assure melting during an emergency situation. Analysis, performed by GE, indicate that a loss in insulation effectiveness allows safe temperatures to be maintained within the heat source.

In determining feasibility of a melting insulation system, transient and steady-state temperature response analyses were performed. In addition, accomplishing a scheduled, full-scale, melt down test is expected to provide evidence that the ECS functions as intended.

The melting insulation ECS design concept offers:

(a) High reliability (to be determined)

(b) Low weight

(c) High thermal efficiency

(d) Low development risk

(e) Low development and unit cost

(f) Unlimited operating duration 
The ECS must maintain the heat source (HS) at a safe temperature in the event of power conversion system failure (maximum Hs surface temperature is estimated at $3000^{\circ} \mathrm{F}$ ). During ECS activation, the HS outer surface maximum temperature shall not exceed $2700^{\circ} \mathrm{F}$ for more than 15 minutes.

\section{$3.4 .3 .3 \mathrm{HSHX}$}

HSHX design parameters include:

(a) Material - Columbium (niobium) alloy c-103

(b) Maximum Pressure Drop - 0.22 psi at flow rate of 0.126 $1 \mathrm{~b} / \mathrm{sec}$ and pressure of 35.3 psia

(c) Maximum Leak Rate $-1 \times 10^{-9}$ standard cc/sec of helium

(d) Maximum Design Life Creep Rate - 2-percent (radial direction) and 1-percent (axial direction) at design temperature, plus $50^{\circ} \mathrm{F}$, with $15-$ percent safety margin.

The HSHX is defined on GE Drawing 707E839.

\subsubsection{Development Status}

Under the current NASA Contract (NAS3-18029), detail design is completed with fabrication in progress. First delivered hardware is expected in late 1976.

\subsubsection{Interface Data}

Interface data is TBD. 
AIRESEARCH MANUFACTURING COMPANY OF ARIZONA

A DIVISION OF THE OARERT COMDOAATION

PHOENIX, ARIZLNA

THIS PAGE LEFT INTENTIONALIY BLANK 


\subsubsection{Heat Rejection Heat Exchanger (HRHX)}

A vacuum tank with refrigerated walls and proper emissivity and absorbance would be needed to properly simulate the effective space radiant temperature $\left(217^{\circ} \mathrm{K}\right.$ or $390^{\circ} \mathrm{R}$ is the temperature used for all performance estimates herein) for the space radiator. To simplify system and test facilities designs, a liquid to gas HRHX, that simulates space radiator effects, will be designed and fabricated for GDS testing. The HRHX is depicted on Figure 3-17.

It is intended that HRHX design simulate a radiant cooler, as nearly as possible. This includes heat exchanger effectiveness, pressure drop, and dynamic responses to transients. The design must also have structural integrity compatible with system reliability and safety objectives.

\subsubsection{Steady-State Performance}

Basic HRHX performance meets the engine defined steady-state performance criteria. Drawing $\mathrm{L} 3621587$ represents the required HRHX envelope, for integration with the system. It has been determined that this envelope is compatible with cooler requirements.

\subsubsection{Dynamic Simulation}

It is important to achieve reasonable dynamic similarity between the HRHX and FS radiator designs to assess overall effects on system performance. Since the cooler time constant is expected to be long, relative to major system dynamics, an exact dynamics match should not be required. However, a comparative evaluation will be made, using the digital computer Dynamic Simulation Model, in the event that heat exchanger characteristics are significantly different. 


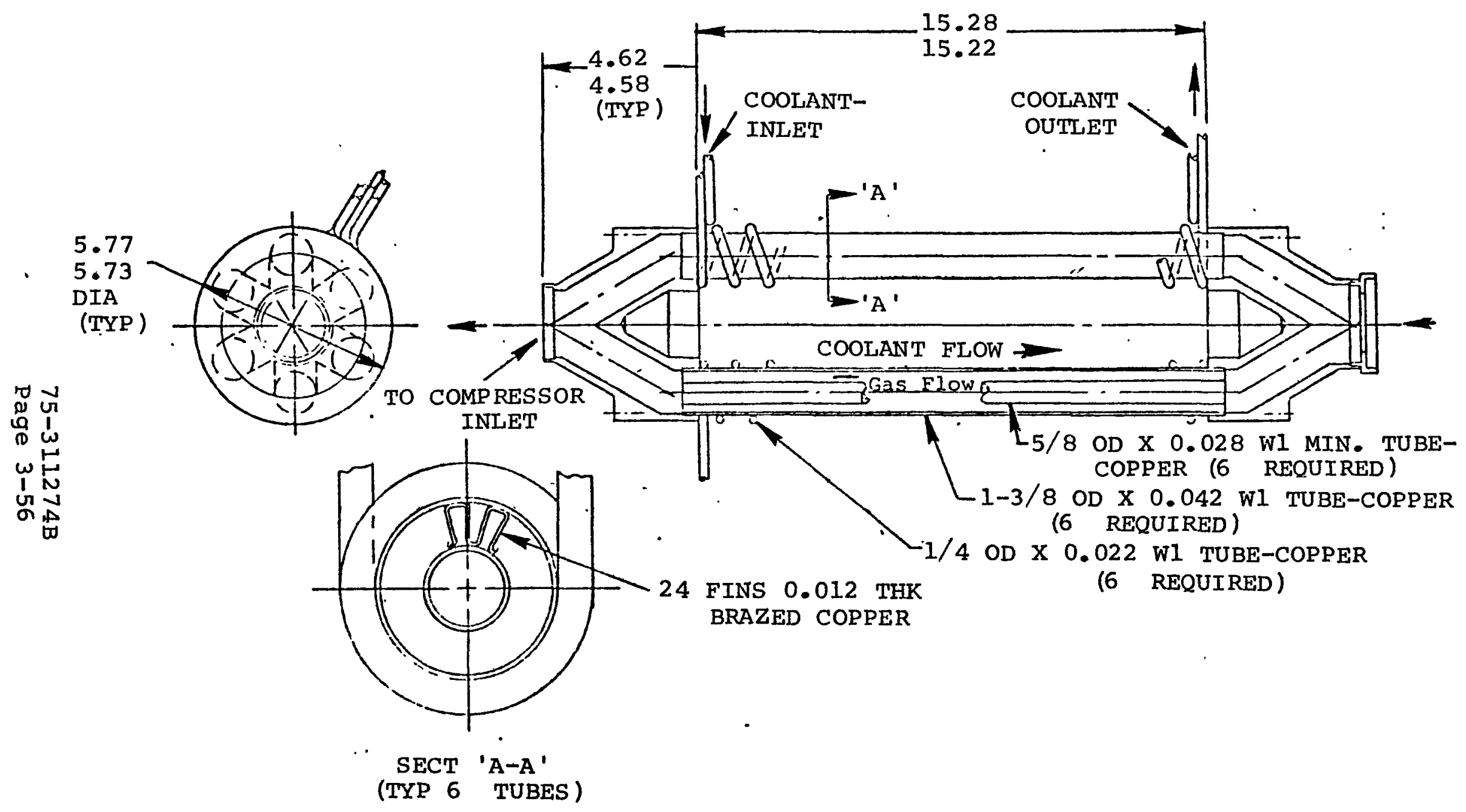

HEAT REJECTION HEAT EXCHANGER BIPS-GDS

FIGURE 3-17 


\subsubsection{Structural Analysis}

To ensure system integrity, HRHX stress and vibration analyses will be made. Since this is a simple, non-flight configuration, only the analyses that assure safety and reliability will be performed.

\subsubsection{Structural Integrity}

Proof pressure testing will be conducted to obtain pressure drop data and structural integrity confidence. Testing pressure and temperature will be specified as a result of a stress analysis.

\subsubsection{Performance Verification}

A heat transfer performance test will be conducted, after the HRHX is assembled into the GDS, using air on the working fluid side of the heat exchanger. The cooling side temperature control loop will be operating during this test to verify heat exchanger operation, as a system. 


\section{4 .5 Controls}

The GDS control system is designed to perform the following major functions :

$-\quad$ Engine starting
- Engine shutdown
Load-following capability
- Component protection

GDS controls will be designed to implement control functions that are expected in the FS. Controls will employ "breadboard" electronic circuit hardware. During GDS design and development, consideration will continually be given to ultimately miniaturize controls hardware for the FS.

A major design requirement is to provide the flexibilities to modify design, alter individual circuits, and adjust set points and gains. This permits exploration of a variety of control modes, and maximum accumulation of engineering data during the development phase.

\subsubsection{Development Status}

A control system developed by AIRPHX for the NASA "B" Engine (a $15 \mathrm{kw}$ e closed Brayton cycle) has been tested for over 32,500 hours. A follow-on system was breadboarded by NASA-Lewis Research Center, which also conducted initial functional tests and derived system performance characteristics.

This system is currently being evaluated for use on the GDS. The design provides considerable latitude for improving functional characteristics and reliability, through redesign and adding redundant components. 
An AIRPHX designed alternate control scheme is also being evaluated. Although similar in philosophy, this scheme differs considerably from the NASA control in circuit implementation. However, the alternate control scheme does provide a basis for trade-off.

\subsubsection{Reliability}

Control system reliability requirements are TBD.

\subsubsection{Physical Data}

Control system physical data are TBD.

\subsubsection{Description of Operation}

Controls and instrumentation required for GDS ground testing are shown on Figure 3-18 and schematically on Drawing 306960. This schematic shows the basic engine loop and nomenclature used to define various state points around the loop, along with major required laboratory connections.

The electrical heat source is supplied electrical power, from the facility, to provide heat to the closed Brayton cycle loop. Power to the electrical heater will be constant to simulate isotope heat source input. The laboratory setup contains an argon supply, and vacuum system, to allow the heat source to be pressurized and conduct heat to ambient, or to be evacuated. This greatly reduces conduction to ambient, and allows heat to enter the Brayton loop.

The basic loop contains a turbine bypass shutoff valve (SV-I) and a pressure relief valve $(P R V-1)$ in the control loop for development testing protection. (To enhance reliability and avoid inadvertent system shutdowns, SV-l will consist of two normally open valves, 


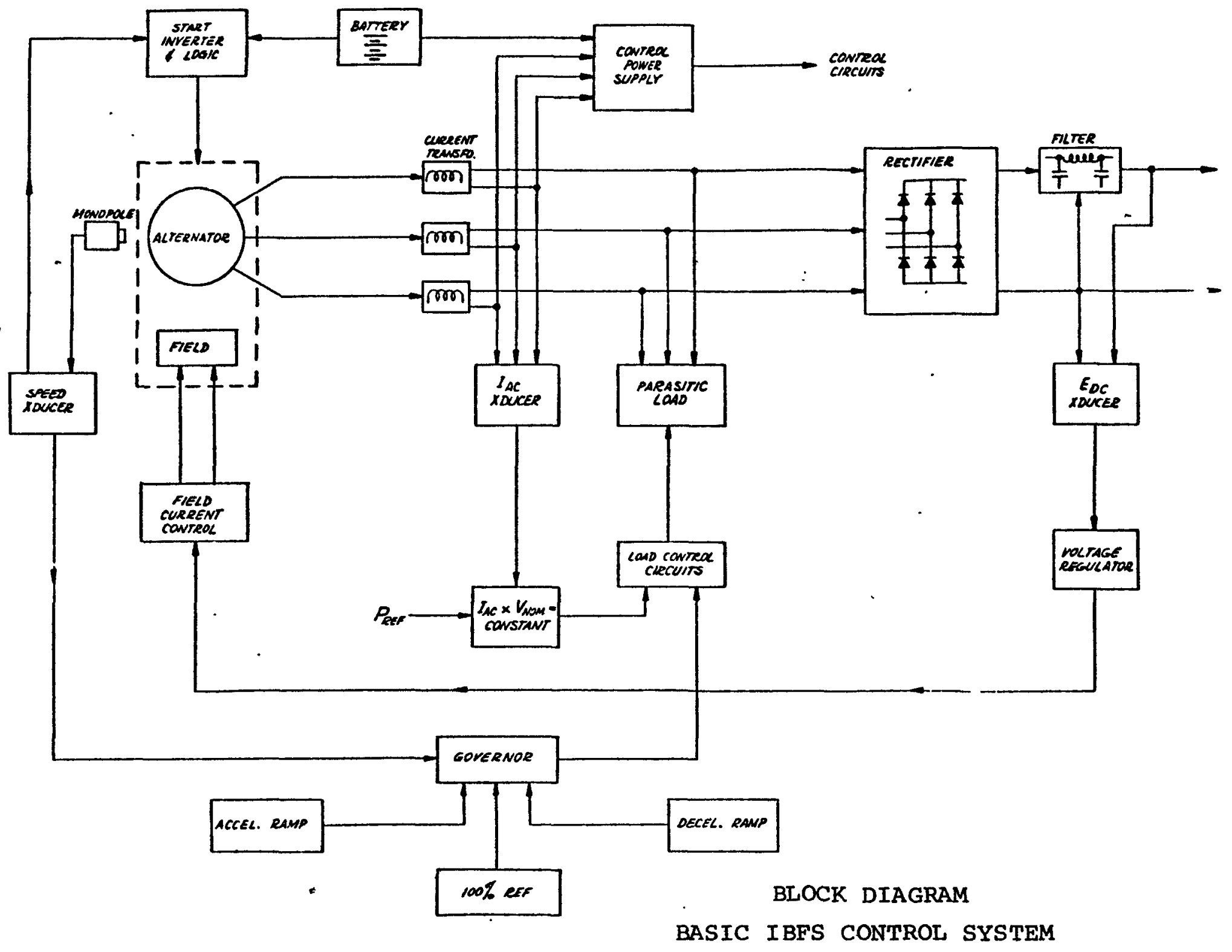

FIGURE $3-18$ 
in series.) The bypass is used to accept flow directly from the compressor to turbine discharge, thus bypassing the turbine and reducing engine power. Although the compressor continues to require energy for gas flow compression in bypassing the turbine, the rotating group power and speed are both reduced. This bypass applies to fault and overspeed protection only, since normal speed control is provided by the electrical parasitic load, which is a function of speed, $T_{6}$, and user load. $P R V-1$ is a safety feature to prevent overpressuring the entire loop and damaging ducting and heat exchangers.

Check valve $(\mathrm{CV}-1)$, in the compressor discharge, prevents reverse flow during startup. The possibility of removing $\mathrm{CV}-1$ will be investigated during engine testing.

The HRHX (radiator simulator) will be supplied with liquid coolant. HRHX inlet, and outlet, gas stream temperatures will be monitored and an automatic control will adjust cooling flow to control the outlet temperature.

The test loop will not be as well sealed as the flight configuration, because the test loop contains extensive instrumentation and more potential leak paths. For this reason, in addition to the initial charge, a He-Xe tank is connected to the loop for charging during operation. A pressure regulator is used to control inlet pressure into the Brayton closed loop, and will replenish leakage as required, to maintain constant pressure.

As stated above, the turbine bypass valve is a fault and overspeed device used only for system protection. The bypass is actuated by faults, which could be damaging to the engine, including:

- Engine overspeed

- Overtemperature of compressor inlet, turbine inlet, bearings, or alternator 


\section{- Underpressure of bearings}

In addition to the automatic shutdown feature, an alarm is initiated when dc voltage is too high, or too low, or when compressor discharge pressure is too low (requiring make-up gas), or when the engine is motored for too long a period during the start cycle.

Start is initiated by momentarily depressing a start switch. This applies power, from the batteries through the inverter, to the alternator, which motors the compressor and turbine. The electric heaters will be separately controlled and at operating temperature, it is only necessary to create flow through the heater by driving the compressor to sufficient speed. Heated gas then enters the turbine and a net positive torque can be achieved as heat to the turbine increases.

Since thermal stress is a major consideration, it may be desirable to limit the heat exchangers temperature rise rate. The temperature rise rate can be reduced if the flow rate is lower. It is anticipated that the rate of temperature rise can be limited by the rate of speed rise. Therefore, the speed control set-point may be programmed to be ramped with time or as a function of recuperator discharge temperature. This will control the speed change rate, and subsequently, the temperature rise rate. It is desirable to achieve self-sustaining speed before this scheduling occurs, to minimize battery power required for the start cycle.

Engine shutdown is accomplished by a signal to the speed control that reduces the speed set point. An overload that drives the engine below self-sustaining speed will be produced by the alternator. The engine should then roll down rapidly, and the heater pressurized with argon, or helium, to short circuit the insulation and allow thermal energy dissipation. 
The flight monitoring system will be included in the GDS to a limited degree. It is anticipated that transducers selected for flight, and some associated electronics, will be included in the test. This test provides an opportunity to study installation and to log endurance time on proposed flight monitoring equipment.

\subsubsection{Drawings and Parts List}

Control system drawings and parts list are TBD.

\subsubsection{Interface Data}

The following interface data applies to the control system:

(a) Electrical Power Output - See Section 3.1, item (f) and Table I-1, Appendix I.

(b) Electrical Connectors - TBD.

(c) Electrical Power Input for EHS - Provided by Power Supply Console, which requires $120 \pm 5$ percent vac $(60 \pm 3 \mathrm{~Hz})$ facility power. 


\subsubsection{Ancillaries}

Data on the following ancillary components will be documented, pending further design definition.

\subsubsection{Bi-Metallic Joints}

Materials of various components in the GDS require that two types of bi-metallic joints be developed. Materials in the ducting sections between the MBR and HSHX inlet(s), and MBR and Mini-BRU turbine exhaust require Hastelloy " $X$ " to Columbium Alloy C-103 joints. The space radiator will require an aluminum alloy and/or beryllium alloy to stainless steel ducting joint. This joint will be made by brazing in accordance with commercially available procedures.

The high temperature Hastelloy $x$ to Columbium Alloy C-103 joint is being developed at NASA, with two configurations under study. One configuration provides a joint by direct brazing, using a nickel-base alloy. The second method involves a transition joint made from blended powder metal $(80$ percent $W, 14$ percent Ni, 6 percent Fe at the Columbium Alloy $C-103$ end, and 30 percent $W, 49$ percent $N i$, 21 percent Fe at the Hastelloy $x$ end). The joint will be brazed to the columbium Alloy c-103 ducting. Brazing and TIG welding are being evaluated for joining to the Hastelloy $x$.

A test program to evaluate mechanical integrity (after joint aging and cycling), and metallurgical stability (of joint combinations) will be performed prior to final joint configuration testing.

\subsubsection{Ducting}

To optimize the GDS ducting system and facilitate interface design of all system components, four basic requirements were considered. These are: 
(a) Orientation of components relative to one another

(b) Orientation of Mini-BRU during launch

(c) Minimize flange loading due to ducting pressure and thermal growth

(d) Thermal loss and pressure drop

The approach developed to meet these basic requirements is shown on Drawing L3621580. Short lengths of straight ducting were utilized, whereever possible, to minimize flange loading, especially in the turbine plenum area where temperatures and stresses are highest. By reducing the number of bends, pressure drop is minimized, and, short duct lengths minimize thermal 1oss. Multiple bellows links are used to absorb the large relative thermal growths of components.

Three duct diameters were used; $1.50,1.60$, and 2.50 OD. Wall thicknesses remain TBD. Fusion welding will be used in joining the system.

Figure 3-19 presents a duct size summary, listing requirements for each duct in the system. Included in this summary are the required size and number of each bellows in the system, plus the number and locations of all duct weld joints. Figure 3-20 is a working fluid system schematic that represents the ducting in Figure 3-19. It should be noted that two joints per bellows (connecting bellows convolutions to the weld cuffs) are not shown on Figure 3-20.

Sheet 3 of Drawing L3621580 shows locations and configurations of the Columbium Alloy C-103 welds to be made. Sheet 4 of Drawing L3621583 shows all GDS joints. 
GDS DUCT SIZING SUMMARY

\begin{tabular}{|c|c|c|c|c|c|c|c|c|c|}
\hline $\begin{array}{c}\text { Duct } \\
\text { No. }\end{array}$ & $\begin{array}{l}\text { No. of } \\
\text { Joints }\end{array}$ & Material & $\underset{{ }^{\circ}}{\text { Temp }}$ & $\begin{array}{r}\text { Press } \\
\text { Psia }\end{array}$ & $\begin{array}{l}O . D . \\
\text { in. }\end{array}$ & $\begin{array}{l}\text { Wall } \\
\text { in. }\end{array}$ & $\begin{array}{l}\text { Duct* } \\
\text { Length }\end{array}$ & $\begin{array}{l}\text { No. of } \\
\text { Bellows }\end{array}$ & $\begin{array}{l}\text { Bellows } \\
\text { Length }\end{array}$ \\
\hline 1 & 6 & Hast-X & 1757 & 57.7 & 2.50 & 0.035 & 46.3 & 3 & 3.00 \\
\hline 2 & 3 & Hast-X & 1757 & 57.7 & 1.60 & 0.035 & 10.0 & 1 & 2.00 \\
\hline 3 & 2 & Hast-X & 1757 & 57.7 & 1.60 & 0.035 & 6.0 & 1 & 2.00 \\
\hline 4 & 1 & C103 & 2060 & 57.6 & 1.60 & 0.050 & 6.5 & 1 & 3.35 \\
\hline 5 & 1 & $\mathrm{ClO3}$ & 2060 & 57.6 & 1.60 & 0.050 & 6.5 & 1 & 3.35 \\
\hline 6 & 9 & Hast-X & 1778 & 37.7 & 2.50 & 0.035 & 48.6 & 4 & 3.00 \\
\hline 7 & 10 & Cres & 672 & 37.6 & 2.50 & 0.035 & 86.0 & 2 & 3.00 \\
\hline 8 & 11 & Cres & 480 & 37.0 & 2.50 & 0.035 & 67.0 & 3 & 3.00 \\
\hline 9 & 3 & Cres & 628 & 57.8 & 1.50 & 0.035 & 16.0 & 1 & 2.00 \\
\hline 10 & 3 & Cres & 628 & 57.8 & 1.50 & 0.035 & 18.0 & 1 & 2.00 \\
\hline 11 & 3 & Cres & 628 & 57.8 & 2.50 & 0.035 & 13.00 & - & - \\
\hline 12 & 5 & Cres & 672 & $57.8 \max$ & 0.75 & 0.025 & TBD & - & - \\
\hline 13 & 2 & Cres & 480 & 37.0 & TBD & TBD & TBD & - & - \\
\hline
\end{tabular}

*Includes bellows length 


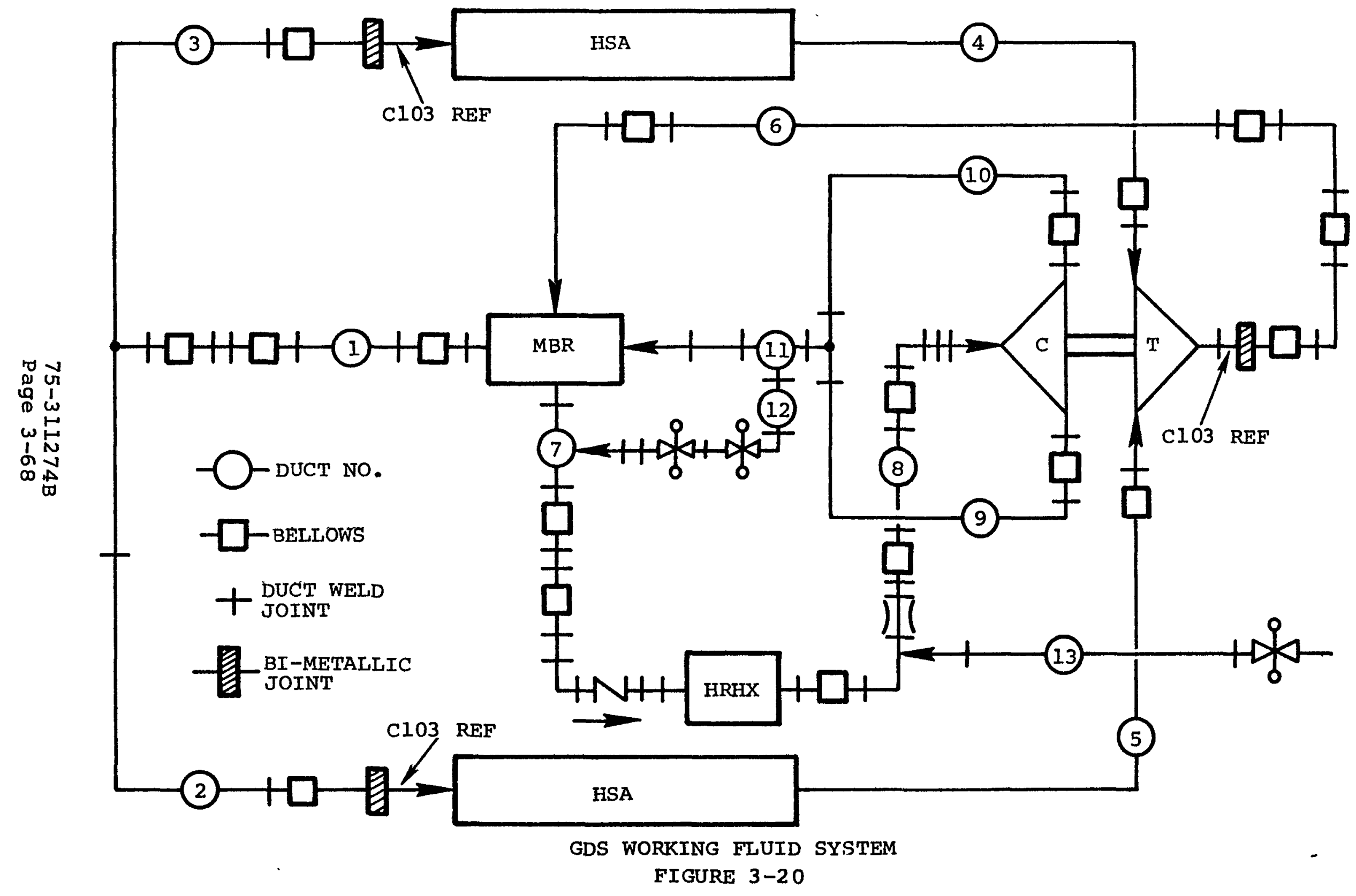


Drawing SKP 32749 shows the HSA assembIY sequence, tentatively agreed upon by GE and AIRPHX. As shown, AIRPHX will supply stub end ducts for inlet and outlet ports to the HsHX.

The inlet stub end duct will consist of a Bi-metallic joint section of Columbium Alloy $\mathrm{C}-103$ to Hastelloy $\mathrm{X}$ with a Hastelloy $\mathrm{X}$ bellows and cuff. The outlet stub end duct will comprise Columbium Alloy C-103 duct, and bellows, with a plenum interface weld flange.

\subsubsection{Structure}

Drawing $\mathrm{L} 3621586$ represents the GDS support structure, without the radiator. The structure comprises three sections as follows:

(a) Upper support structure that supports the HSA

(b) Lower support structure that supports the Mini-BRU and MBR

(c) Interim struts that tie the upper structure to the lower structure and radiator.

Tubular construction is used to minimize weight, while maintaining a high degree of stiffness and strength. The GDS structure basic material is aluminum with mount interfaces and fasteners made of stainless steel or titanium.

Basic GDS design criteria, as currently defined by applied mechanics, is a lowest natural frequency of $60 \mathrm{~Hz}$ with all mounts and mount interfaces designed for $50 \mathrm{~g}$ limit loading. All struts and beams are designed for $25 \mathrm{~g}$ limit loading. 


\subsubsection{Insulation System}

Mini-BRU operating temperatures, relatively low output power, and high cost and weight of the radioisotopic heat source, require a low loss insulation system. The system tentatively selected for the GDS (and FS) consists primarily of a multiple layer metal foil insulation. Penetrations in hot areas must be kept to a minimum to limit the effects of these thermal short circuits. A detailed discussion of Thermo Electrons Multi-Foil insulation, and associated fabrication problems, is contained-in Mini-BRU Progress Report, 74-310631(13). Total GDS losses, because extensive instrumentation is required, may be as high as $980 \mathrm{~W}_{t^{*}}$ The FS design goal is $600-650 \mathrm{w}_{t^{*}}$

Multi-Foil denotes a thermal insulation system developed by Thermo Electron Corporation in which thin metal foils are spaced in a vacuum by oxide particles. Examples of cylindrical and planar Multi-Foil constructions are shown in Figure 3-21. Oxide particles are selected on the basis of low thermal conductivity and foil compatibility, depending on application temperatures. The oxide particles are optimized relative to size, and real density, to minimize thermal transport. The multiple foils are effective thermal radiation shields, and the vacuum environment eliminates gas conduction heat transport. oxide particles provide a high thermal impedance to conduction by:

(a) Selecting oxides with low thermal conductivity

(b) High thermal interface resistance between foils and particles

(c) Thermal resistance of the thin foil

Multi-Foil has demonstrated low heat losses perpendicular to the foils. However, extreme care must be taken when designing and fabricating Multi-Foil assemblies, to minimize heat losses at the joints. Typically, joint heat loss is comparable to that directly through the foil. 


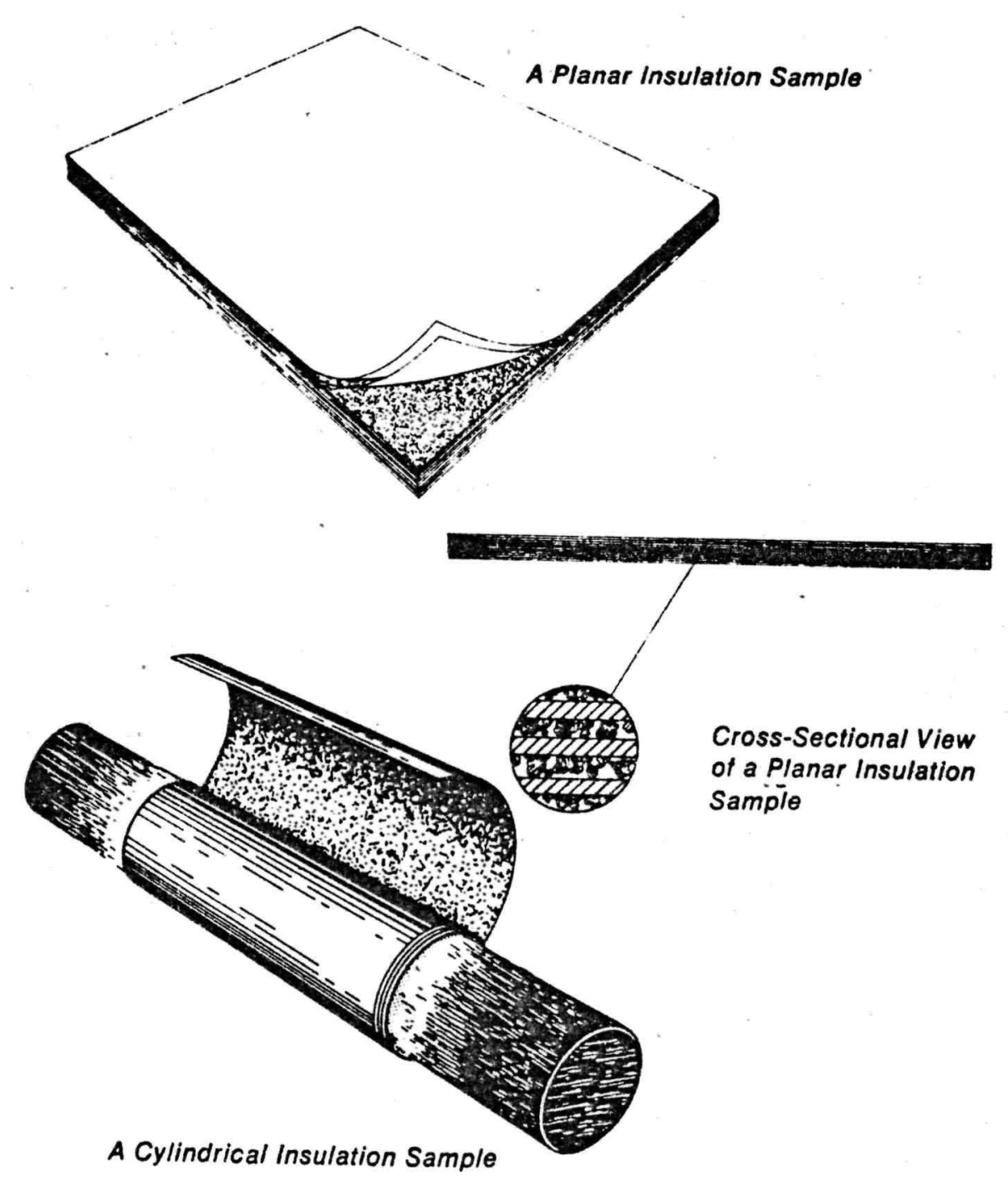

PLANAR AND CYLINDRICAL MULTI-FOIL INSULATION

FIGURE $3-21$

$75-311274 \mathrm{~B}$

Page 3-71 
Three types of Multi-Foil will be evaluated for the GDS (and FS).

- Conventional "cylindrical-planar" Multi-Foil

- "Wrapped" Multi-Foil

- "Electroformed" Multi-Foil

Thermo Electron has supplied AIRPHX with Multi-Foil heat transfer data generated in 1968-69 for the AEC. AIRPHX has reduced this data into the form of effective emissivity.

The effective emissivity derived from 61 TECo data points agrees well with published hemispherical total emittance data for "sandblasted" nickel. Study of other published data suggests that the surface finish of "as received" nickel foil cannot be considered a polished surface, as assumed to date. An RMS surface finish of 0.01 microns (0.4 micro inches) is considered a polished surface. The nickel foil material, as tested, was close to a factor of 40 times this roughness. In light of this information, and effects of zirconia coating, correlation with the sandblasted surface data appears logical.

Current heat flux estimates are made using the semi-empirical equation below:

$$
\frac{Q}{A}=\frac{4.457 \times 10^{-13}}{N} T_{H O T} 4.82703-T_{\text {COLD }} 4.82703
$$

where:

$$
\begin{aligned}
\frac{Q}{A}= & \text { Unit Heat Flux }\left[B T U / \mathrm{hr}^{\left.-\mathrm{ft}^{2}\right]}\right. \\
\mathrm{T}_{\text {HOT }}= & \text { Hot Face or FOil Temperature }\left[{ }^{\circ} \mathrm{R}\right] \\
\mathrm{T}_{\text {COLD }}= & \text { Cold Face or Foil Temperature }\left[{ }^{\circ} \mathrm{R}\right] \\
\mathrm{N}= & \begin{array}{l}
\text { Number of Radiation Gaps Between } \mathrm{T}_{\mathrm{HOT}} \text { and } \\
\mathrm{T}_{\text {COLD }}[\text { Dimensionless] }
\end{array}
\end{aligned}
$$




\subsubsection{GDS Tests}

GDS tests and evaluation will consist of performance and endurance testing.

Performance tests will consist of performance mapping, and a series of start up and shutdown tests. The GDS will be instrumented for measurements to be taken at all key thermodynamic cycle state points, and at selected metal and insulation system temperatures.

The endurance test (following performance) will consist of operating the GDS for 1000 hours, with the following basic objectives:

(a) Substantiate the FMECA

(b) Determine life-limiting components

(c) Determine the potential system lifetime

(d) Detect basic design deficiencies that may exist in the original configuration, including synergistic effects

(e) Detect test facility design discrepancies that could prevent economical long duration tests

(f) Determine precise costs for testing $(\$ / \mathrm{hr}$ for endurance testing).

The 1000-hours endurance test may be expected to accomplish the following:

(a) Contribute in substantiating the FMECA (Objective a) 
(b) May disclose system or component weakness not previously discovered in component tests or performance mapping (Objective d)

(c) Demonstrate GDS ability to operate in a given test facility for 1000 hours (objective e)

(d) Provide an accurate determination of test costs per hour (Objective $f$ ), which is important to follow on program planning

(e) Provide a reasonable confidence level that test facilities and procedures will permit trouble-free GDS running over longer periods, if desired.

It is to be noted that the performance tests will also contribute to satisfying the same objectives, A listing of formal procedures, specifications, and tests, planned for the GDS is provided in AIRPHX Report 76-311737, entitled, "Specification Requirements Summary for the BIPS GDS". 


\subsection{FACILITY}

This section summarizes GDS vacuum system and test facility design objectives and requirements. GDS piping and instrumentation, associated controls, power to the HSAs, vacuum system, etc., are shown on Drawing 306960. The test facility will provide:

(a) Energy and fluid requirements for GDS operation instrumentation, and vacuum facility.

(b) A clean room for GDS assembly and instrumentation.

(c) A vacuum chamber and pumping system for GDS space environment simulation.

(d) Control panel, information readouts, recording equipment, and automatic failure shutdowns and alarms, as required.

(e) Working fluid gas management system.

(f) Vacuum chamber gas management system.

The following sections address the subjects of energy, clean room, and vacuum system requirements.

\subsection{Facility Energies Requirements}

A preliminary tabulation summarizing required energies to support the GDS test facility, has been compiled and is presented in Table 4-1. 
TABIE $4-1$

ERDA BIPS ENERGY REQUIREMENTS

\section{$\underline{\text { Item }}$}

Vacuum System

WFMS Pump (15 scfm)

Ti Pump

Hi Vac Pump

TM (ea.)

16 oil

Fore Pump (100 cfm)

(Roots) (500 cfm)

Ti Pump Cavity Pump

Total

Loop Support

Waste Heat H.X. Refrig Loop (1.5 Ton)

HSA Power In

GE HSA GMS Service Cart

HSA Controls

Total

Miscellaneous

Low Gages (2)

Thermocouple Gages (2)

RGA (2)

Solenoid Valves (ea)

Engine Controls

Instrumentation

D.A.S.

Sanborn (ea)

Tape Recorder (ea)

High Speed Digital

Vac Dry Box

Pump System

Weld
Elec. Req't (KW)
Percent

Usage

$\begin{array}{llr}1 & & 10 \\ 21 & 21 & 100 \\ 1.5 & 0.25 & 10 \\ 10 & 1.5 & 10 \\ 4 & 1 & 10 \\ 3 & (1) & 10 \\ 1 & & 5\end{array}$

21.5

5

7

1

1

14

$\begin{array}{ll}0.2 & 100 \\ 0.2 & 100 \\ 1 & 100 \\ 0.01 & 100 \\ 0.1 & 100 \\ 0.5 & 100 \\ 1 & \\ 1 & 100 \\ 0.5 & 100 \\ & 100\end{array}$

Grand Total

5

5

50
100

100

100

100
4

2 


\subsection{Clean Room Requirements}

As of the publication date of this CCD edition, clean room requirements have not been totally defined. However, the need for a clean room stems from stringent requirement that GDS components be as free from contaminants as possible. Possible contaminants include base material, oxidizer, $\mathrm{H}_{2} \mathrm{O}, \mathrm{O}_{2}, \mathrm{~N}_{2}, \mathrm{CO}, \mathrm{CO}_{2}$, dust, lint, oil and grease. The clean room will provide a highly controlled environment, and all personnel entering will be required to wear ultra-clean clothing. The completed GDS assembly will be bagged in a clean, dry atmosphere before delivery to the test area. However, specific clean room requirements are TBD.

\subsection{Vacuum System Requirements}

Vacuum system requirements are addressed in detail in Engineering Report 76-311736, which includes a study of a reference system. This section of the CCD presents a summary of this study and the vacuum system requirements.

\subsubsection{Vacuum Chamber}

The present 8600-Iiter reference vacuum chamber is large enough to house the GDS except that the HRHX will be mounted external to the chamber, regardless of chamber size, since it is desired that HRHX coolant flow not penetrate the chamber. This precludes any external GDS contamination from leaked coolant. The existing AIRPHX vacuum chamber would require considerable rework to: (1) install a double polymer gasket at the chamber mating flange (83 inch diameter) with intervening groove for evacuation with a roughing pump; (2) add new flanges for GDS operation parameter sensing, controls, power, HRHX piping, ion pressure gages, and various vacuum pumping system inlets; (3) remove the painted interior, perferably by glass bead blasting; and (4) thoroughly clean and degrease. A possible drawback is that 
the existing chamber is a mild steel chamber. Mild steel is subject to oxidation and $\mathrm{H}_{2} \mathrm{O}$ retention to a greater extent than stainless steel. A smooth, unpainted, cleaned surface is required to lessen tank outgassing.

According to results of a system study (76-311736), which assumed an effective pumping speed of 2230 liters/sec pumping capacity and a vacuum chamber the same size as the present chamber ( 8600 liters), the present 8600-liter, mild-steel chamber if reworked as indicated above would be evacuated to $10^{-6}$ Torr in 35 hours. This time reduces to 22 hours if baked to $200^{\circ} \mathrm{F}$ (Figure 4-1). Higher temperatures were not considered due to temperature limits of seals, gaskets, sensor Iines, and other instrumentation, as well as a more stringent insulation requirement. Chamber cleaning and degreasing would be required each time the chamber was evacuated to ensure a reasonable pumpdown time. An aluminum chamber would have essentially the same outgassing, pumpdown characteristics, and cleaning requirements as a mild steel chamber. Plating a mild steel chamber does not significantly affect these characteristics.

By contrast, a cleaned and degreased stainless-steel chamber exhibits a significantly lower outgassing rate, and if a stainlesssteel chamber is not cleaned, it exhibits outgassing characteristics similar to aluminum and mild-steel chambers. For an ultimate pressure of $10^{-6}$ Torr, a cleaned stainless-steel chamber with outgassing rate virtually the same, whether baked or not, gives a 22-hour pumpdown time for the reference system.

Currently known vacuum chamber penetration requirements are presented on Table 4-2. The table is arranged by usage and, in general, penetration locations will be on the chamber non-movable end. Possible exceptions to this are the ion pressure gages, which must be located at some distance from other power sources. Some parts may accomodate more than one usage (i.e., the inert gas backfill, number 5, could be in the same part as electrical power, instrumentation, etc.). 


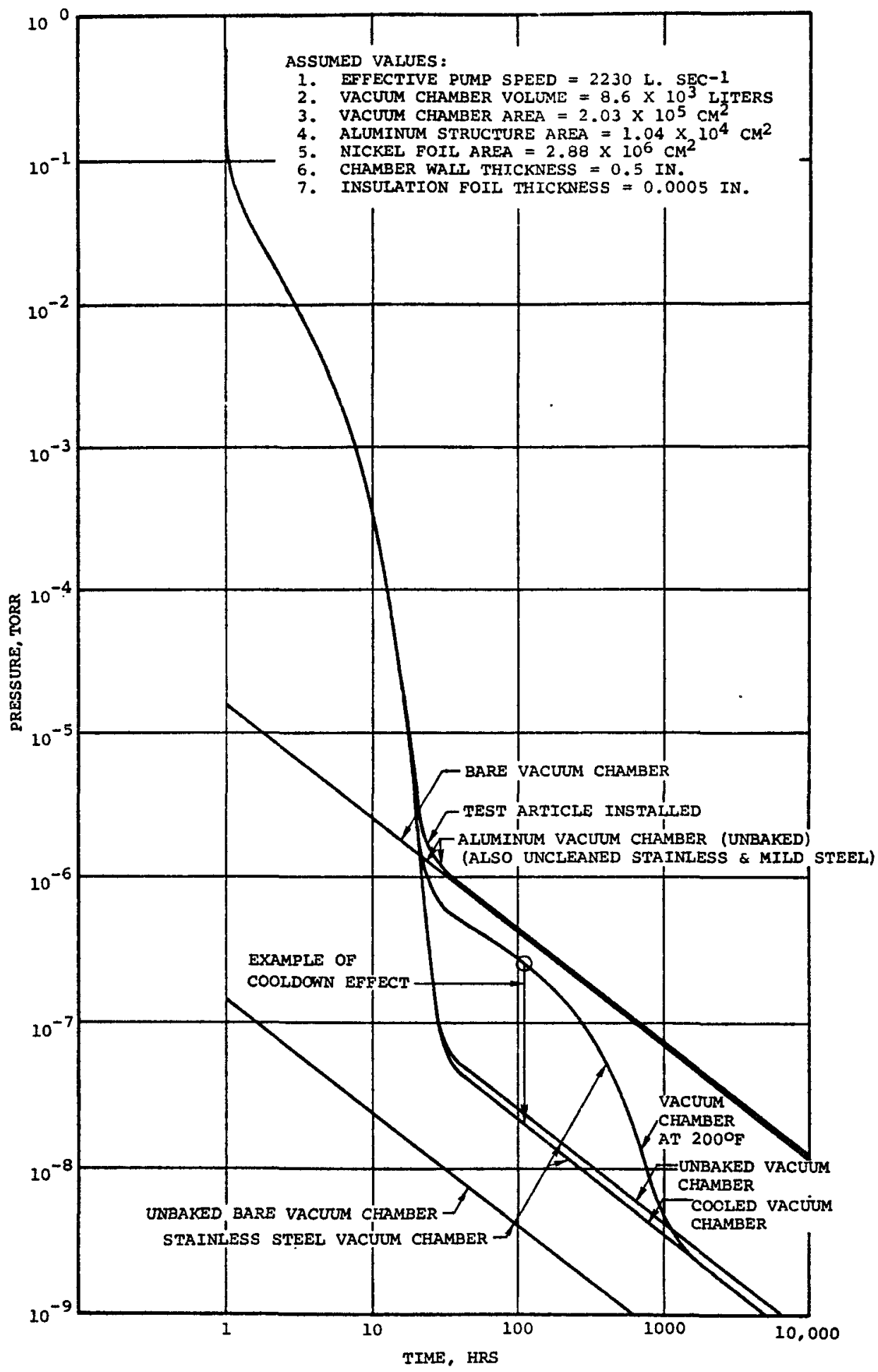

ESTIMATED PERFORMANCE

BIPS GDS VACUUM TEST FACILITY

FIGURE 4-1

$75-311274 B$

Page 4-5 


\section{TABLE $4-2$}

\section{ANTICIPATED CHAMBER PENETRATIONS}

Item

No.

1

2

3

4

5

6

7

8

9
Port

Quantity

1 or 2

1

3

1

1

1

1

2

1
Diameter

12 in. to 16 in.

12 in.

TBD

TBD

TBD

TBD

TBD

TBD

TBD
Remarks

High vacuum pumps

Sustaining pump

Ion gages

Residual gas analyzer

Inert gas backfill

Electrical power leads

Instrumentation

HRHX working fluid ducts

sustaining roughing pump 


\subsubsection{Pumping Requirements}

Vacuum facility pumping requirements can be satisfied by a high vacuum pump of 1000 liters/sec. Under conditions of outgassing, which continues for several days after the ultimate pressure is reached, chamber pressure is proportionally inverse to the pump capacity. Engineering Report 76-311736 reported that the desired ultimate pressure of $10^{-6}$ Torr could be reached in approximately 22 hours, using a stainless steel chamber and an effective pumping speed of $2230 \mathrm{liters} / \mathrm{sec}$. If this capacity were reduced to 1000 liters/sec, the pressure would be $2.23 \times 10^{-6}$ Torr after 22 hours of pumping. Due to the steep negative pressure versus time curve (Figure 4-I) slope, additional pumping time required to bring the pressure to $10^{-\frac{6}{}}$ Torr, for the assumed 1000 liter/sec pump, is only a matter of hours.

The type of pump to be used is still TBD, since all pumps have peculiar advantages and disadvantages. Requirements and candidate pump criteria that must be considered are:

(a) Pump life and reliability

(b) Need for isolation valves of adequate time response and sealing ability in case of pump failure and/or lubricant backstreaming into the chamber.

(c) Need of some types of pumps to be furnished with a continuous supply of liquid nitrogen.

(d) Iiquid (refrigerant or water) cooling of some pumps may be required.

(e) Isolation from the chamber may be required for pump rejuvination while a vacuum is held in the chamber (i.e., a titanium sublimation pump ball or an absorption pump exchange). 
(f) Size the roughing pump so that it may also be placed downstream of a mechanical or fluid entrainment pump to be used as a forepump.

(g) Adequate shutdown and alarm sequencing is to be provided to preclude any detrimental effects on the GDS.

(h) Startup, control, shutdown, power failure shutdowns, and subsequent restarts must all be as automatic and as failsafe as possible. 


\author{
APPENDIX I \\ BRAYTON ISOTOPE POWER SYSTEM FLIGHT SYSTEM (BIPS FS)
}

\title{
1.0 INTRODUCTION
}

This CCD is for a GDS designed to be representative of a flight system utilizing the Mini-BRU, MBR, and HSA designed for application in a space power system. This appendix briefly describes the BIPS FS design, operating parameters used in performance parametric studies, and design-point operating conditions. A conceptual system layout ( 13621582 ) is included in Appendix III, which is based on $4800 \mathrm{w}_{t}$ total from two radioisotope heat sources. Conceptual BIPS FS estimated performance is shown in Figure I-I, and the energy balance in Figure I-2.

BIPS FS design is such that optional features can easily be incorporated into delivered units. One such feature is one-g bearings that may be desirable for low power-level applications, or high-g bearings required for operation during launch.

The Mini-BRU is designed as an "all purpose" machine, capable of operating over a wide spectrum of power levels $\left(0.35\right.$ to $\left.2.1 \mathrm{kw}_{e}\right)$ and orbital environments (near earth, synchronous, and deep space), with little compromise in performance. An example of this flexibility is that the "all purpose" Mini-BRU designed for $2.1 \mathrm{kw}$ output adds only a six percent weight penalty to the BIPS FS when integrated into a 0.4 $k w_{e}$ system.

GDS features, not in the BIPS FS, include a turbine bypass valve for overspeed protection, and a valved fill system. The BIPS FS will have no valves with external stems that could result in working fluid (gas) leakage. 


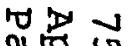

م

苗要

至

$x$

$H \stackrel{\leftrightarrow}{\leftrightarrow}$

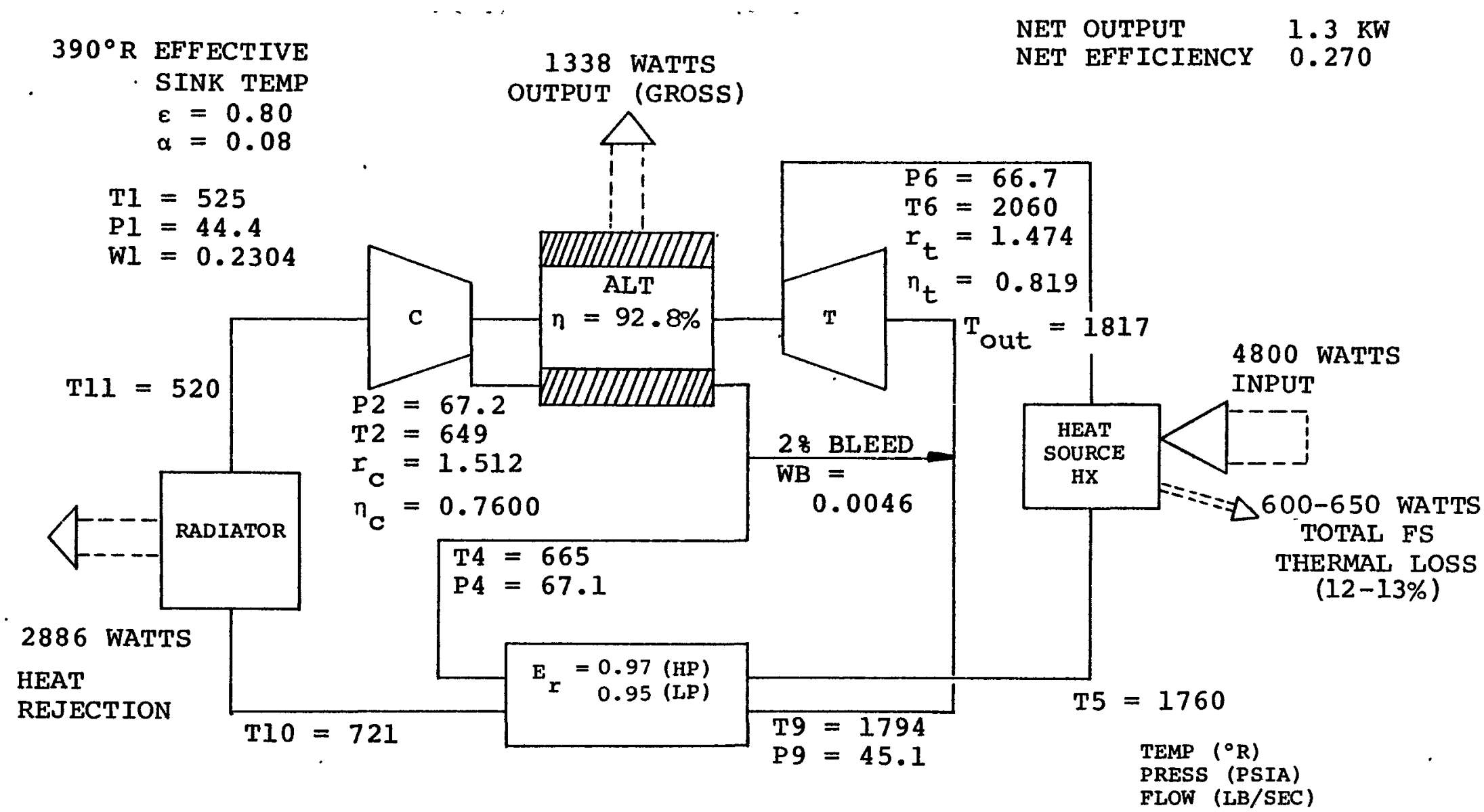

FLOW SCHEMATIC AND ESTIMATED PERFORMANCE

FOR THE $4800 \mathrm{w}_{t}$ ERDA BIPS FS

EIGURE I-1 

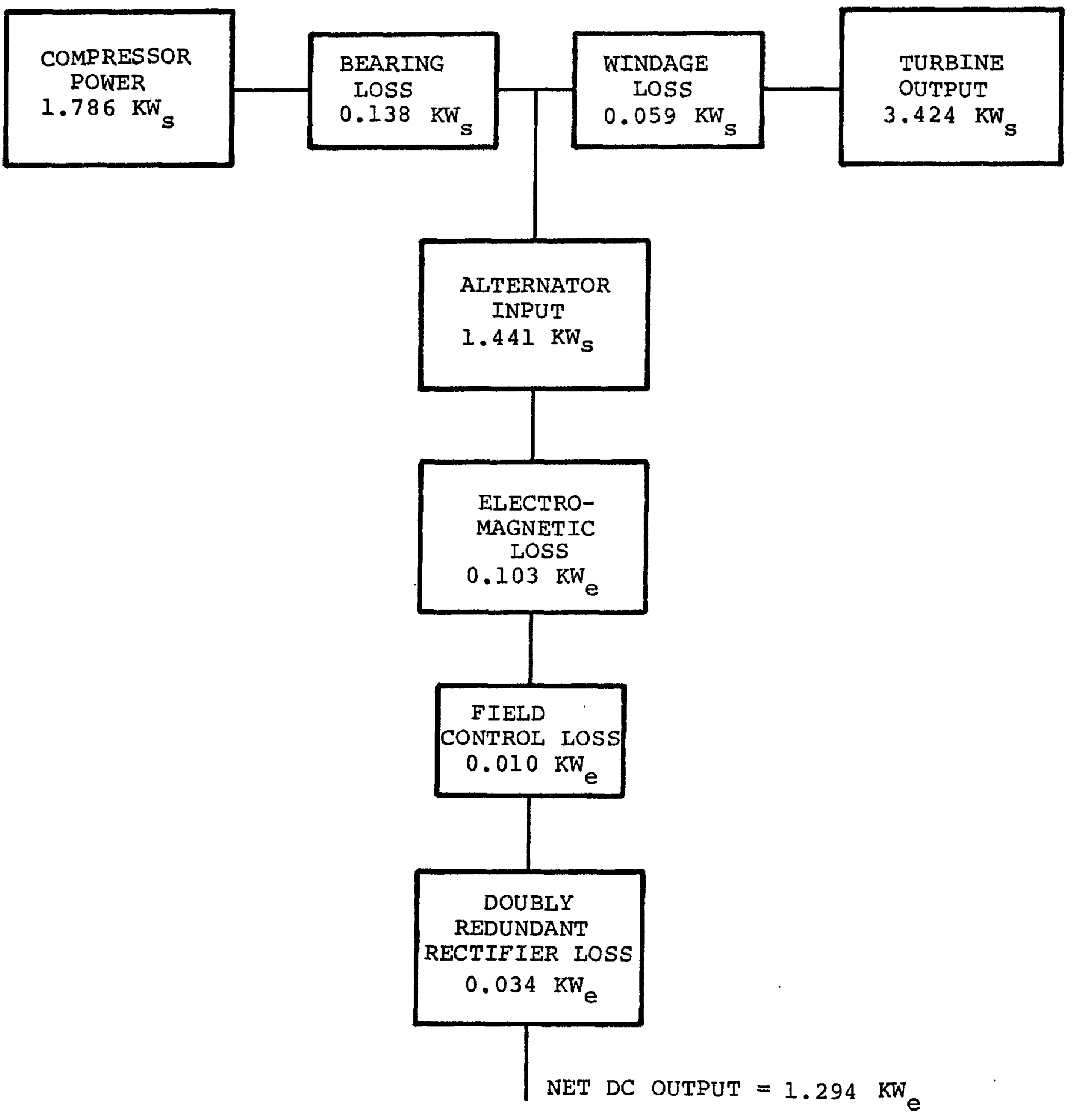

BEARING

LOSS

$0.138 \mathrm{KW}_{\mathrm{S}}$

INPUT

$1.441 \mathrm{KW}_{\mathrm{S}}$

ELECTRO-

MAGNETIC

LOSS

e

INDAGE

OUTPUT

$3.424 \mathrm{KW}_{\mathrm{s}}$ 
The GDS HRHX (radiator simulator) will be replaced by a space radiator for the BIPS FS. The ducting system will necessarily be different, but will have a similar pressure drop. 


\subsection{BIPS FS OBJECTIVES AND DESIGN}

The FS performance objectives are delineated on Table I-I. GDS design is based on these objectives except that an HRHX replaces the space radiator, and electrical resistance heat sources replaces radioisotope heat sources. FS components and subcomponents are delineated in Table $\mathrm{I}-2$.

The BIPS FS conceptual layout (I3621582) shows the Mini-BRU in the vertical position (same as GDS). This orientation was selected for two reasons :

(a) For gyroscopic compatibility with a spin-stabilized spacecraft when mounted with the vehicle axis coincident with (or parallel to) the BIPS Mini-BRU axis.

(b) Launch loads are usually greater in the vertical direction, and as presently designed, thrust bearings will withstand more load than journal bearings.

A horizontal orientation is equally feasible, but requires that some support structure and ducting be changed with the result that the MBR will be slightly lowered.

Because of potential future system requirements, some configuration changes may be required. These are:

(a) Provision for Operation Through Launch - Since the BIPS FS is designed to operate in a space environment hard vacuum, a bell-jar approach must be taken to provide an inert gas atmosphere for refractory metals and MultiFoil insulation protection. Bearings must also be checked for load adequacy (present journal and thrust bearing configurations are designed to accept 7 and $10 \mathrm{~g}$ acceleration loads, respectively). 
TABLE I-I

FS PERFORMANCE OBJECTIVES

(1) The FS will be capable of power output from 500 to $2000 \mathrm{~W}_{e}$ EOM, with minimum redesign and requalification.

(2) $28 \pm 2$ percent vdc is the reference output voltage.

NOTE

A capability for higher ac voltage output may be advantageous

if the output can be achieved directly from the generator.

(3) The control system will be capable of modulating power to the spacecraft from 0 to 100 -percent in $20 \mathrm{milliseconds}$ response times. This will be accomplished by a parasitic load.

(4) FS life time requirements is $L=7$ years and mean mission duration (MMD) = 5 years.

where MMD $=\int_{0}^{I} R d t$

and $R=$ probability of producing design power at time $t$

(Notwithstanding this requirement, AIRPHX has established a more stringent objective of $R=0.95$ after 5 years operation)

Prelaunch, launch, and operational phase failure modes will be identified.

(5) Based on a GFE heat source cost of $\$ 1000$ per $W_{t}$, the recurring cost goal for the FS at $1300 \mathrm{w}_{e}$ will be less than $\$ 5000$ per $W_{e} \cdot$

(6) A FS weight goal, at $1300 \mathrm{w}_{\mathrm{e}}$, is 450 pounds.

(7) The FS will be capable of launch on the space shuttle.

(8) Due to a potential explosive vapor environment, the on-pad temperature of exposed surfaces will be maintained below $380^{\circ} \mathrm{F}$.

(9) The system will be designed with an assumed sink temperature equal to, or greater than, that of a geo-synchronous orbit $(19,323 \mathrm{~nm})$. The system will be capable of stable operation with unbalanced solar input.

(10) Thermal input to the spacecraft must be of an amount that will not cause the spacecraft to rise above $100^{\circ} \mathrm{F}$.

(11) The magnetic field at one meter is not yet defined.

(12) The on-pad biological dose at one meter will be $\leq 0.20$ REM per hour.

(13) The FS will be resistant to natural and man-made radiations.

(14) FS components will be inherently flexible in mounting to facilitate integration with the required spacecraft configuration.

(15) On pad and in-orbit fueling capabilities should be provided. 
TABLE I-2

BIPS-FS COMPONENTS

$\underline{M i n i-B R U}$

- $1600^{\circ} \mathrm{F}$ turbine inlet temperature (working fluid is $\mathrm{Xe}-\mathrm{He}, M=83.8$ )

- Single shaft turbine, Rice alternator and compressor supported on foil bearings with compressor bleed cooling

- Alternator cooled by compressor discharge

- Refractory metal turbine plenum (Columbium C-103)

Recuperator

- Hastelloy $x$ construction with gold alloy braze

- Fin/plate counterflow design

Radiator

- Material [Be, aluminum alloy or Lockalloy (alloy of $\mathrm{Al}$ and $\mathrm{Be}$ )]

- Cylindrical design, offset fin/tube geometry

- Sink temperature, $390^{\circ} \mathrm{R}$

- Micrometeroid survival, 0.99 (assumed)

- Used as part of a low gage pressure vessel to contain an inert gas for protection of the C-103 and multifoil insulation from iaunch to orbit.

\section{Heat Source}

- ERDA Multi-Hundred Watt (MHW) heat source, (advanced ERDA HS concepts will also be investigated)

- Electrically heated heat source simulator (EHS) for Fs checkout

Heat Source Assembly (HSA)

- Columbium Alloy C-103 Heat source Heat Exchanger (HSHX)

- Auxiliary Cooling system - Helium short circuit of HSHX Multi-Foil insulation

- Emergency Cooling system - Melting of HSHX Multi-Foil insulation (alternatives have been identified)

\section{Insulation}

- High temperature Multi-Foil insulation

- Eight percent heat loss from HSA (Goal)

- Two percent heat loss from turbine and hot interconnecting ducting (Goal)

\section{Controls}

- Motor start inverter

- Parasitic load

- Speed control

- Voltage regulator

- Power supply

- Rectifier/filter

\section{Piping and Structure}

- Ducting

- Bellows

- Support structure (Beryllium or aluminum alloy)

- Radiator is used as part of the support structure 
(b) Operation on a Spin-Stabilized Platform - Bearing load limits must not be exceeded [see (a) above]. If the Mini-BRU axis is transverse to the vehicle spin axis, the resulting coning angle must not exceed that allowed by mission requirements. For a spinning vehicle and Mini-BRU combination, the coning half-angle $(\phi)$ is defined by:

$$
\phi=\mathrm{M}_{\mathrm{m}} / \mathrm{M}_{\mathrm{v}}
$$

where:

$$
\begin{aligned}
M_{\mathrm{m}} & =\text { Mini-BRU angular momentum }(0.68 \text { lb-ft rad sec) } \\
M_{\mathrm{V}} & =\text { Vehicle polar moment of inertia, lb-ft } \mathrm{sec}^{2} \\
\phi & =\text { Vehicle coning angle, rad }
\end{aligned}
$$

Presuming that $\mathrm{M}_{\mathrm{v}}$ is 500 , the coning half-angle would be approximately 0.08 degrees.

(c) Spacecraft Integration - Launch vehicle constraints, heat input to the space vehicle, and/or BIPS placement on the space vehicle may require that the assumed BIPS FS be reconfigured. As presently configured, the BIPS can be mounted on any flat surface, and be designed to limit heat input to the spacecraft. The BIPS power supply furnishes the most power at $120 \mathrm{vdc}$, but by adding other power conversion components, any desired voltage and frequency combination may be obtained. 
The BIPS FS schematic, Figure I-3, shows all components within the working fluid loop, and inter-connecting ducting. The duct numbers correlate with Table I-3 data. Note that the radiator and radiator ducting materials have not yet been selected. Approximate duct sizes, and lengths of ducts $7,8,12,13$, and 14 (Table I-3) are based on the conceptual design, shown on Drawing 13621582 and will vary with different radiator configurations. 

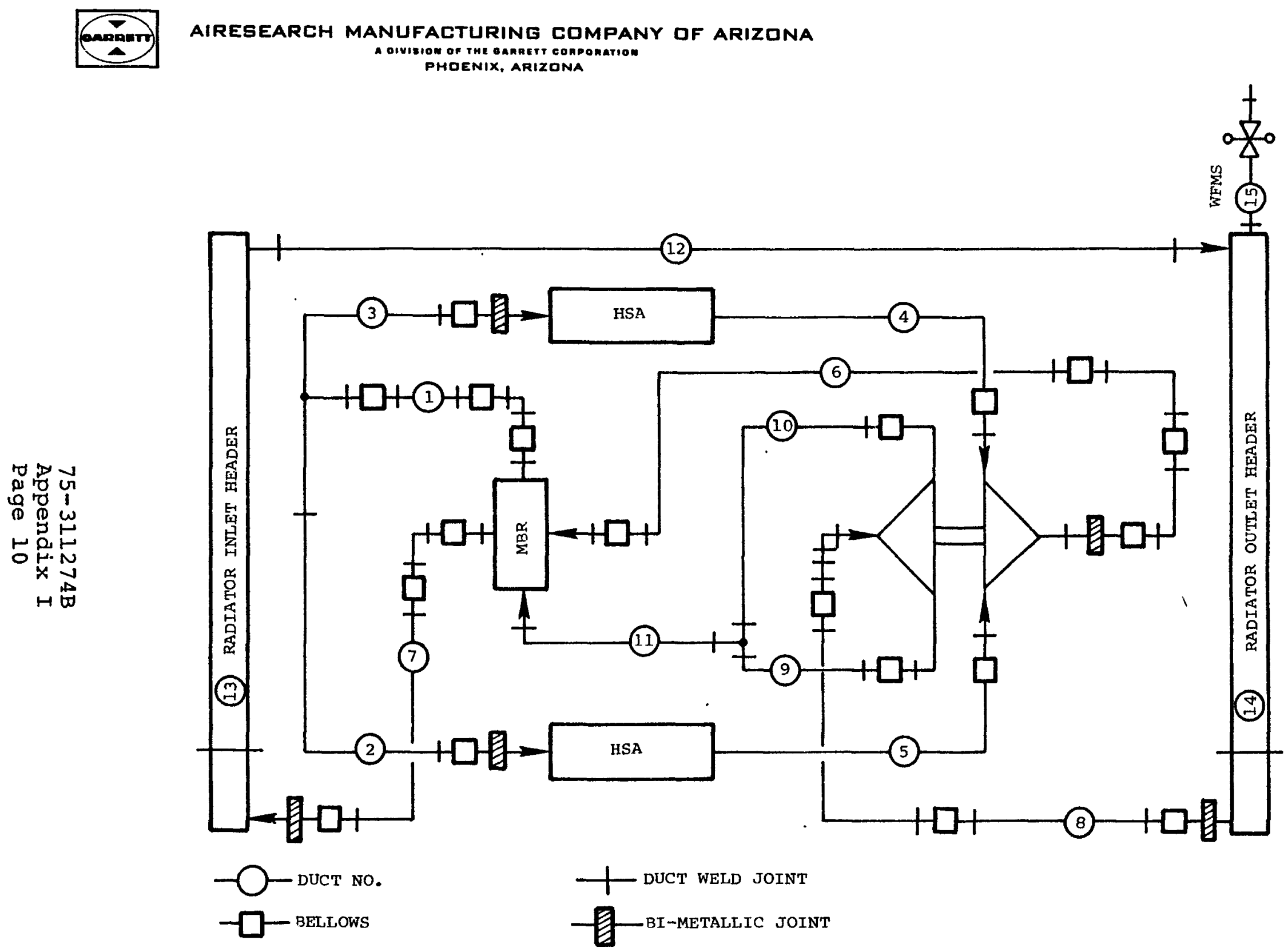

BIPS-FS DUCT SCHEMATIC

FIGURE I-3 


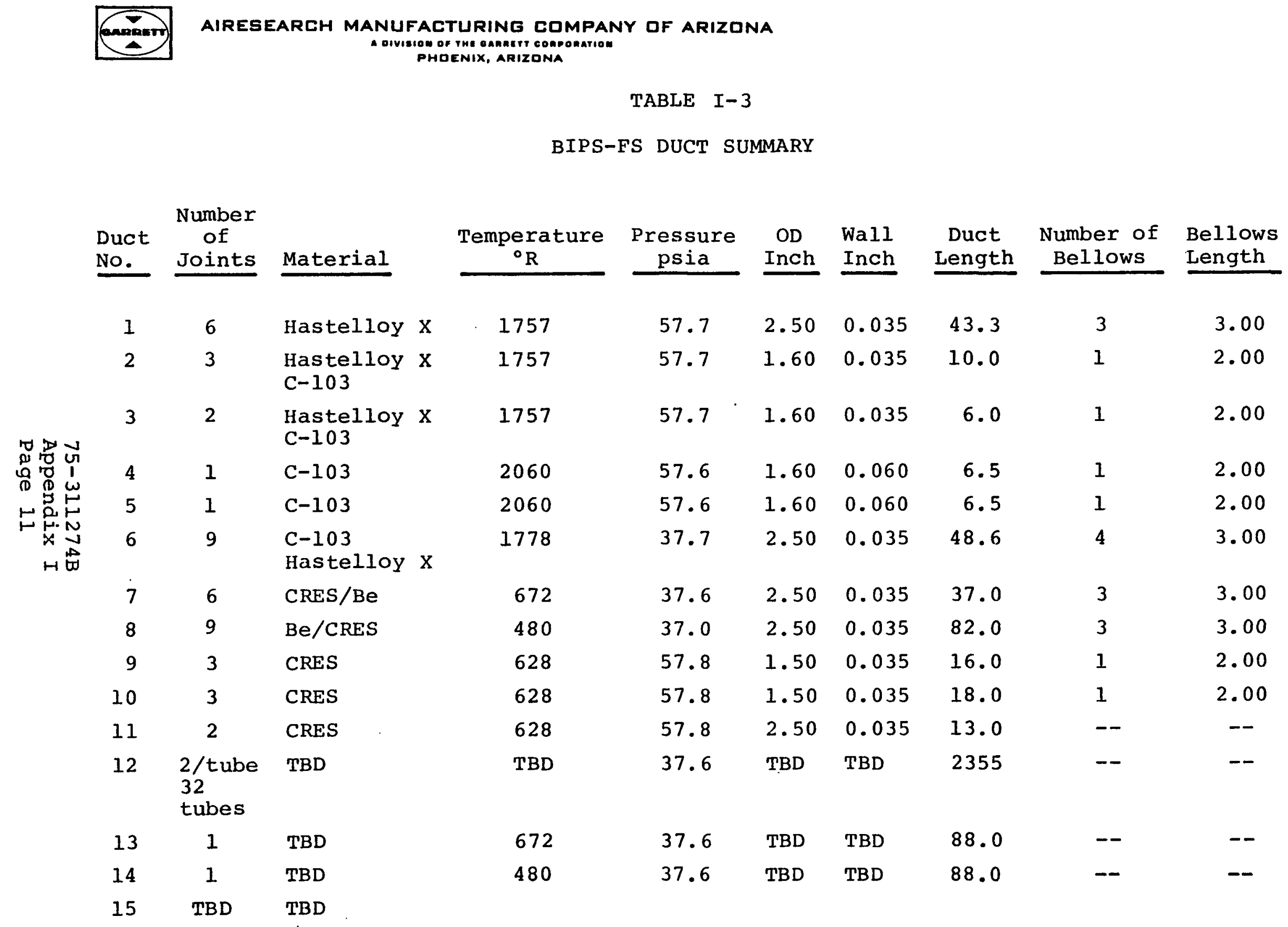




\subsection{PRELIMINARY SHOCK AND VIBRATION DESIGN CRITERIA}

When considering structural dynamics, the BIPS consists of a cylindrical radiator within which four discrete masses are supported by means of interface structure consisting of beams and struts. The four discrete masses are; two heat source assemblies, recuperator, and MiniBRU power package. As presently known, the BIPS will be mounted to the spacecraft, which will be mounted to the interim upper stage (IUS). The IUS will be mounted in a cradle or carrier in the space shuttle orbiter. This series of components comprises the orbiter payload. The Space Shuttle and IUS specifications (References 1 and 2 , respectively) imply that the payload be cantilever-mounted, from the orbiter mount points when in the stowed configuration.

The principal source of structural vibration occurs during space Shuttle powered ascent. Principal vibration levels the BIPS will experience depend on the payload dynamic response to orbiter vibration with the payload in the stowed configuration.

The principal source of shock occurs when using pyrotechnic devices on the IUS vehicle, such as that used for spacecraft separation. Principal shock levels the BIPS will experience depend on the payload dynamic response to pyrotechnic explosions, with the payload in the deployed configuration.

Shock and vibration levels at various interfaces, as estimated for conceptual design by the various referenced sources, are shown below.

(1) and (2) Refer to List of References. 
(a) Peak Random Vibration Levels

- Shuttle Vehicle Payload Interface (Reference 1) $0.1 \mathrm{~g}^{2} / \mathrm{Hz}(90$ to $275 \mathrm{~Hz})$ estimated response for an unloaded interface structure. Actual response should be lower due to mass of payload.

- IUS-Spacecraft Interface (Reference 2) -0.125 $\mathrm{g}^{2} / \mathrm{Hz}$ (100 to $1000 \mathrm{cps}$ ) recommended for conceptual design.

- BIPS-Spacecraft Interface (Reference 3) -0.1875 $\mathrm{g}^{2} / \mathrm{Hz}$ ( 900 to $1400 \mathrm{~Hz}$ ) GE estimate based on LES $8 / 9$ and Mariner $\mathrm{J} / \mathrm{S}$ experience.

These vibration levels appear to represent a vibratory amplification through the payload. However, the levels are assumed to be estimates of the three reference sources that were determined independently. It will not be known whether the vibratory input to the payload will be amplified or attentuated until the total payload structure is defined and total payload dynamic analyses are conducted.

(b) Peak Shock Levels

- IUS-Specification (Reference 2, Figure 6) - The stock response spectra gives a dynamic response of $115 \mathrm{~g}$ at the IUS-Spacecraft interface with a "Q" equal to ten for a 100 cps system. Although

(3) Refer to List of References. 
the BIPS response to shock at the IUS-Spacecraft interface is undefinable, it will be attenuated due to cantilever mounting and remoteness from the interface.

$\circ$ GE Specification Recommendations (Reference 3) 50-g dynamic response for the Isotope Heat Source, and support structure, in the HSA housing and $25-\mathrm{g}$ dynamic response for the overall BIPS structure, based on a shock response to a 775-g half sine pulse of 0.2 millisecond duration.

As noted above, actual shock and vibration levels the BIPS will experience depend on payload dynamic responses to the principal sources of excitation.

The space Shuttle is well defined and the BIPS is conceptually defined. However, the spacecraft, IUS, and IUS support structure to the shuttle craft, are currently undefined except for the decision to utilize a solid rocket motor. It is anticipated that the solid rocket motor and structure will possess a high degree of stiffness. Because of many unknowns, no meaningful dynamic analyses can be made, at this time, for predicting BIPS, vibratory and shock responses. However, criteria does exist that system dynamics must satisfy to maintain BIPS responses within tolerable structural design limits. These are:

(a) The cantilevered payload support structure must be designed to avoid coupling payload and space shuttle fundamental frequencies. To avoid this interaction the cantilevered payload fundamental frequencies should be at least two times greater than space shuttle fundamental frequencies. The shuttlecraft fundamental frequency range is estimated to be within 4 and $12 \mathrm{~Hz}$. Therefore, the fundamental of the cantilevered payload should not be less than $24 \mathrm{~Hz}$. 
(b) Support structures of BIPS discrete masses should be designed to avoid coupling the cantilevered payload fundamental frequencies with the rigid body fundamental frequencies of the BIPS masses. This means that BIPS components fundamental frequencies should be approximately $60 \mathrm{~Hz}$.

(c) Criteria (a) and (b) define cantilevered payload and BIPS components fundamental frequency limits. However, it is desirable to maintain the upper limits of natural frequencies no higher than necessary to satisfy (a) and (b), and to minimize BIPS components dynamic responses to shock and vibration. It is anticipated that the cascade of components, comprising the cantilevered payload, will respond to shock as a succession of simple systems, when each succeeding structure has a low mass relative to the next supporting structure.

\subsection{Design Criteria}

BIPS FS components (i.e., HSA, MBR, Mini-BRU) and mounting pads should be designed to a minimum limit loading of $50 \mathrm{~g}$. BIPS interface structures (i.e., struts, beams, etc.) should be designed to a minimun limit loading of $25 \mathrm{~g}$. The higher acceleration loading requirement provides increased structural integrity for BIPS components and mount pads. This is needed to compensate for the lower degree of mounting redundancy than the interface support structure (i.e., beans and struts). In the case of a staticalily determinate mounted component such as the MBR, failure of a single mount could result in separation of the component, whereas the interface structure is a many times redundant system capable of tolerating a number of member failures without catastrophic results. The design criteria of providing sufficient stiffness to the BIPS interface structura, to maintain BIPS component 
natural frequencies above $60 \mathrm{cps,} \mathrm{will} \mathrm{inherently} \mathrm{result} \mathrm{in} \mathrm{high}$ strength. It is anticipated that this built-in strength will exceed $25 \mathrm{~g}$. This limit loading should satisfy requirements for all other loadings such as pre-launch, launch, and operational environments, and in the case of an abort mission, crash landing requirements. This design criteria should be adequate for the BIPS preliminary design phase. After IUS and spacecraft definitions, dynamic analyses should be conducted on; the orbiter cantilever-mounted payload, and the payload as deployed from the orbiter. The cantilevered payload and support design should minimize the BIPS dynamic response. Considerable latitude exists in designing the payload structure to minimize BIPS dynamic loading. 


\subsection{ESTIMATED PERFORMANCE}

The estimated FS Mini-BRU performance, for 1, 2, and 3 HSA $(2400$ $W_{t}$ each), is shown on Table I-4. The data was generated assuming the systems were optimized at minimum weight by changing the MBR and radiator sizes. The GFE recuperator was used for the 3-capsule design only and the weight of hypothetical recuperators of 1- and 2-capsule designs was lowered, mainly by shortening lengths. Note that for the 1-capsule case, the optimum system weight was achieved with a radiator larger than for the 2-capsule case. The same performance could be achieved with some weight penalty by using a smaller radiator and larger recuperator. Users of this data are referred to the objectives stated in Table I-I.

Table I-5 delineates those performance variables with linear sensitivity factors. For sink temperatures, and turbine inlet temperature, non-linear effects refer to Figures $I-4$ and I-5. Performance variables are those parameters that may change due to build technique, aging, intent, or usage. The partial differentials of cycle efficiency, thus obtained, can be added to estimate the effects of small changes on any of the three system sizes studied.

To illustrate the use of sensitivity factors, consider the parameter changes to a two-capsule BIPS shown in Table I-6, (refer to Table I-4 for the original value and to Table I-5 for the sensitivity factor).

Off-design performance of these three systems is given in Figure I- 6 , to aid in assessing performance of a given system after the radioisotopes have degraded. In each case, since surface temperatures would be nearly constant, it was assumed that the change in thermal loss would be insignificant. 
TABLE I-4

CYCLE DATA OPTIMIZED FOR MINIMUM WEIGHT

Compressor Efficiency

Turbine Efficiency

Alternator Efficiency

Lost Pressure Ratio Parameter

Recuperator Effectiveness

Bearing Loss (kw)

Windage (kw)

Turbine Inlet Temperature $\left({ }^{\circ} \mathrm{R}\right)$

Compressor Inlet Temperature $\left({ }^{\circ} R\right)$

Compressor Pressure Ratio.

Turbine Pressure Ratio

Compressor Inlet Pressure (psia)

Radiator Area ( $f t^{2}$ )

Recuperator Length (inch)

Percent Heat Loss

Net Output Power (kw)

Net Cycle Efficiency

Radiator Emissivity

Radiator Sink Temperature $\left({ }^{\circ} R\right)$

Compressor Flow Rate (lb/sec)

Turbine Flow Rate ( $\mathrm{lb} / \mathrm{sec}$ )

Heater Inlet Pressure (psia)

Heater Inlet Temperature $\left({ }^{\circ} R\right)$

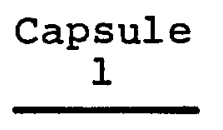

0.746

0.791

0.905

0.959

0.970

0.124

0.030

2060.0

440.0

1. 615

1. 549

18.2

112.0

15.7

13.0

0.619

0.2578

0.83

390.0

0.1064

0.1043

29.11

1738.9

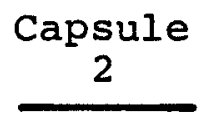

0.757

0.818

0.927

0.972

0.975

0.137

0.053

2060.0

500.0

1. 537

1.493

42.3

110.6

20.4

13.0

1. 356

0.2825

0.83

390.0

0.2262

0.2217

64.60

1758.4
Capsule

3

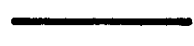

$$
0.760
$$

0.831

0.921

0.9755

0.9758

0.151

0.073

2060.0

520.0

1. 514

1. 477

$-66.2$

134.2

24.0

13.0

2.067

0.2872

0.83

390.0

0.3442

0.3347

99.74

1762.5 
TABLE I-5

BIPS FS CYCLE EFFICIENCY SENSITIVITY FACTORS*

\begin{tabular}{|c|c|c|c|c|c|c|}
\hline \multirow{2}{*}{\multicolumn{3}{|c|}{ Independant Variable }} & \multicolumn{4}{|c|}{ Sensitivity Factors } \\
\hline & & & \multirow[b]{2}{*}{ Multiplier } & \multicolumn{3}{|c|}{ Number of $2400 \mathrm{w}_{t}$ Capsules } \\
\hline Name & $\begin{array}{c}\text { Calculation } \\
\text { Range }\end{array}$ & Symbol & & 1 & 2 & 3 \\
\hline Compressor Efficiency & 0.761 to 0.701 & $n_{c}$ & $n_{c}$ & 0.55 & 0.55 & 0.55 \\
\hline Turbine Efficiency & 0.832 to 0.772 & $\cdot n_{t}$ & " & 0.55 & 0.55 & 0.55 \\
\hline Alternator Efficiency & -0.02 to -0.04 & $n_{A}$ & $\Delta n_{\mathrm{A}}$ & 0.32 & 0.32 & 0.32 \\
\hline $\begin{array}{l}\text { Compressor Inlet } \\
\text { Temperature }\end{array}$ & $-40^{\circ} \mathrm{F}$ to $40^{\circ} \mathrm{F}$ & $\Delta \mathbf{T}_{1}$ & $\Delta \mathrm{T}_{1}$ & -0.0006 & -0.0006 & -0.0006 \\
\hline Emissivity & 0.83 to 0.74 & $\varepsilon$ & $\Delta \varepsilon$ & 0.05 & 0.077 & 0.075 \\
\hline Pressure Drop & 0.005 to 0.010 & $\frac{\Delta \mathrm{P}}{\mathrm{P}}$ & $\Delta\left(\frac{\Delta \mathrm{P}}{\mathrm{P}}\right)$ & -0.8 & -0.8 & -1.0 \\
\hline Bearing Loss & 0.50 to 1.00 & $\frac{\Delta w_{t}}{w_{t}}$ & $\Delta\left(\frac{\Delta W_{t}}{W_{t}}\right)$ & -0.056 & -0.031 & -0.02 \\
\hline Recuperator Effectiveness & 0.00 to -0.03 & $\Delta E_{1}$ & $\Delta \mathrm{E}_{1}$ & 1.25 & 1.20 & 1.15 \\
\hline Heat Loss & 0.00 to -0.04 & $\Delta W_{t}$ & $\Delta\left(\frac{\Delta W_{t}}{t}\right)$ & -0.37 & -0.30 & -0.25 \\
\hline
\end{tabular}

$* \Delta n_{C y}=$ (Sensitivity Factor) $x$ Multiplier 


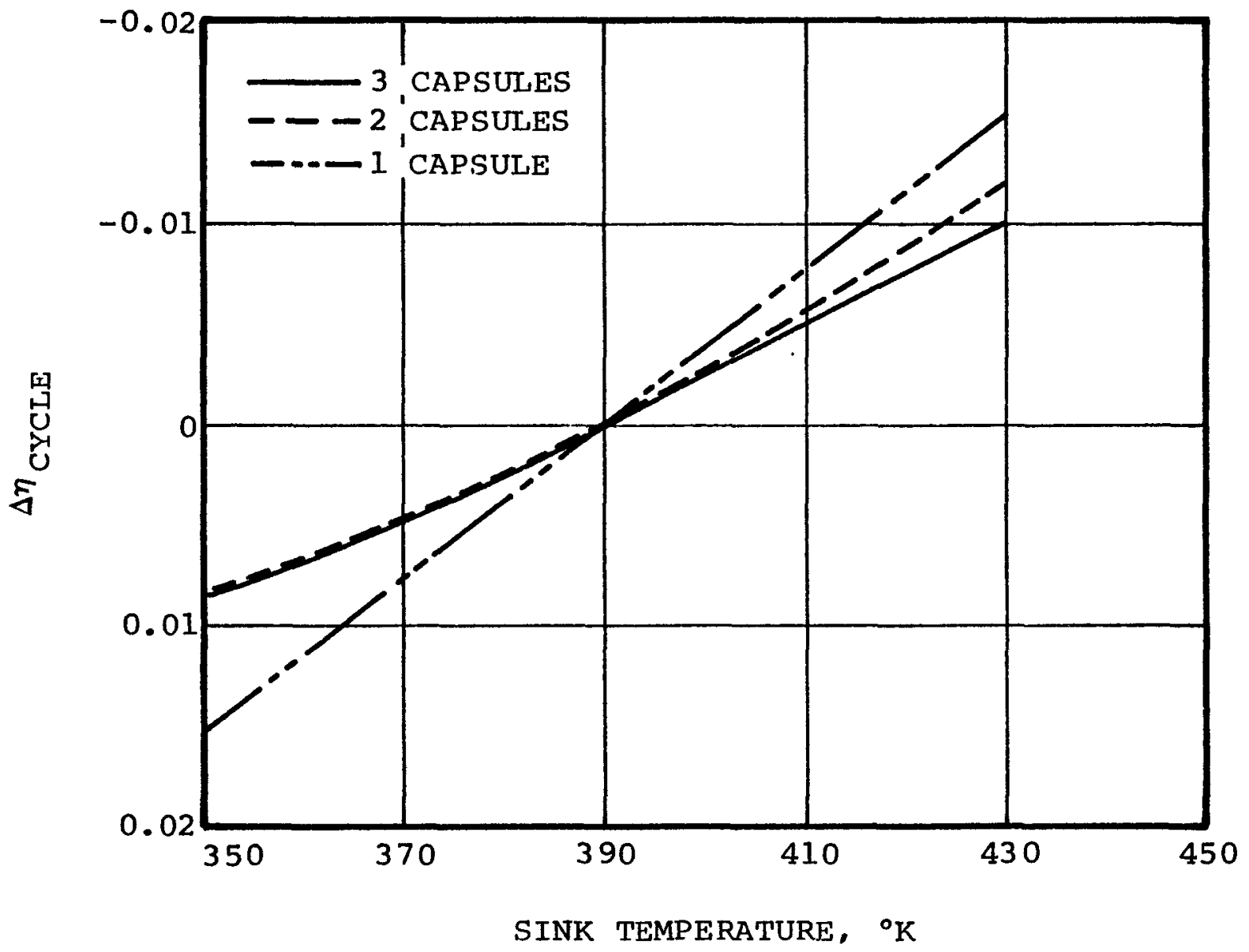

SINK TEMPERATURE EFFECTS

FIGURE I-4 


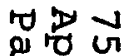

車

(1) $\omega$

苗

슬

$x \underset{\infty}{\mathbb{N}}$

$H \stackrel{\oplus}{0}$

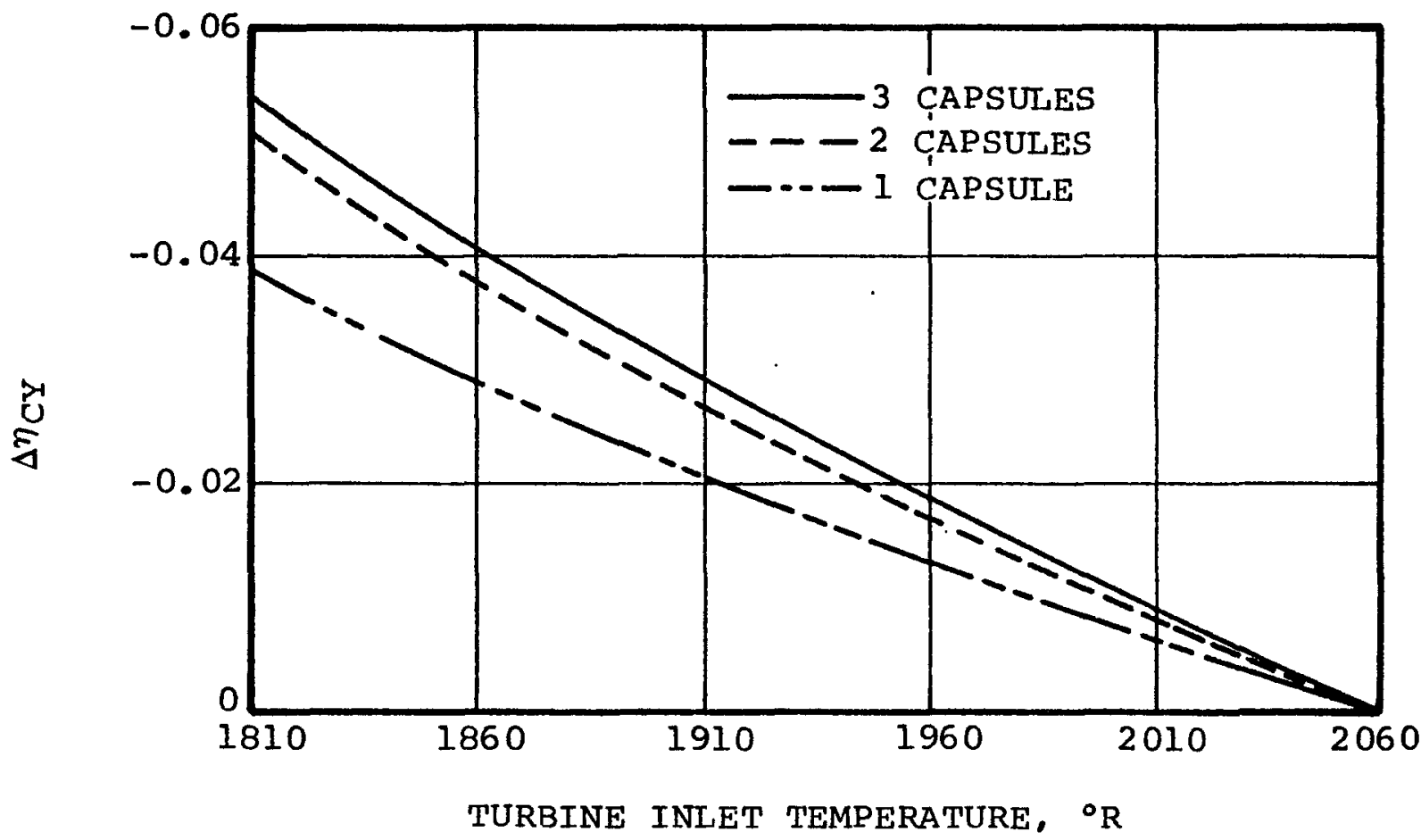

EFFECT OF TURBINE INLET TEMPERATURE

ON OVERALL PERFORMANCE

FIGURE I-5 


\section{TABLE I- 6}

OFF-DESIGN PERFORMANCE

Parameter

Compressor Efficiency

Turbine Efficiency

Alternator Efficiency

Compressor Inlet Temperature

Emissivity

Pressure Drop

Bearing Loss

Recuperator Effectiveness

Heat Loss

Sink Temperature

Turbine Inlet Temperature
New Value Delta Multiplier $\underline{\Delta n} c_{y}$

$\begin{array}{llll}0.747 & -0.01 & -0.01 & -0.0055\end{array}$

$\begin{array}{llll}0.808 & -0.01 & -0.01 & -0.0055\end{array}$

$\begin{array}{llll}0.917 & -0.01 & -0.01 & -0.0032\end{array}$

510

10

10.0

$-0.0060$

0.08

$-0.03$

$-0.03$

$-0.0023$

0.975

0.03

0.003

$-0.0024$

0.145

0.008

0.0584

$-0.0018$

0.950

$-0.025$

$-0.02$

$-0.0240$

16.0

$+3.0$

0.23

$-0.0690$

420

$+30$

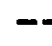

$-0.0088$

2010

$-50$

$-0.008$

Total $-0.1365$

$(\operatorname{or}-13.658)$ 
AIRESEARCH MANUFACTURING CDMPANY OF ARIZQNA

D DIVIEIOU OF THE GAMAETr COMDOMATIOO

PHOENIX, ARIZONA
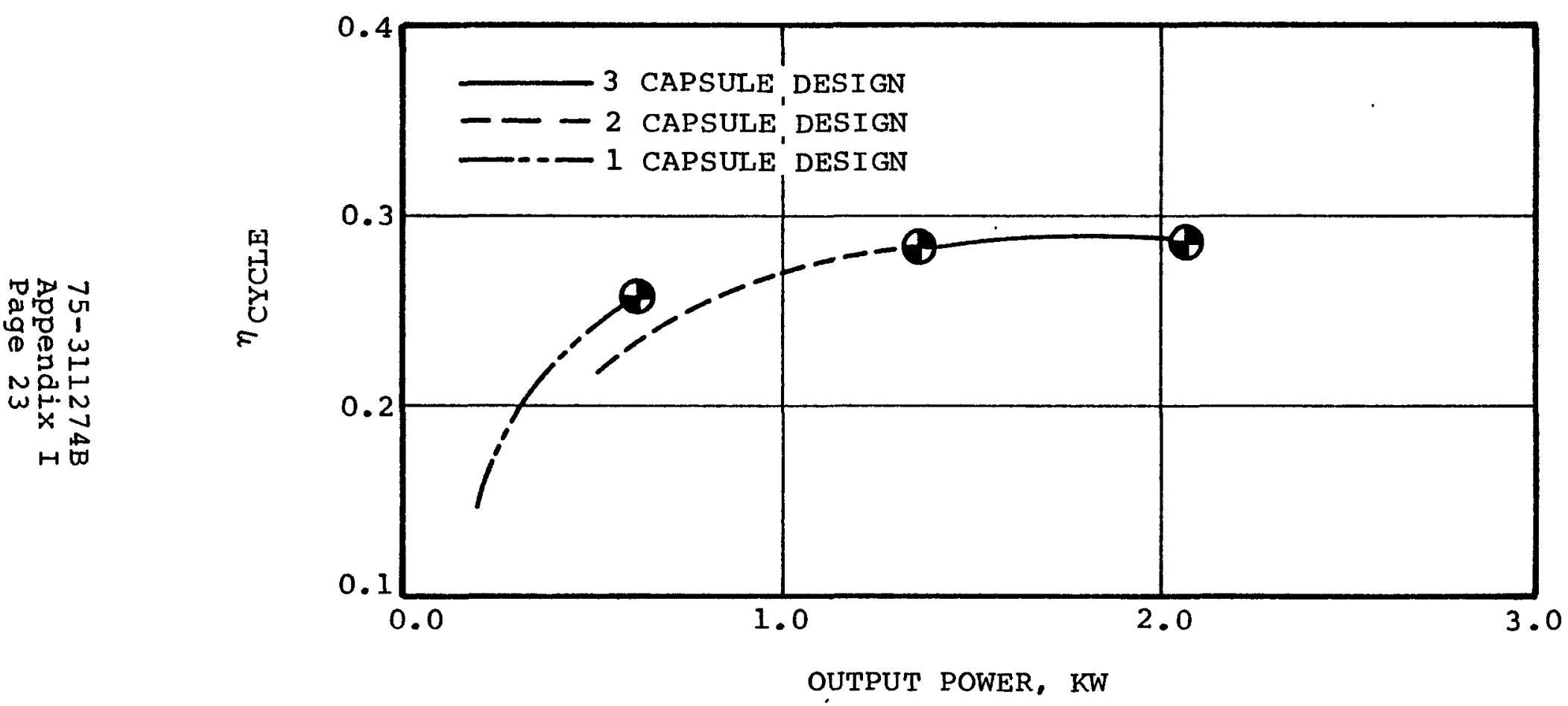

PERFORMANCE SPECTRUM OF 3 MINI-BRAYTON SYSTEMS

FIGURE I-6 
In more practical cases, only a few performance variables would generally be considered at one time. Assuming that compressor efficiency, radiator emissivity, and bearing loss have new values as indicated in Table I-6, cycle efficiency would then be reduced 0.96 percent.

To bring the cycle efficiency back to the original value, the compressor inlet temperature sensitivity factor is used to determine the required increased temperature:

$\mathrm{T}_{1_{\text {new }}}=500+0.0096 /(-0.0006)=484^{\circ} \mathrm{R}$ from Figure $\mathrm{I}-7,(\Delta$ area $) /$ $\left(\Delta \mathrm{T}_{1}\right)=-1.03$ and the required radiator area increase is therefore:

$\Delta$ Area $=-16 \times(-1.03)=16.48 \mathrm{ft}^{2}$, for a total of $127.08 \mathrm{ft}^{2}$, which represents a 14.5 percent increase.

This simplified approach to performance parameters effects on cycle efficiency, loses accuracy as parameters increase. Also, when the radiator size is changed, the performance of other components are changed slightly. Therefore, sensitivity factors, etc., should be used with caution. 


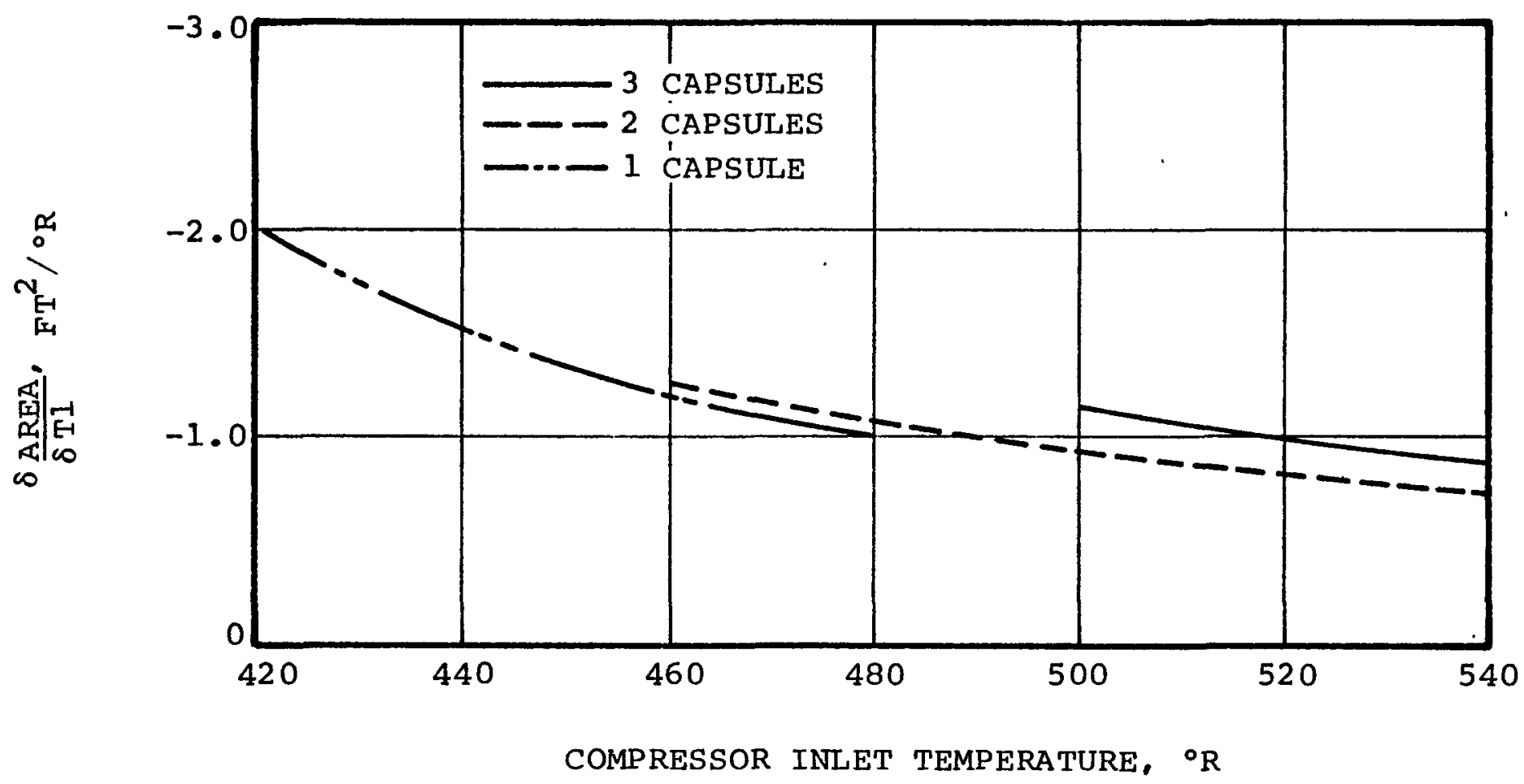

RADIATOR AREA EFFECTS

FIGURE I 7 


\subsection{LEAKAGE RATES}

Estimated leakage rates of GDS components and joints are discussed in section 3.3.5. FS hardware can be expected to meet or exceed existing estimates of leak tightness. However, assuming that all Fs components and joints leak at the maximum rates estimated for GDS components, the total loss rate is calculated as:

\section{Component}

Mini-BRU

MBR

2 HSA at $1 \times 10^{-9}$

Space Radiator

Duct Welds (46)

Bellows (19 with 2 welds each)

\section{Rate (Standard cc He/Sec)}

$$
\begin{aligned}
& 2.74 \times 10^{-8} \\
& 1 \times 10^{-7} \\
& 2 \times 10^{-9} \\
& 1 \times 10^{-9} \\
& 4.6 \times 10^{-9} \\
& 3.8 \times 10^{-9}
\end{aligned}
$$

Based on these rates the system total leakage rate is $1.387 \times 10^{-7}$ standard CC He/sec. Since the allowable MBR leakage rate is 72 percent of the total, it may prove feasible to allow only a $1 \times 10^{-9}$ standard $\mathrm{cc} / \mathrm{sec}$ of He leakage rate in the FS MBR.

A constant maximum leakage rate for five years will result in 21.87 standard cc total loss. This loss equates to only 0.0146 percent of inventory, since the FS contains 1.16 pounds $(150,079$ standard cc) of $\mathrm{Xe} / \mathrm{He}(\mathrm{MW}=83.8)$ gas at standard conditions. The resultant effects of this loss are negligible.

It is recognized that leakage rates do not normally remain constant, but rather, tend to grow with time. However, this is not considered a problem because the FS can tolerate leakage rates exceeding two orders of magnitude greater than the above noted maximum rate. For example assume the total working fluid loss percentage after 5 years will be as high as the thermal input reduction resulting from 
radioisotope decay. This is the ideal and desired condition because the turbine inlet temperature and system efficiency remain constant.

It is estimated that thermal input will degrade to 96.13 percent after 5-years. An equivalent reduction in working fluid is $0.0387 \mathrm{x}$ $150,079 \mathrm{cc}$, which equates to 5808 standard cc. This computes to a constant system loss of $3.68 \times 10^{-5}$ standard $\mathrm{cc} \mathrm{He} / \mathrm{sec}$, which is 265 times greater than the assumed $1.387 \times 10^{-7}$ maximum rate. From this, it is obvious that the FS can tolerate an average maximum leakage rate exceeding $3 \times 10^{-5}$ standard Cc He/sec.

The FS control system will compensate for thermal input, and working fluid decreases. This is accomplished by altering engine speed to maintain a constant turbine inlet temperature $\left(T_{6}\right)$. 


\section{LIST OF REFERENCES}

1. JCS 07700 Volume XIV Revision D, "Space Shuttle System Payload Accommodations."

2. SS-STS-100 Volume 3 Code Identification 07868 "Interim Upper Stage System Segment Basic Requirements for January 76.

3. GE-BIPS-20-001. "Mission Environments for The Isotope Brayton Flight System (Preliminary), August 8, 1975", Memo No. BIPS-GDSG0017, 10-22-75. 
Since the early 1960's, NASA has funded closed Brayton cycle development work for the purpose of achieving "technology readiness" by 1980. This effort has culminated in the operation of a 2-16 kw closed Brayton cycle engine for over 20,000 hours at NASA LeRC. This endurance test, which is continuing, has convincingly demonstrated the inherent reliability of this power generation equipment. A list of documents concerning BIPS component development is presented in Appendix III, and documents that are a part of the Statement of work by reference are included in Table II-l.

Development contracts with NASA have been in existence since mid1974 for the Brayton rotating unit and recuperator. (Table II-2 presents a list of contracts related to the MB-IBFS.) Design and testing of a GDS comprising these GFE components, will be accomplished during Phase I of the MB-IBFS development program. Advanced component development will also be conducted in Phase $I$.

The long-term scheduling of Phase I (Figure II-1) and of Phases II and III (Figure II-2) are included in this appendix. The individual component program schedules are:

- Figure II-3 - Mini-BRU (Brayton Rotating Unit)

- Figure II-4 - Mini-Brayton Recuperator (MBR)

- Figure II-5 - Heat Source Assembly (HSA)

The BIPS functional engineering organization chart is presented on Figure II- 6. 


\section{TABLE II -1}

INCORPORATION OF GOVERNMENT DOCUMENTS AND SPECIFICATIONS

The following documents referenced in the statement of Work are hereby incorporated by references and made a part hereof:

$\begin{array}{ll}\text { MIL-G-2I480A } & \begin{array}{l}\text { Generators and Regulators, Air } \\ \text { Cooled, A-C, Aircraft General } \\ \text { Specification for }\end{array} \\ \text { MII-STD-810B } & \text { Environmental Test Methods } \\ \text { MII-STD-202C } & \text { Test Methods for Electronic and } \\ \text { Electrical Component Parts } \\ \text { MII-STD-462 }\end{array}$


TABLE II-2

CONTRACTS RELATING TO THE MB-IBFS

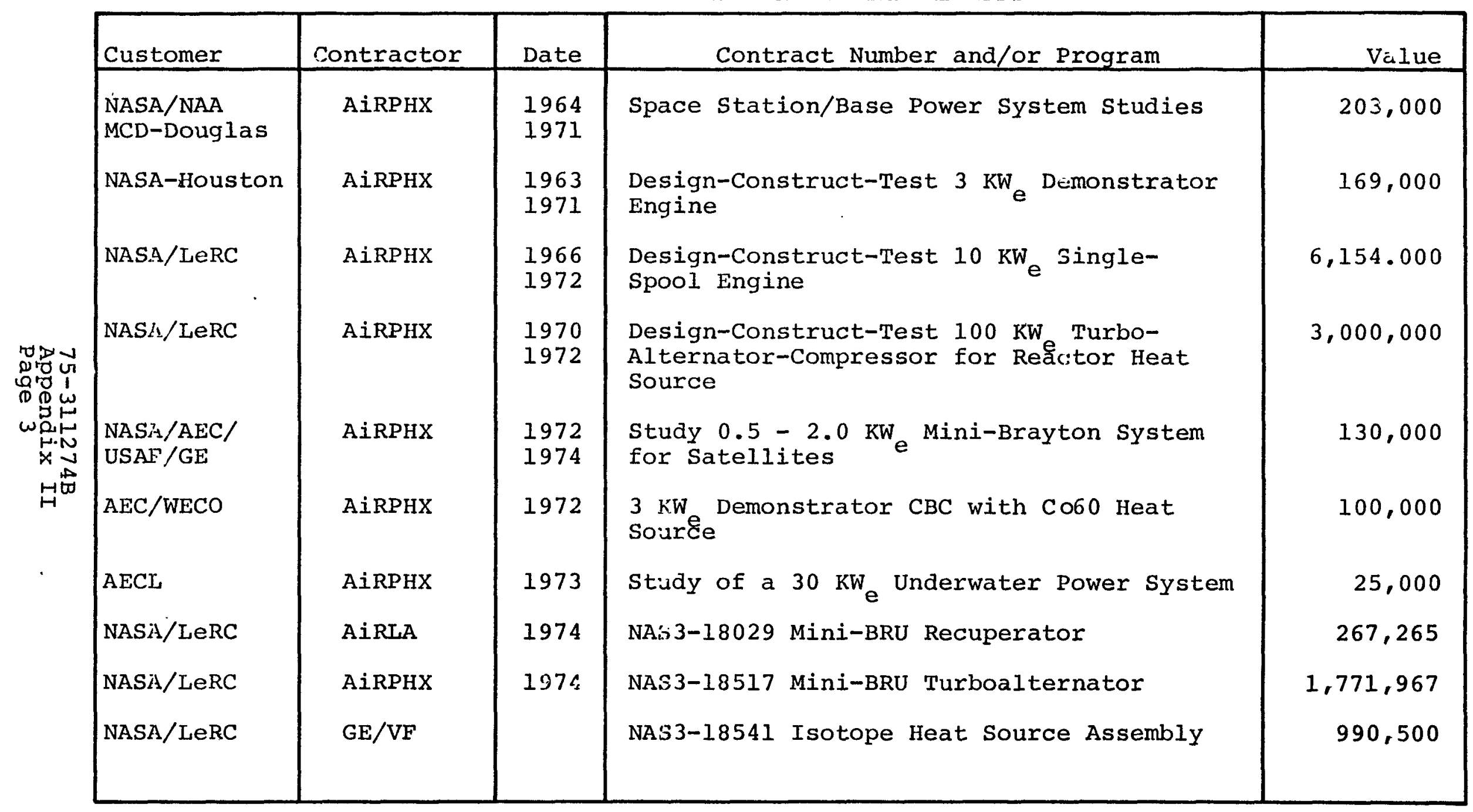




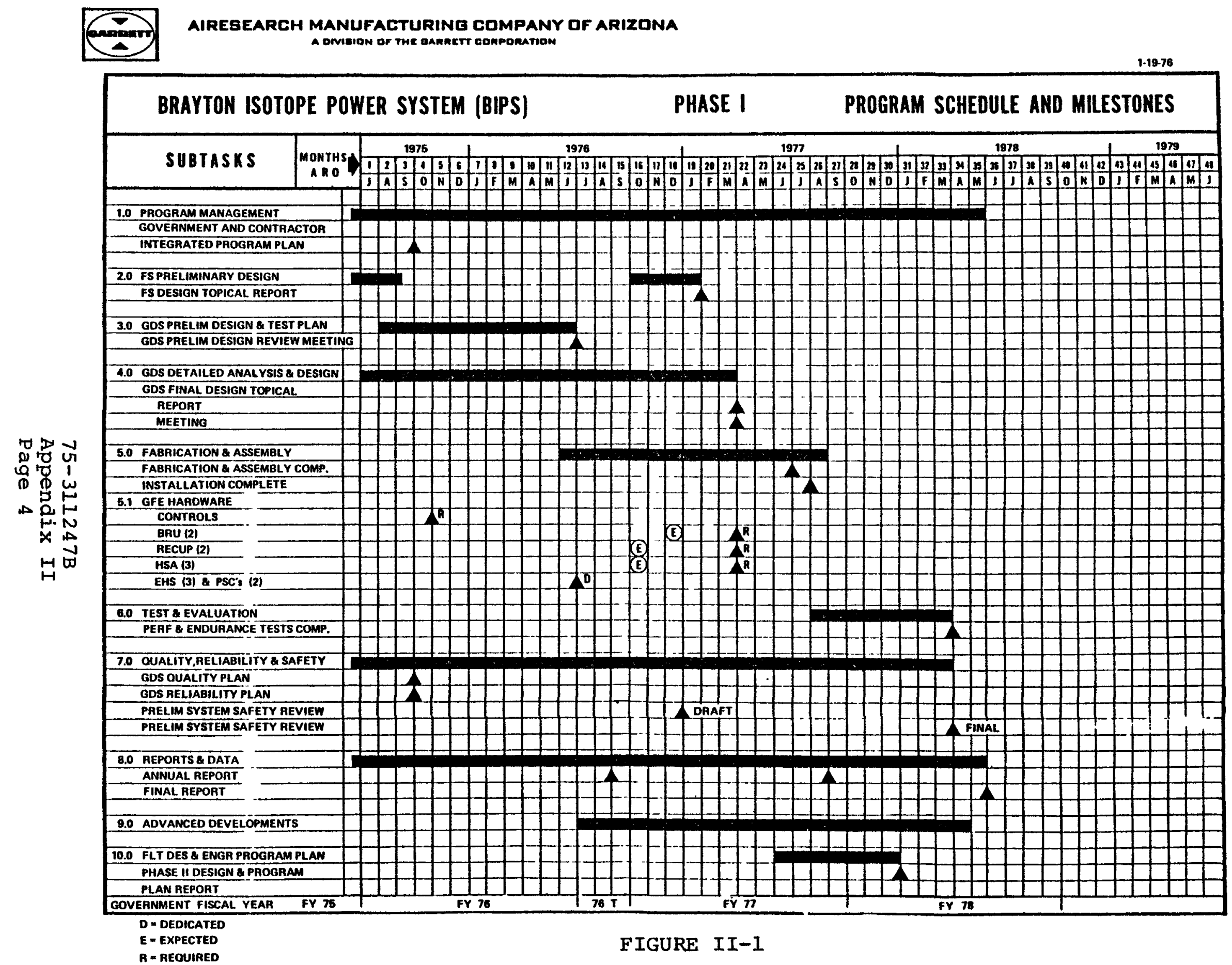


AIRESEAREH MANUFACTURINE COMPANY OF ARIZONA

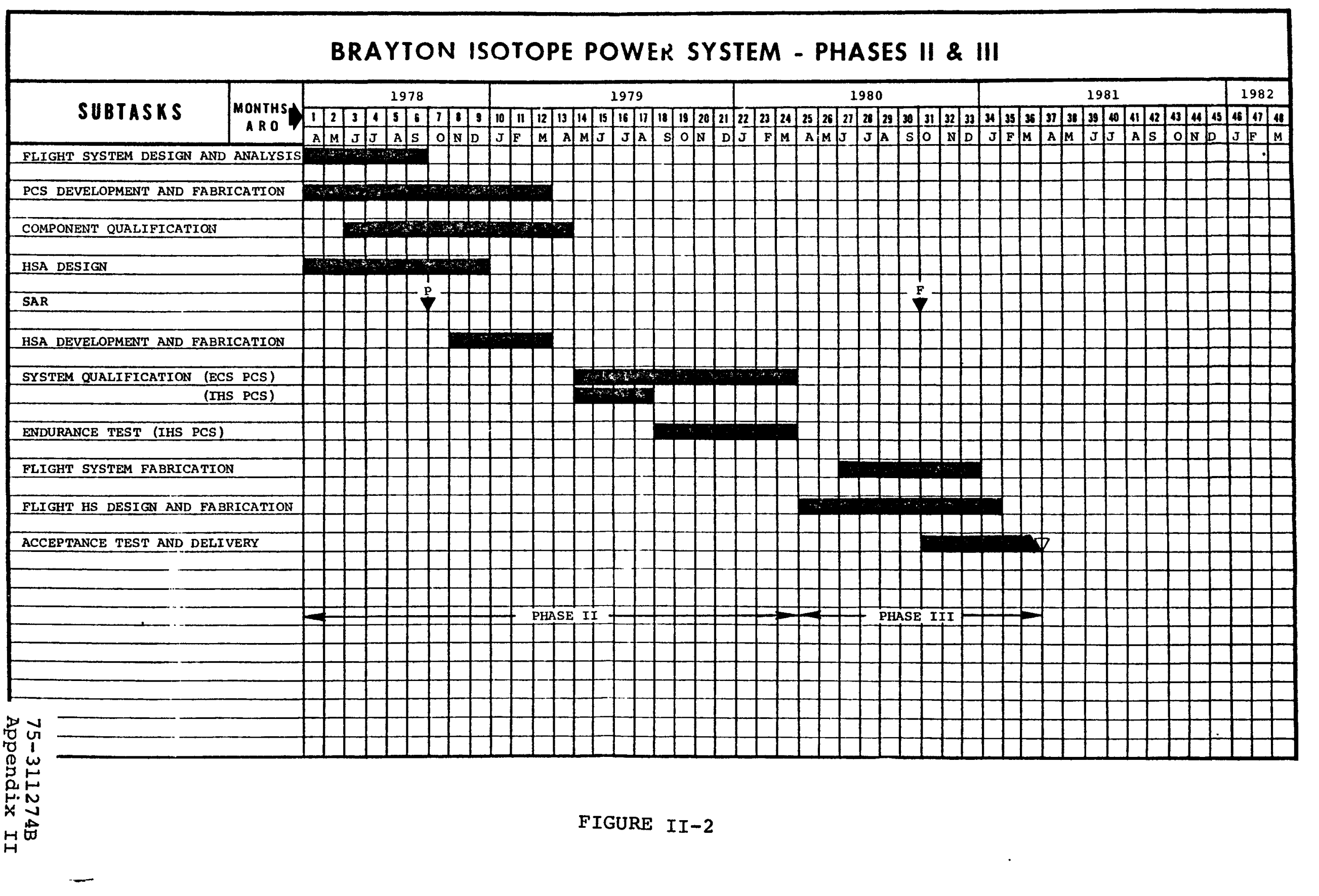




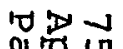

(2)

象思

कू

선

H苗

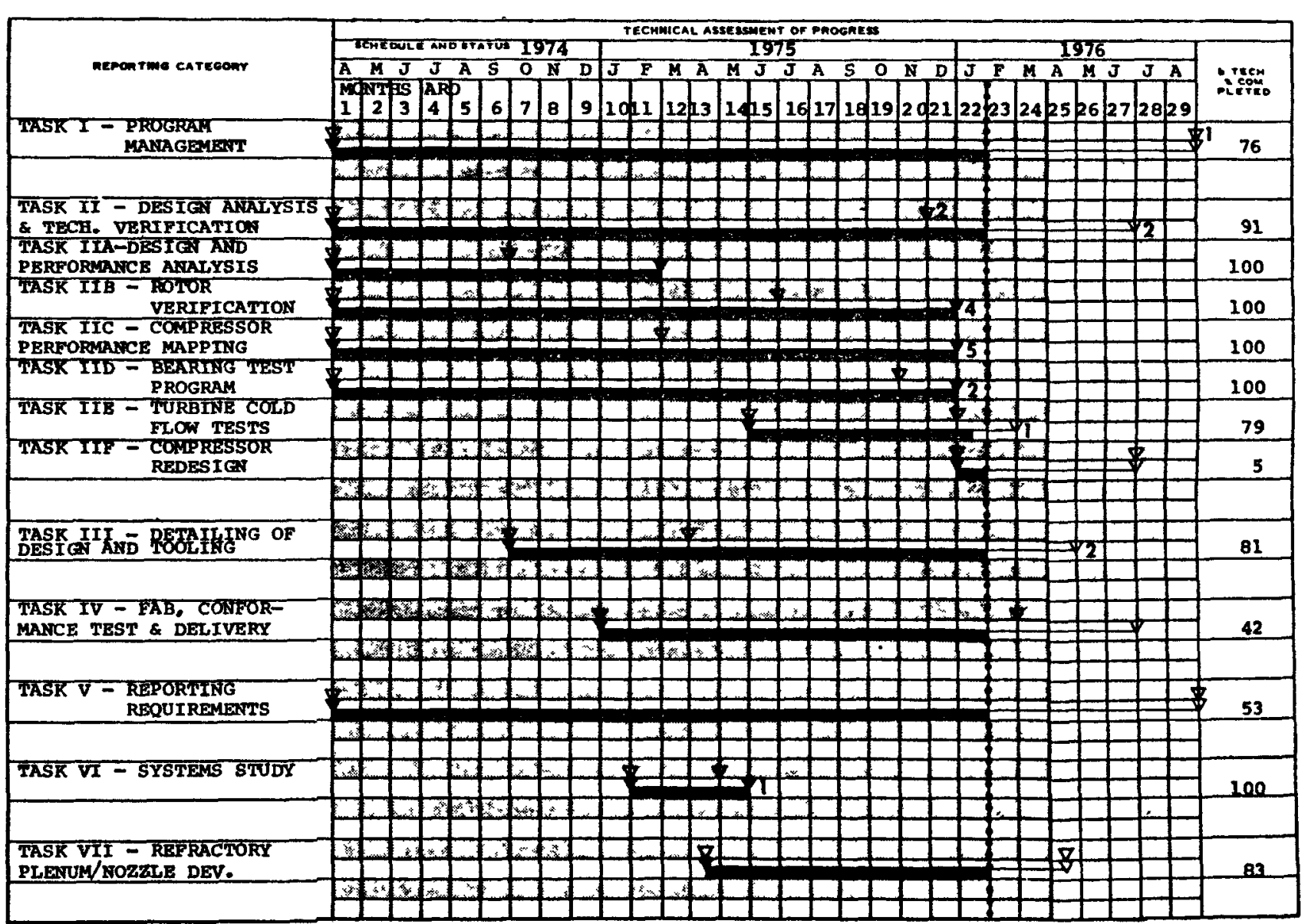

MINI-BRU PROGRAM SCHEDULE

FIGURE II-3 


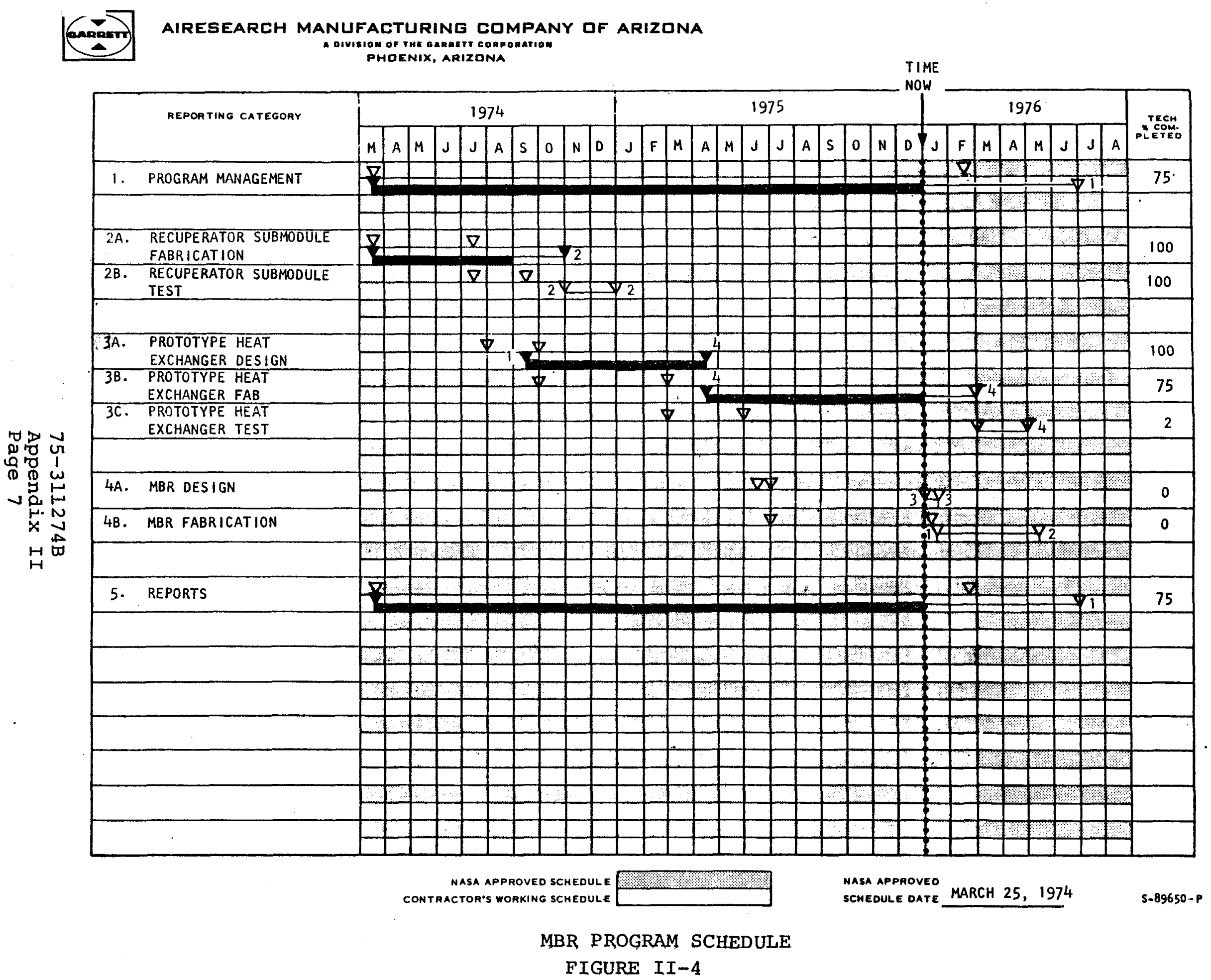



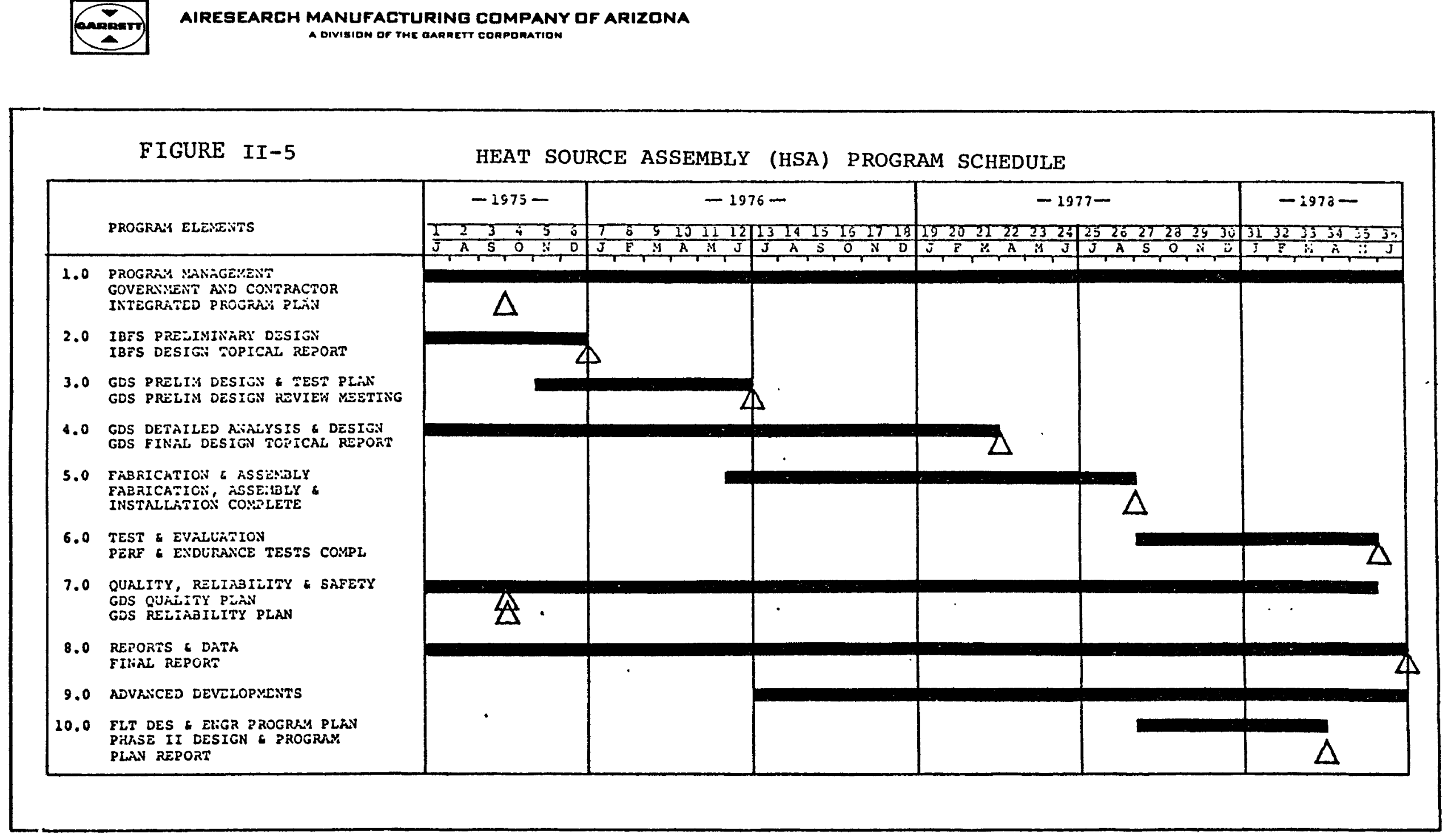

ब为藏

090

D.

$\infty \stackrel{1}{2}$

.

$\underset{H}{\mathbb{E}}$ 


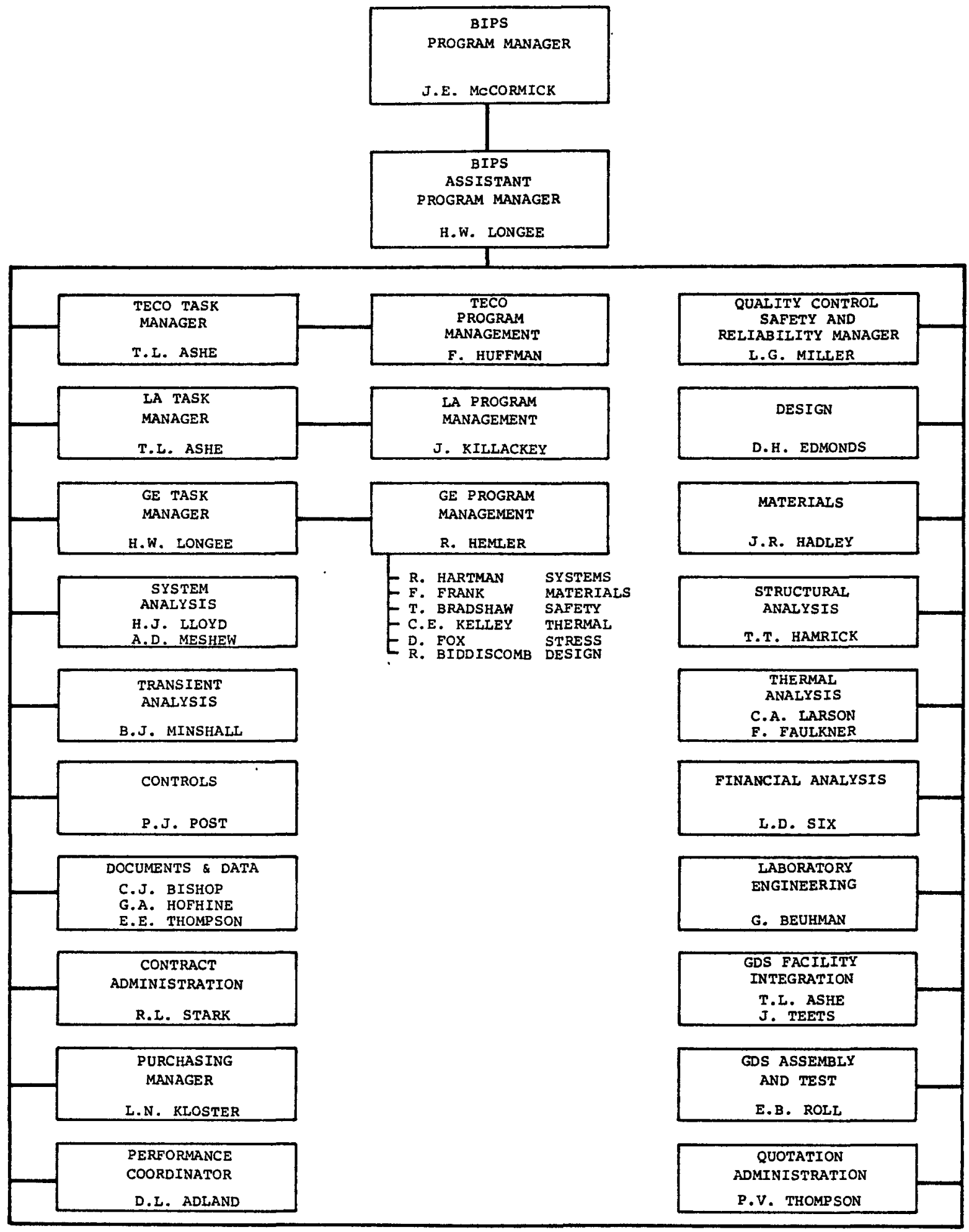

FIGURE II-6 
Document No.

SNS-RFP-75-1-CAO

QC-048, Rev. 4

QCGI No. 137

(Rough Draft)

74-310631

$74-310831$

74-311015-1, -2

$75-311221$

$75-311267$

$75-311274 B$

$75-311279 A$

$75-311360$

$75-311375 A$

AIRPHX
AIRPHX

Company

or Agency

ERDA-SNS

AIRPHX

AIRPHX

AIRPHX

AIRPHX

AIRPHX

AIRPHX

AIRPHX

AIRPHX

AIRPHX
Title

Request for Proposal, Ground

Demonstration Test of a 1.3

KW Isotope Power Conversion System Leading Toward Development of an Isotope Space Power System for the 0.5 to $2 \mathrm{KW}$ Power Engine

AiResearch Manufacturing Company of Arizona General Quality Program Plan

Quality Control Program Supplement for ERDA-Brayton Isotope Power System (BIPS)

Progress Reports of Design and Fabrication of CompressorAlternator-Turbine for the Mini-Brayton Rotating Unit (Mini-BRU) Contract NAS3-18517

System studies of closed-Cycle Gas Turbine Engines Utilizing the Mini-Brayton Rotating Unit (Mini-BRU)

Isotope Brayton Ground Demonstration Testing and Flight Qualification Technical Proposal, Volumes 1 and 2

System Safety Program Plan for the Isotope Brayton Ground Demonstration System (Phase I)

Final Design Report Analysis and Design to the Mini-Brayton Rotating Unit (Mini-BRU)

Brayton Isotope Power System Configuration Control Document (CCD)

Transient Analysis Isotope Brayton Flight System

Reliability Program Plan for the Isotope Brayton Ground Demonstration System (Phase I)

Statement of Work for General Electric as Major Subcontractor for the Design, Fabrication, and Test of the Ground Demonstration System Brayton Isotope Power System
Publication Date

November 4,1974

October 1, 1974

September 30,1975

May 1974 - (Initial Issue)

August 10,1974

December 9, 1974

September 30, 1975

December 15, 1975

March 1976

(Proposed)

May 1976

(Proposed)

September 30,1975

December 9, 1975 
TABLE III-1 (CONTD)

\begin{tabular}{|c|c|c|c|}
\hline & Company & & \\
\hline Document No. & or Agency & Title & Publication Date \\
\hline $75-311376 B$ & AIRPHX & $\begin{array}{l}\text { Program Plan for the Brayton } \\
\text { Isotope Power System Phase I } \\
\text { Design, Fabrication, and Test } \\
\text { Brayton Isotope Power System }\end{array}$ & October 22, 1975 \\
\hline $75-311446$ & AIRPHX & $\begin{array}{l}\text { Statement of Work - Application } \\
\text { of Multi-Foil Insulation to the } \\
\text { Isotope Brayton Ground Demonstra- } \\
\text { tion system and Conceptual Design } \\
\text { of Super Insulation for the IBFS }\end{array}$ & August 14,1975 \\
\hline $75-311457$ & AIRPHX & $\begin{array}{l}\text { Monthly Technical Progress Reports } \\
\text { Brayton Isotope Power System (BIPS) } \\
\text { Phase I Design, Fabricate, and Test } \\
\text { of the Ground Demonstration System }\end{array}$ & $\begin{array}{l}\text { August } 1975 \text { (Ini- } \\
\text { tial Issue) }\end{array}$ \\
\hline $75-311472 \mathrm{~A}$ & AIRPHX & $\begin{array}{l}\text { Statement of Work to AiResearch, } \\
\text { Los Angeles for the Isotope Brayton } \\
\text { Ground Demonstration System (IBGDS) } \\
\text { and Isotope Brayton Flight System } \\
\text { (IBFS) }\end{array}$ & February 11, 1976 \\
\hline $76-311499 A$ & AIRPHX & $\begin{array}{l}\text { Statement of Work to Thermo Elec- } \\
\text { tron Corporation for Application } \\
\text { of Multi-Foil Insulation to the } \\
\text { Brayton Isotope Power System and } \\
\text { Conceptual Design of super Insula- } \\
\text { tion for the Flight System }\end{array}$ & December 15, 1975 \\
\hline $75-311574$ & AIRPHX & $\begin{array}{l}\text { Brayton Isotope Power System (BIPS) } \\
\text { Phase I Integrated Program Plan } \\
\text { (IPP) }\end{array}$ & November 20,1975 \\
\hline $75-3115.91$ & AIRPHX & $\begin{array}{l}\text { Electronic Analog Simulation of } \\
\text { ERDA BIPS Using "Bang-Bang" Speed } \\
\text { and Voltage Regulation }\end{array}$ & October 23, 1975 \\
\hline $75-311629$ & AIRPHX & $\begin{array}{l}\text { Preliminary Hazard Analysis for the } \\
\text { Isotope Brayton Flight Systen }\end{array}$ & November 30,1975 \\
\hline $75-311665$ & AIRPHX & $\begin{array}{l}\text { Preliminary Failure Modes, Effects, } \\
\text { Brayton Isotope Ground Demonstration } \\
\text { System (Including Vacuum Test Chamber) }\end{array}$ & November 30,1975 \\
\hline $76-311709$ & AIRPHX & $\begin{array}{l}\text { Preliminary Failure Modes, Effects, } \\
\text { and Criticality Analysis (FMECA) } \\
\text { Brayton Isotope Power System Flight } \\
\text { System }\end{array}$ & January 12, 1976 \\
\hline $76-311737$ & AIRPHX & $\begin{array}{l}\text { Specification Requirements Summary } \\
\text { for the Brayton Isotope Power Sys- } \\
\text { tem (BIPS) Ground Demonstration } \\
\text { system (GDS) }\end{array}$ & February 10, 1976 \\
\hline $76-311742$ & AIRPHX & BIPS-GDS System Design Specification & \\
\hline $76-311770$ & AIRPHX & $\begin{array}{l}\text { ERDA-BIPS Frogram Update - February } \\
19,1976\end{array}$ & February 16,1976 \\
\hline $74-10188$ & AIRIA & $\begin{array}{l}\text { Recuperator Progress Reports } \\
\text { (Monthly) }\end{array}$ & \\
\hline GEMS -4117 & GE-ESP & Mini-BRU Economic RTG study & January 1974 \\
\hline & GE & HSA Progress Reports (Monthiy) & \\
\hline TBD & AIRPHX & $\begin{array}{l}\text { Preliminary System Safety } R \\
\text { Report }\end{array}$ & TBD \\
\hline
\end{tabular}




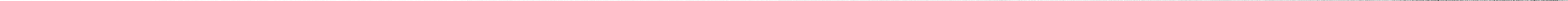




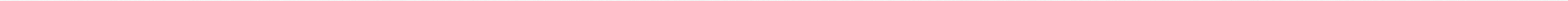






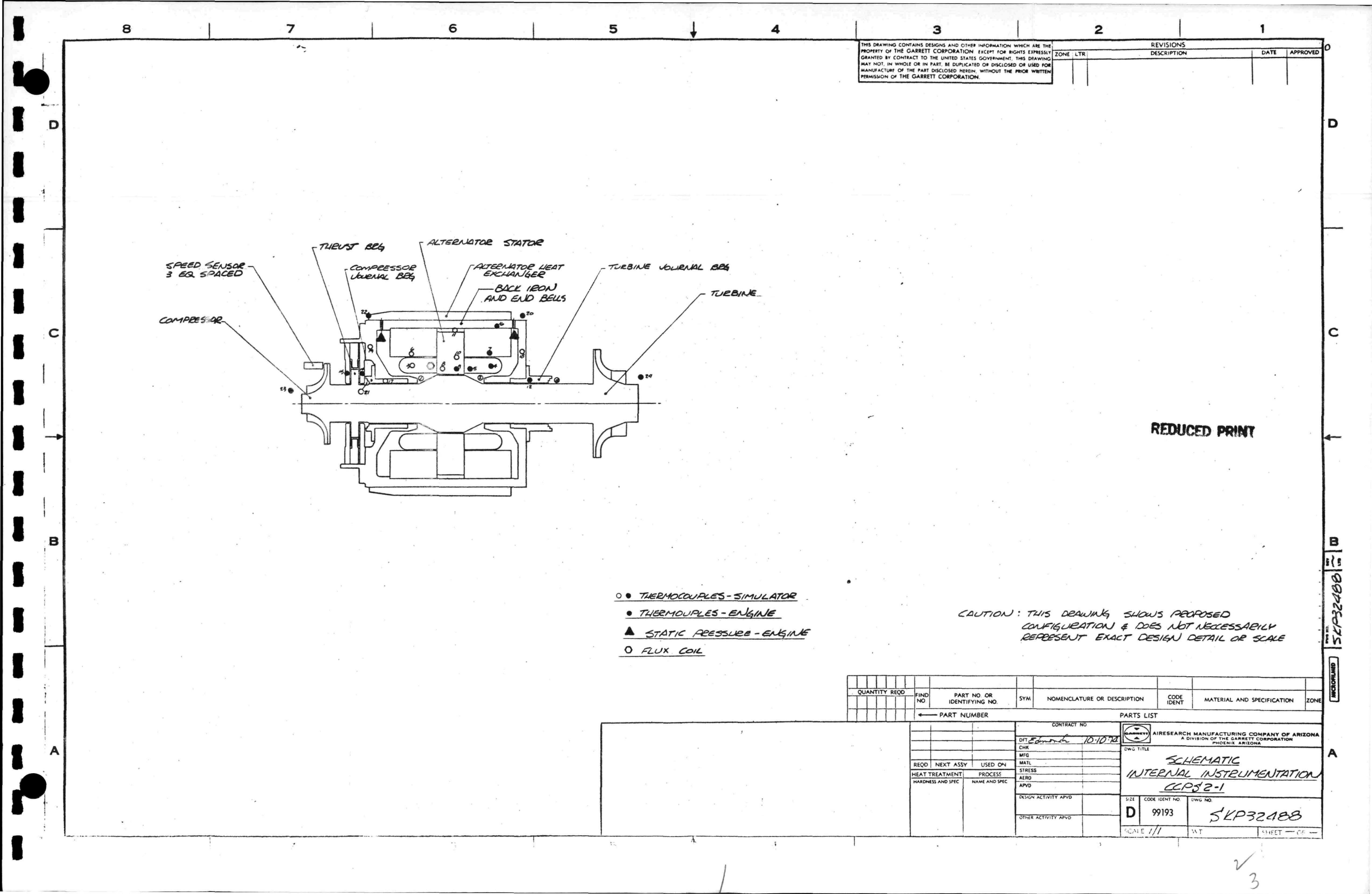




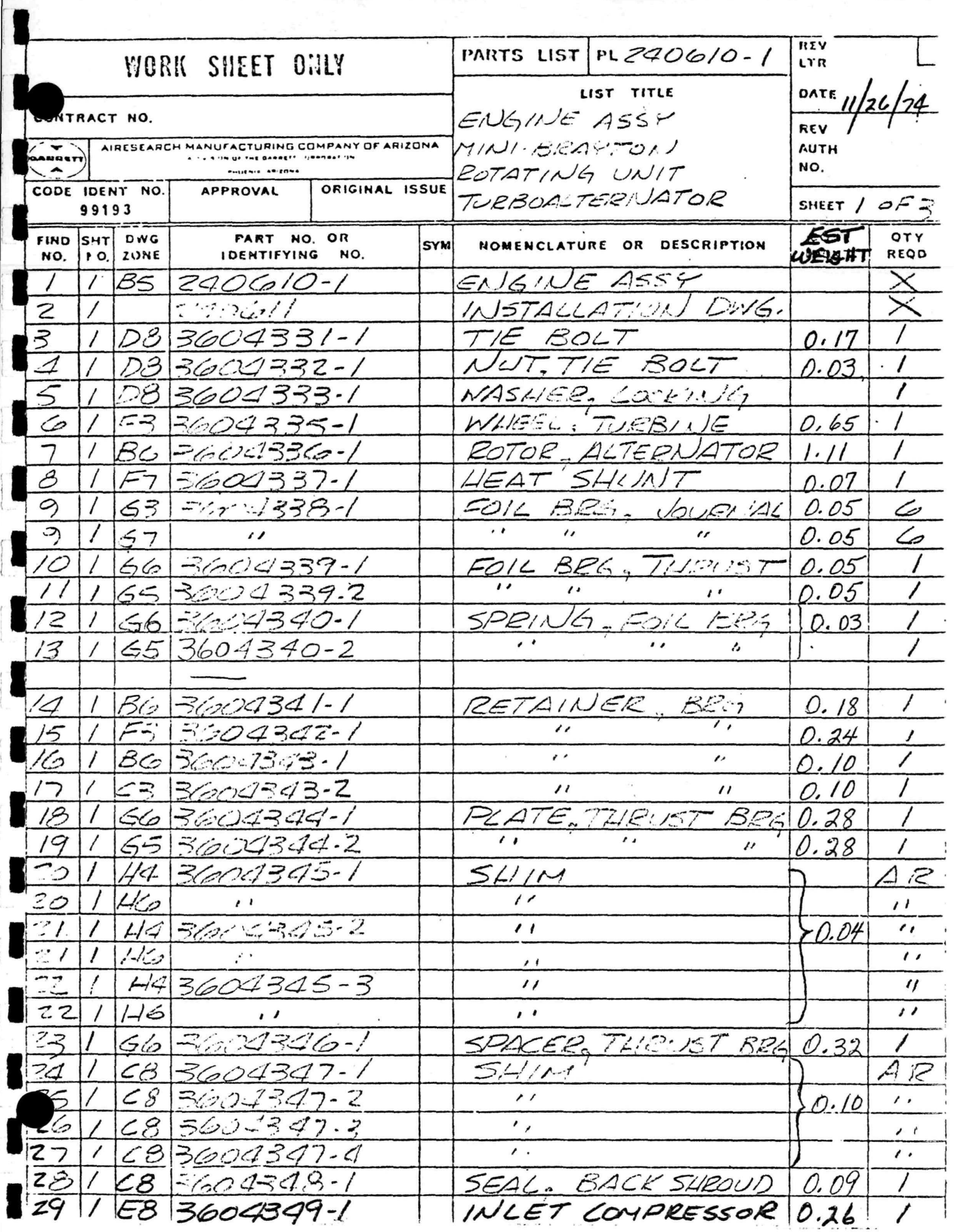




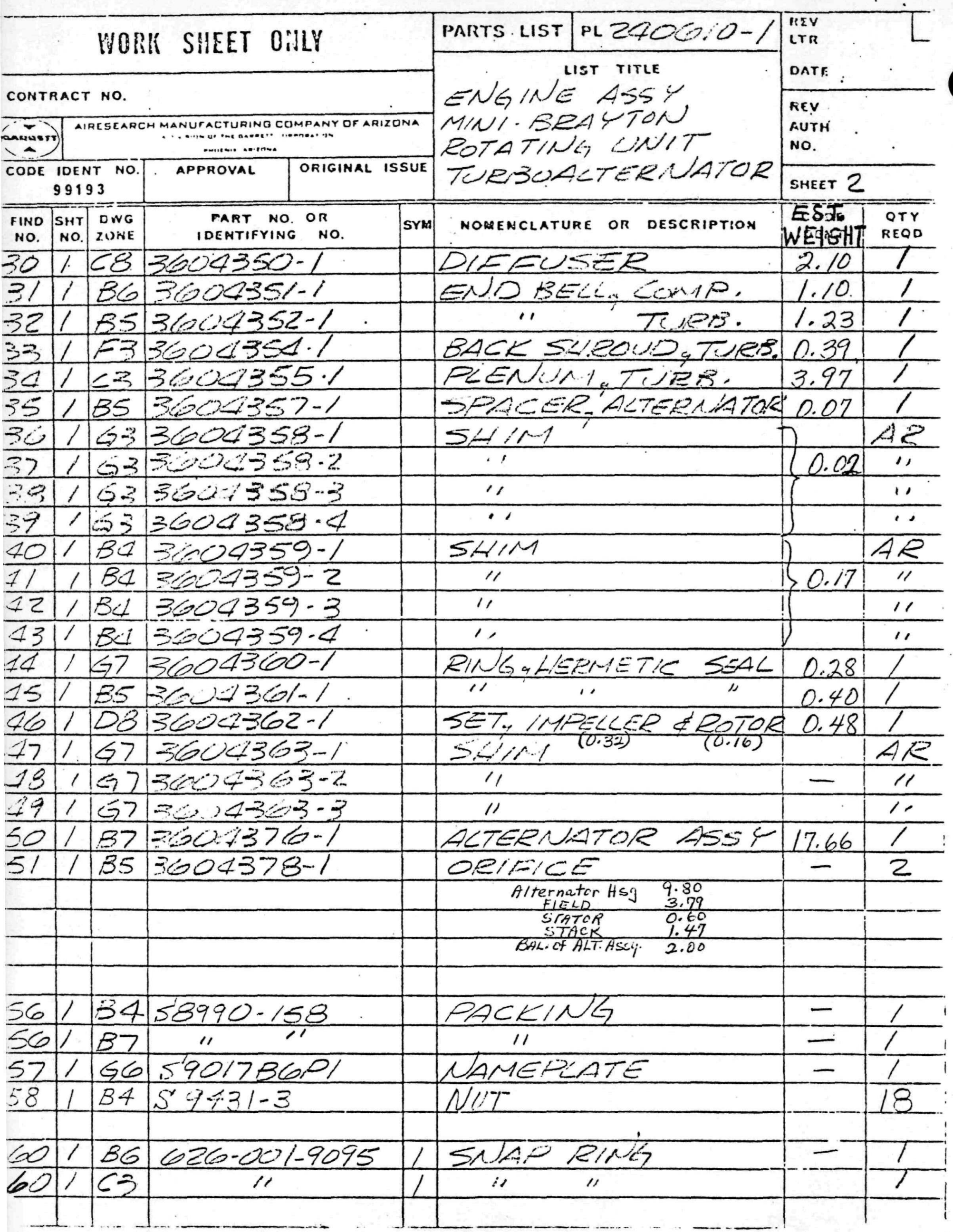




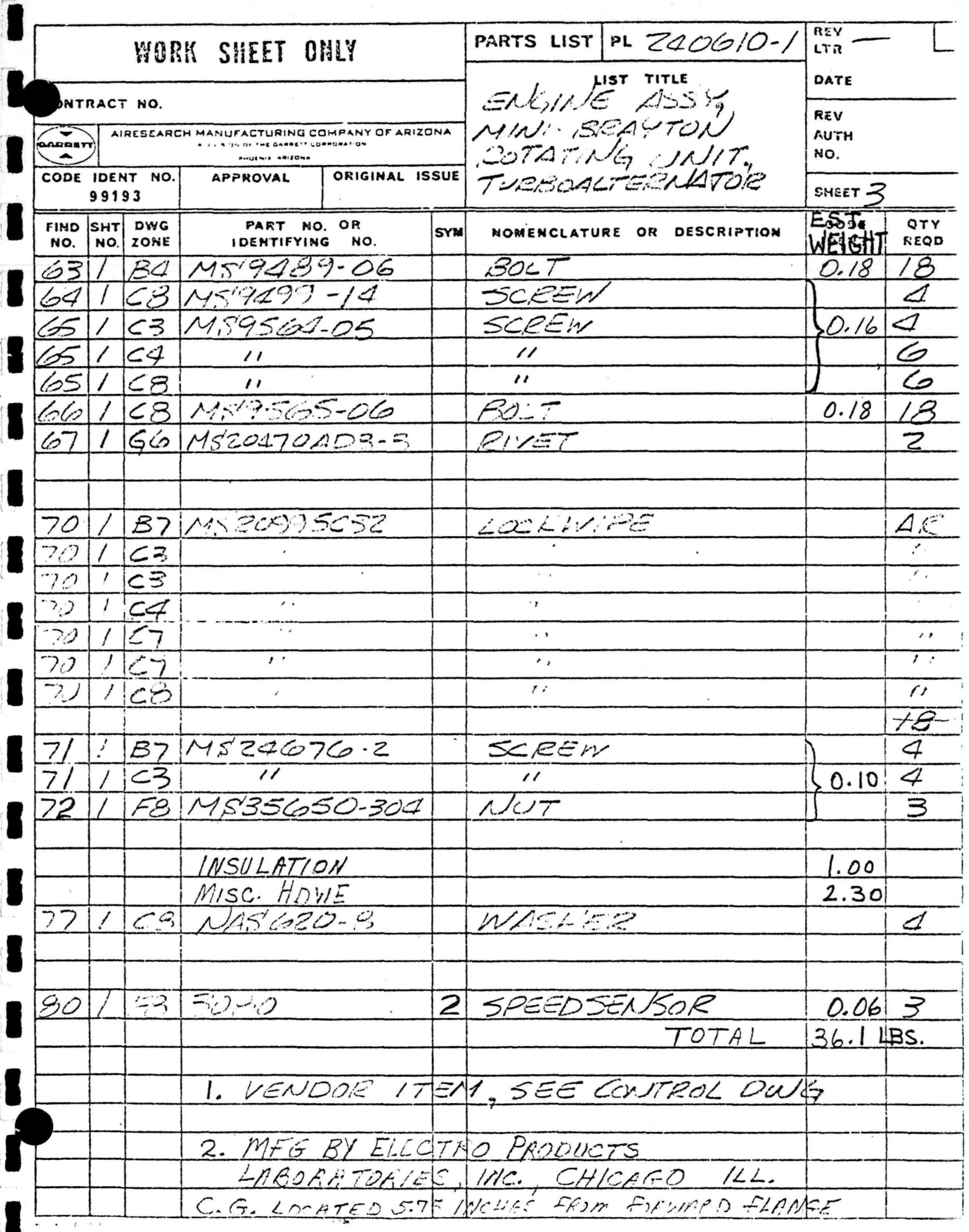




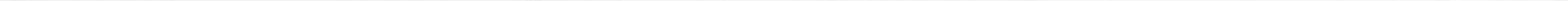




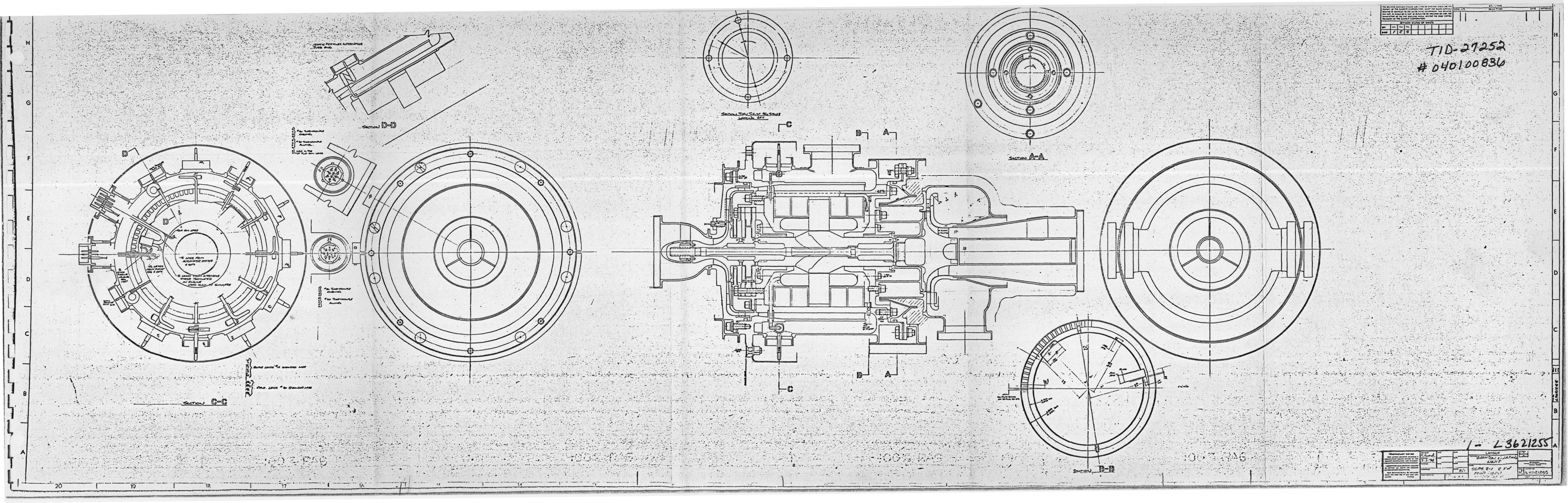




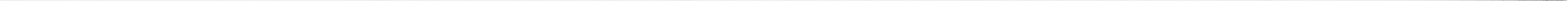




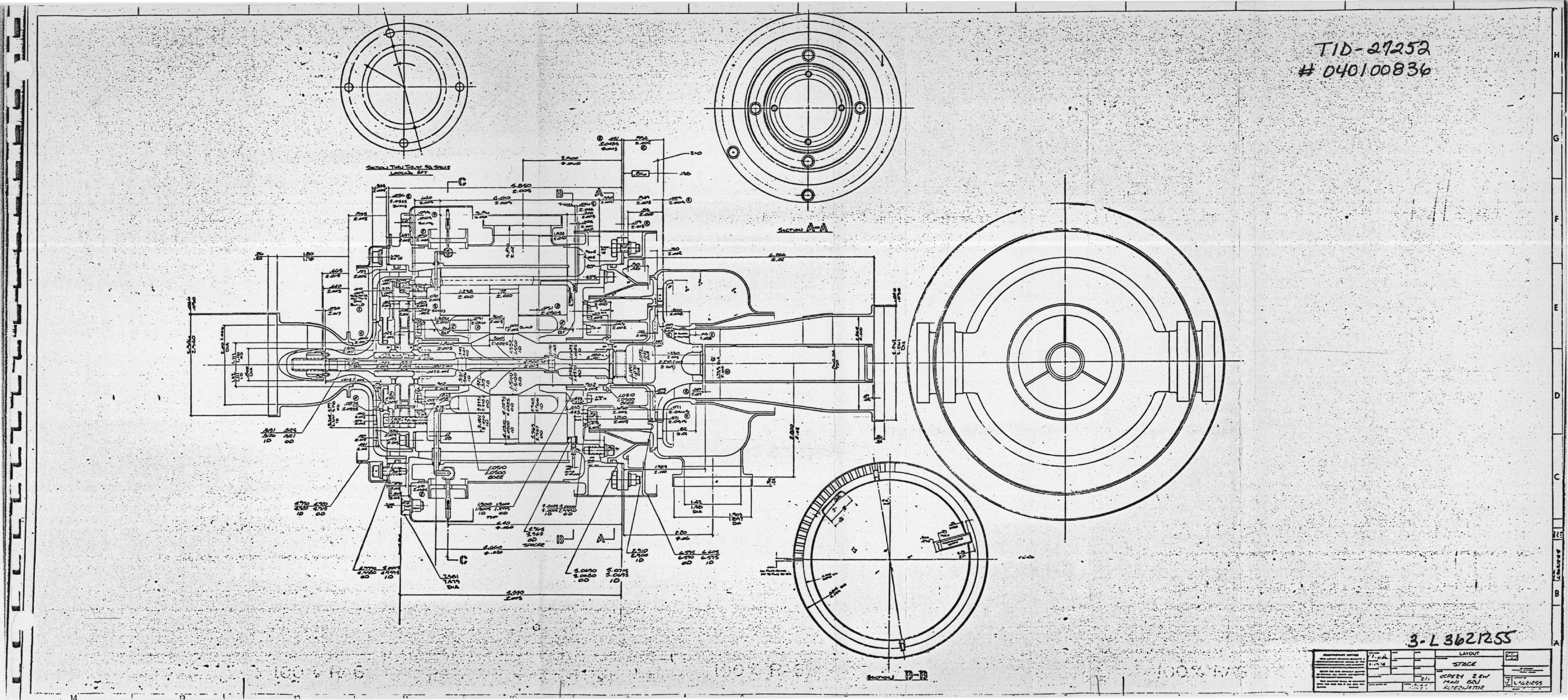



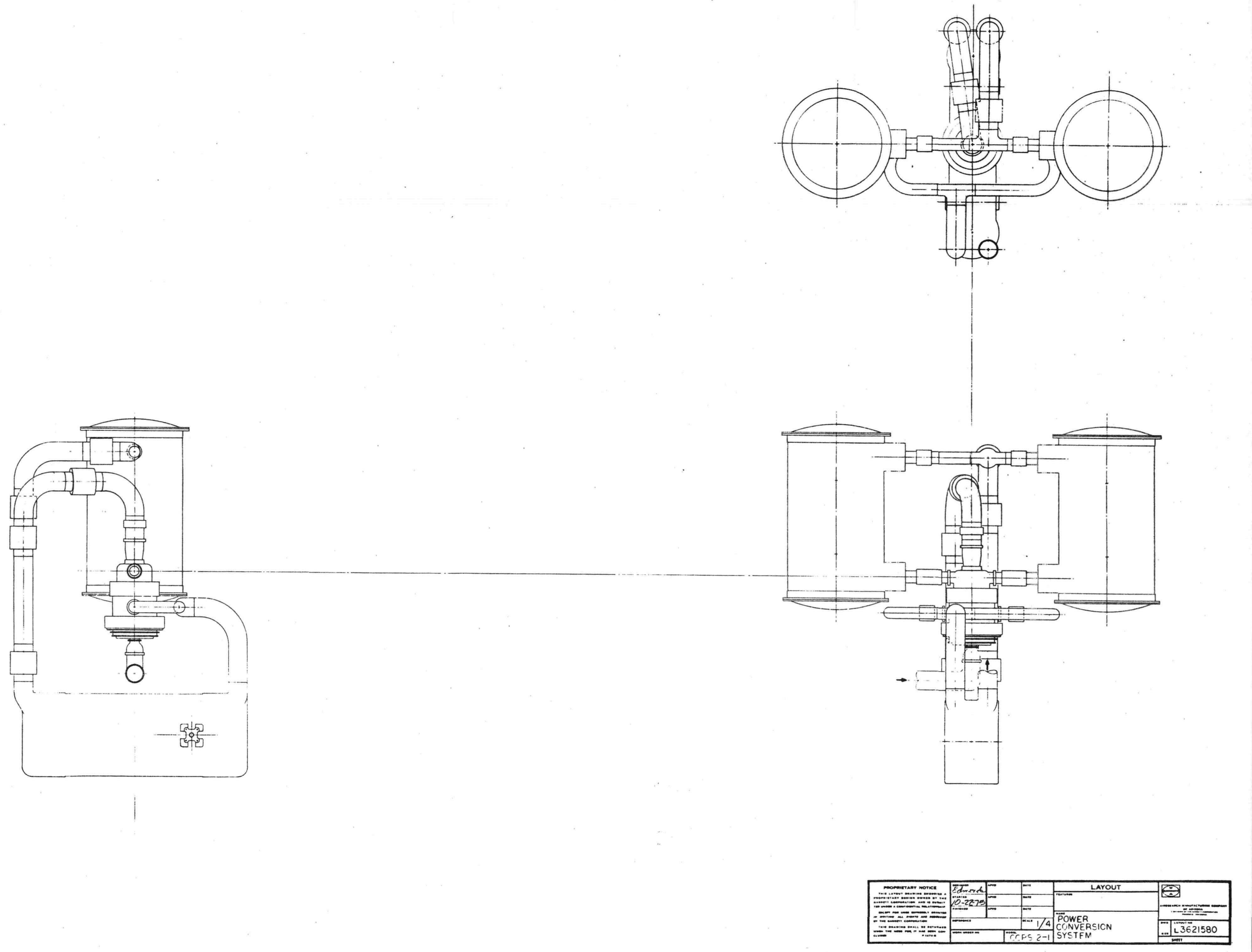

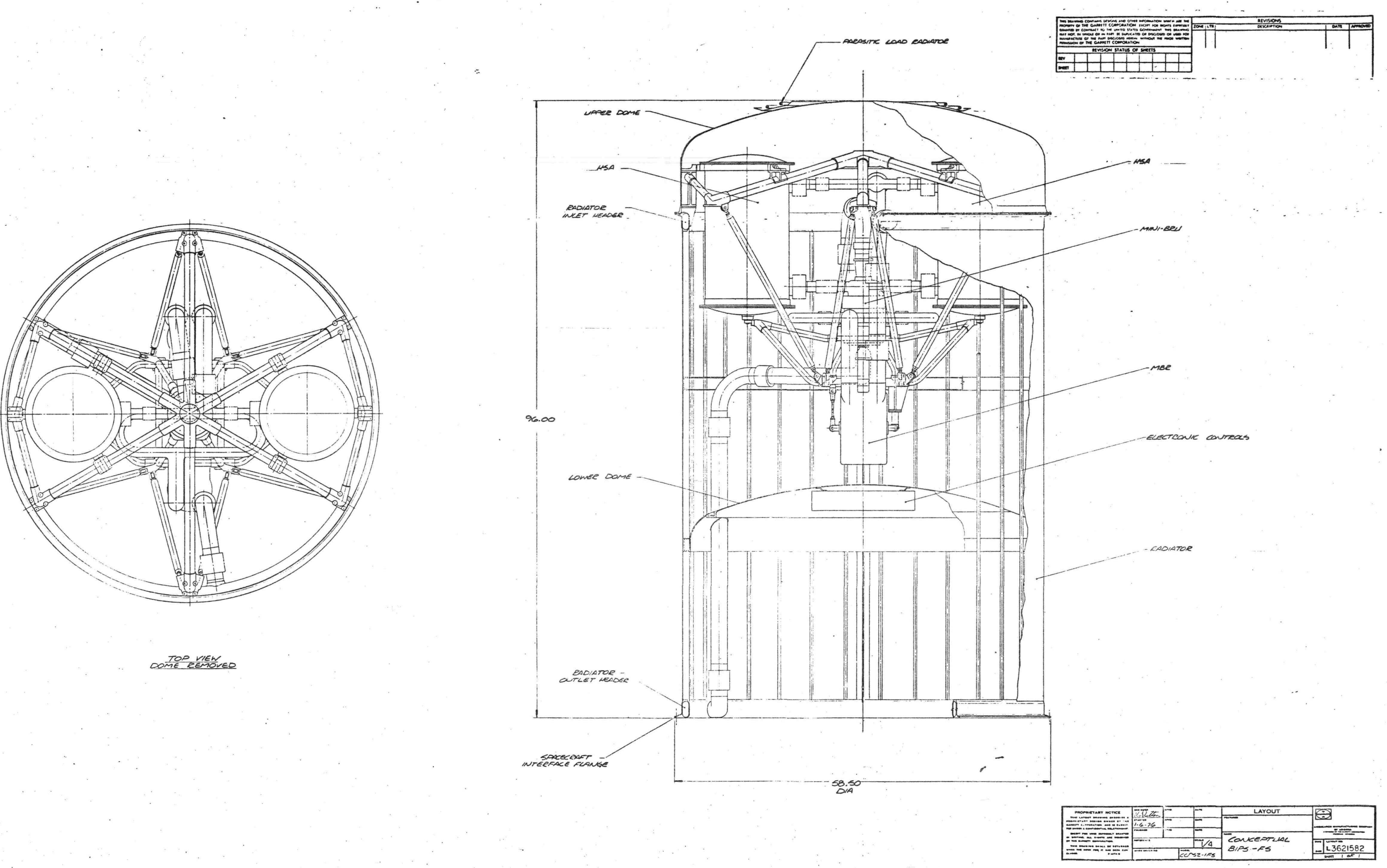


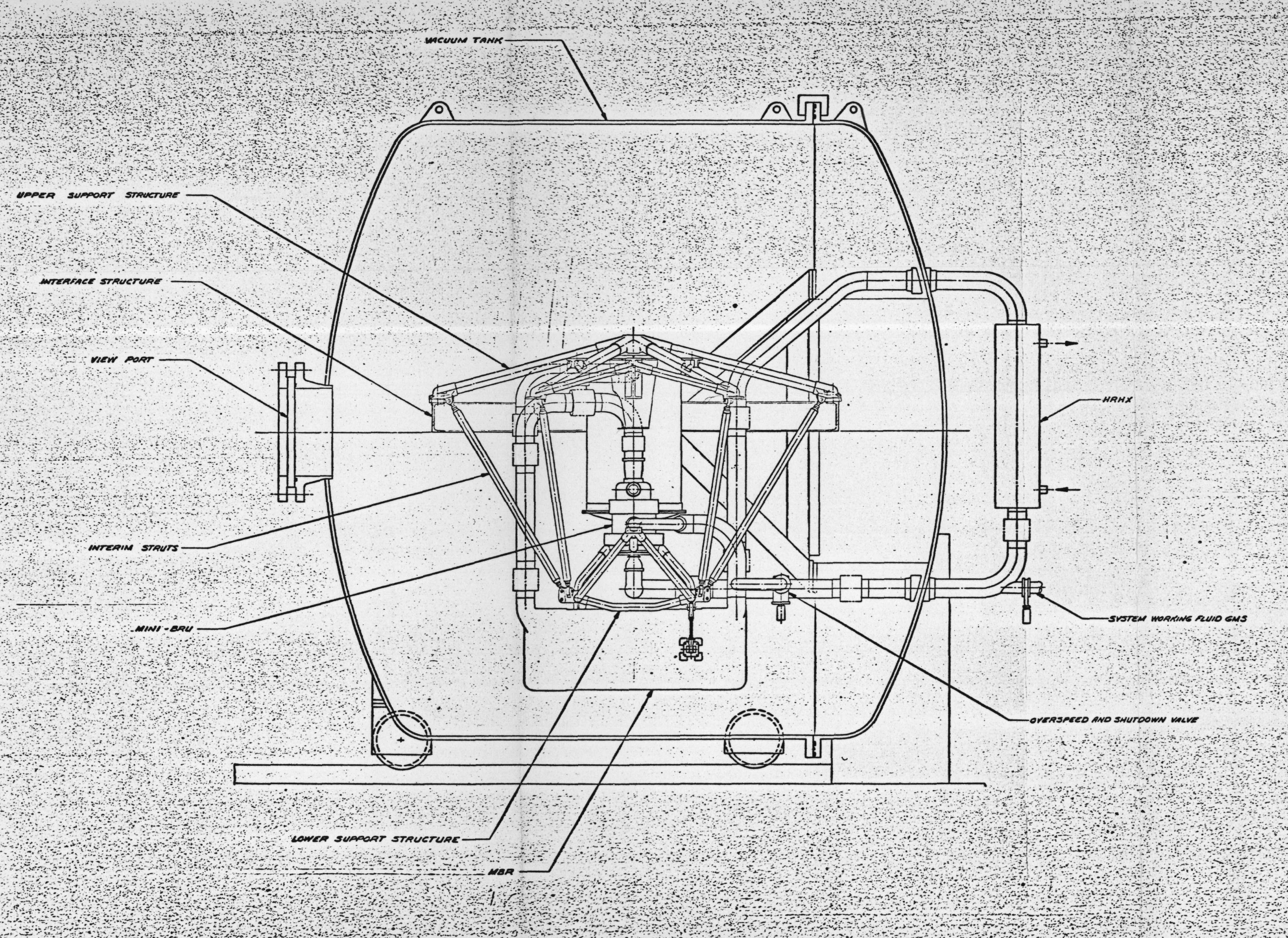

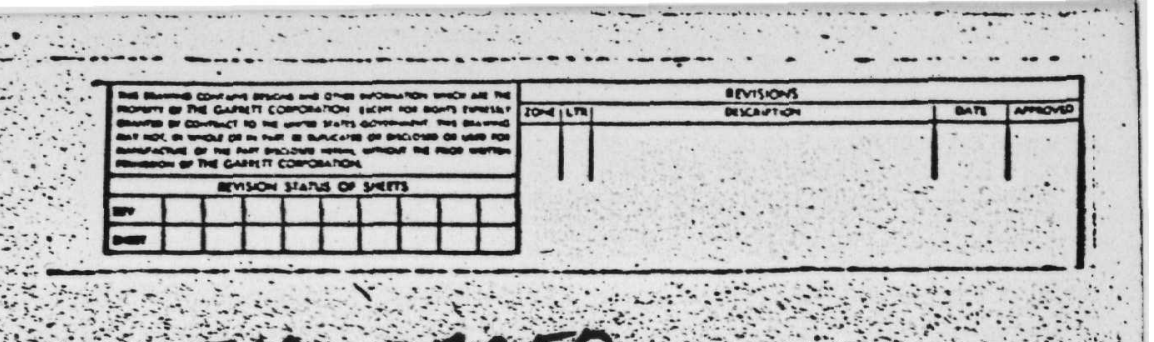
$+10-27252$
404010 00656

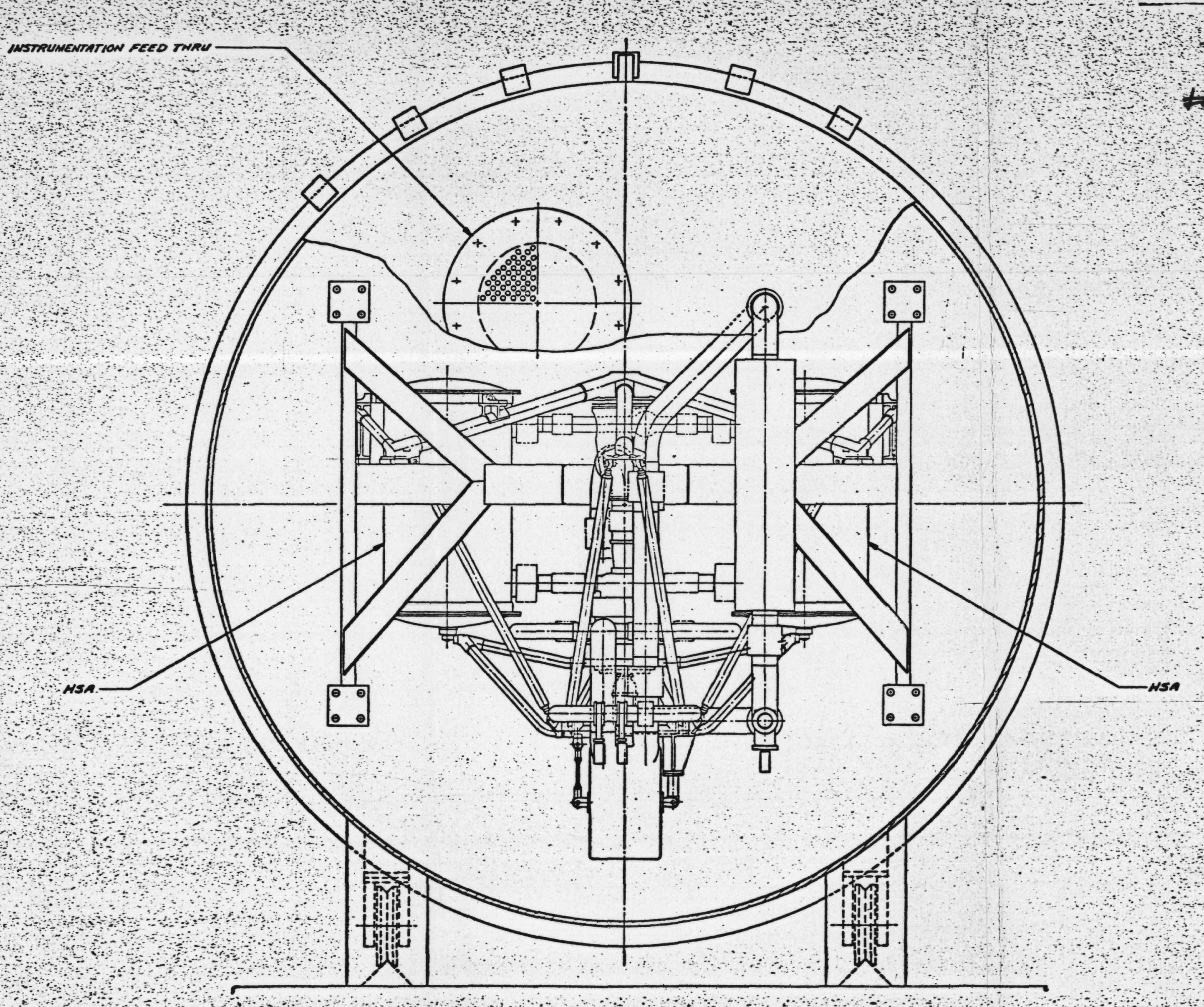

236.215830

$=0$ 



$$
\mathbb{N}, \nabla .
$$




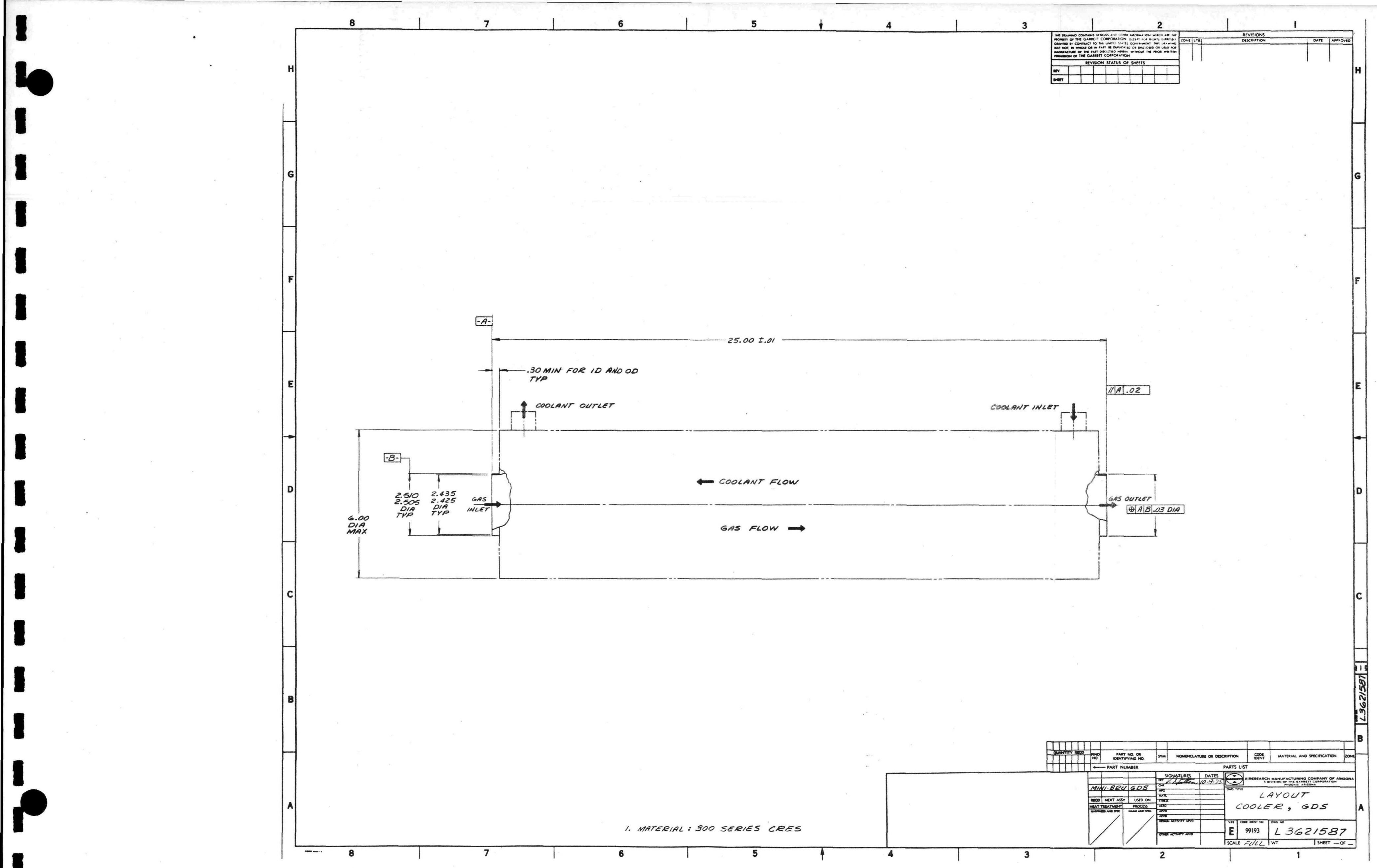




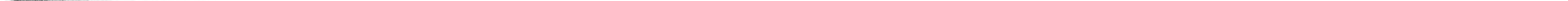

